\title{
IN HOT WATER a lobster tale
}

by

Katherine Gillis

\begin{abstract}
A thesis submitted to the Faculty of Graduate and Postdoctoral Affairs in partial fulfillment of the requirements for the degree of
\end{abstract}

Master of Architecture

Carleton University

Ottawa, Ontario

(C) 2020

Katherine Gillis 
You can really have no notion How delightful it will be When they take us up and throw us With the lobsters, out to sea! -Lewis Carroll, The Lobster Quadrille 
Arisaig, Nova Scotia is one of many rural communities in Canada's Maritime Provinces that relies on natural resources to sustain the economy and quality of life. The lobster has become so iconic to the province of Nova Scotia that it is emblazoned on tourist merchandise, marketed as the special in restaurants, and can even be purchased live at the Halifax Airport and taken home in your carry-on on a plane.

In northeastern Nova Scotia, tourists come to swim in the waters of the Northumberland Strait, the narrow, shallow body of water with the warmest ocean temperatures in Atlantic Canada, while the American Lobster, Homarus Americanus, thrives under these conditions. Here, owner-operated inshore lobster fishing occurs every spring, and is directly responsible for the socioeconomic well being of small, rural communities. But what happens if this cycle is interrupted in the form of rising water temperatures due to climate change? Higher water temperatures threaten the lifecycle of the American Lobster, and a hatchery added to the site at Arisaig Harbour could help maintain stocks to retain lobster fishing in the area, while providing a place for education and research. At the same time, rising water temperatures are ideal for those looking for water recreation.

This thesis is a speculative form of survival through adaptation for both humans and lobsters in a rural, coastal site. By hybridizing buildings, infrastructure, and landscape that support both industries, the symbiotic relationship between humans and lobsters becomes apparent, through cycles of seasons, lobster growth, and human activity. Through studying the vernacular craft tradition of building, a framework for the architectural design of the thesis is established. By drawing in section, relationships between 
lobsters, fishermen, visitors, and locals are understood across the site, both in water and on land. Water temperature is used to illustrate how these relationships can shift over the next century.

Fisheries, tourism, and culture are separate, yet interconnected elements of rural coastal life, where industry not only is economic, but also ingrained in the culture of the place. This triad forms the basis of investigation of this thesis. The result is a synthesis of layers of interconnectivity of industries and species that work together to nurture survival of each other. 


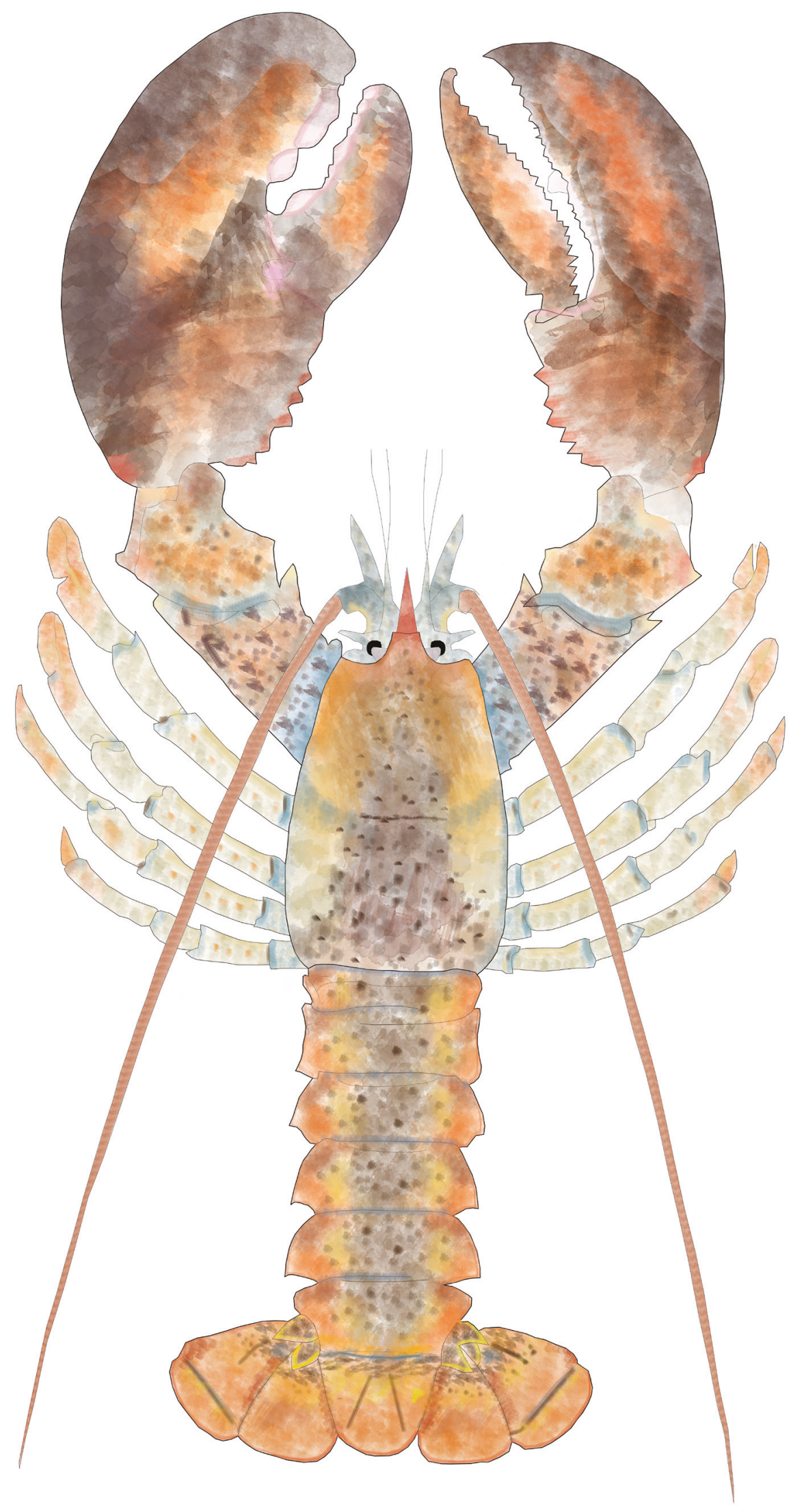

FIGURE 1 
To my advisor, Catherine Bonier, for your continued support, encouragement, and guidance in seeing me through this thesis,

To my friends and colleagues in room 510, for our shared laughs, sarcasm, and grumbles,

To my mother, Bonnie Gillis, for everything,

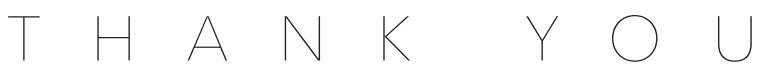




\begin{tabular}{l|r} 
Abstract & iii \\
Acknowledgements & vi \\
List of Figures & viii \\
List of Terms & xi \\
Introduction & 01 \\
Chapter One: VERNACULAR AND VACATION & 04 \\
Chapter Two: TEMPERATURE AND TIDES & 16 \\
Chapter Three: LABOUR AND LEISURE & 30 \\
Chapter Four: INTERVENTION AND INTERDEPENDENCE & 40 \\
Conclusion & 86 \\
Appendix: CASE STUDIES & 87 \\
Bibliography & 95
\end{tabular}




\begin{tabular}{|c|c|}
\hline Fugure 01 & Illustration of a lobster \\
\hline Figure 02 & Map of the Nova Scotia \\
\hline Figure 03 & Map of Lobster Distribution \\
\hline Figure 04 & Map of Lobster Landings in New England and Maine \\
\hline Figure 05 & Map of the Maritime Provinces \\
\hline Figure 06 & Map of Arisaig, NS \\
\hline Figure 07 & Map of Arisag Harbour \\
\hline Figure 08 & Building Typology Documentation \\
\hline Figure 09 & Materiality Study \\
\hline Figure 10 & Sketch of Arisaig Lighthouse \\
\hline Figure 11 & Arisaig Tartan \\
\hline Figure 12 & Map of Nova Scotia \\
\hline Figure 13 & Map of the Northumberland Strait \\
\hline Figure 14 & Tide Chart June 2019 \\
\hline Figure 15 & Diagram of Occupying the Tides \\
\hline Figure 16 & Wind and Waves \\
\hline Figure 17 & Breakwater Iterations \\
\hline Figure 18 & Rising Water Levels \\
\hline Figure 19 & Surface and Bottom Ocean Temperature Projections \\
\hline Figure 20 & Surface and Bottom Ocean Temperature 2040 \\
\hline Figure 21 & Surface and Bottom Ocean Temperature 2070 \\
\hline Figure 22 & Surface and Bottom Ocean Temperature 2100 \\
\hline Figure 23 & Rising Water Levels and Temperatures \\
\hline Figure 24 & Lobster Larvae Lobster Institute. University of Maine. https://umaine.edu/lobsterinstitute/. \\
\hline Figure 25 & Lobster Life Cycle \\
\hline Figure 26 & Temperature Diagram: Water, Humans, Lobsters \\
\hline Figure 27 & Photo of Arisaig from the Boat \\
\hline
\end{tabular}




\begin{tabular}{|c|c|}
\hline Figure 28 & Photo of Arisaig Harbour from the Boat \\
\hline Figure 29 & Map of the Lobster Fishing Areas (LFAs) \\
\hline Figure 30 & Chart of LFA fishing seasons \\
\hline Figure 31 & Photo Series of Fishing Day \\
\hline Figure 32 & Lobster Trap \\
\hline Figure 33 & Maritime Vernacular https://journals.lib.unb.ca/index.php/Acadiensis/article/view/11174 \\
\hline Figure 34 & Nova Scotia Doers and Dreamers Guide Tourism Nova Scotia \\
\hline Figure 35 & Lobsterland Poster \\
\hline igure 36 & Crate to Plate Poster \\
\hline Figure 37 & Lobster Larvae https://www.nationallobsterhatchery.co.uk/. \\
\hline Figure 38 & Releasing the Larvae https://www.nationallobsterhatchery.co.uk/. \\
\hline Figure 39 & Early Sketch of wall releasing larvae \\
\hline Figure 40 & Program Zoning \\
\hline Figure 41 & Extending Breakwater \\
\hline Figure 42 & 2040 Site Plan \\
\hline Figure 43 & 2040 Hatchery Section \\
\hline Figure 44 & 2070 Site Plan \\
\hline Figure 45 & 2070 Wharf and Lobster Pound Section \\
\hline Figure 46 & 2070 Wharf and Lobster Pound Section with spring water temperatures \\
\hline Figure 47 & 2070 Lobster Hatchery Section with summer water temperatures \\
\hline Figure 48 & 2070 Breakwater Section \\
\hline Figure 49 & 2070 Breakwater Section with spring water temperatures \\
\hline Figure 50 & 2070 Breakwater Section with summer water temperatures \\
\hline Figure 51 & 2070 Breakwater Section with autumn water temperatures \\
\hline Figure 52 & 2070 Breakwater Section with winter water temperatures \\
\hline Figure 53 & 2100 Site Plan \\
\hline Figure 54 & 2100 Hatchery Section with autumn water temperatures \\
\hline Figure 55 & 2100 Wharf and Pound Section with spring water temperatures \\
\hline gure 56 & 2100 Restaurant Section \\
\hline gure 57 & 2100 Restaurant Section with spring water temperatures (high tide) \\
\hline
\end{tabular}


Figure 58

Figure 59

Figure 60

Figure 61

Figure 62

Figure 63

Figure 64

Figure 65

Figure 66

Figure 67

Figure 68

Figure 69

Figure 70

Figure 71

Figure 72

Figure 73

Figure 74

Figure 75

Figure 76

Figure 77

Figure 78

Figure 79
2100 Restaurant Section with spring water temperatures (low tide)

2100 Restaurant Stone Wall Section with spring water temperatures (high tide) 80

2100 Restaurant Stone Wall Section with spring water temperatures (low tide) 80

2100 Site Section

81

2100 Site Section with spring water temperatures

Interior View of Lower level of Lobster Hatchery

Exterior View of Hatchery from the Ocean

Underwater View of Lobster Wall

Case Study: Boa Nova Tea House Sketch "Revisit Leca De Palmeira." The Architectural Review, April 2019.

Case Study: Boa Nova Tea House Photo https://www.archdaily.com/355077/ad-classics- 87 boa-nova-tea-house-alvaro-siza.

Case Study: Leca Swimming Pools Photo https://www.archdaily.com/150272/ad-clas- 88 sics-leca-swimming-pools-alvaro-siza.

Case Study: Leca Swimming Pools Plan "Revisit Leca De Palmeira." The Architectural Review, April 2019.

Case Study: Under Section https://www.archdaily.com/913575/under-snohetta.

Case Study: Under Photo https://www.archdaily.com/913575/under-snohetta.

Case Study: Faaborg Harbour Bath Plan https://www.archdaily.com/518083/faaborg-har- 90 bor-bath-urban-agency-jds-creo-arkitekter.

Case Study: Faaborg Harbour Bath Section https://www.archdaily.com/518083/faaborg- 90 harbor-bath-urban-agency-jds-creo-arkitekter.

Case Study: Oyster-Tecture Collagehttps://www.scapestudio.com/projects/oyster-tecture/

Case Study: Oyster-Tecture Collagehttps://www.scapestudio.com/projects/oyster-tecture/ 91

Case Study: Hedmark Museum Section Sverre Fehn: Works, Projects, Writings, 1949-1996.92

Case Study: Hedmark Museum Section Sverre Fehn: Works, Projects, Writings, 1949-1996.92

Case Study: Lobster Pods https://www.nationallobsterhatchery.co.uk/.

Case Study: Lobster Farming https://news.cgtn.com/news/3549444d7a6b7a6333566d54/ 94 share_p.html. 


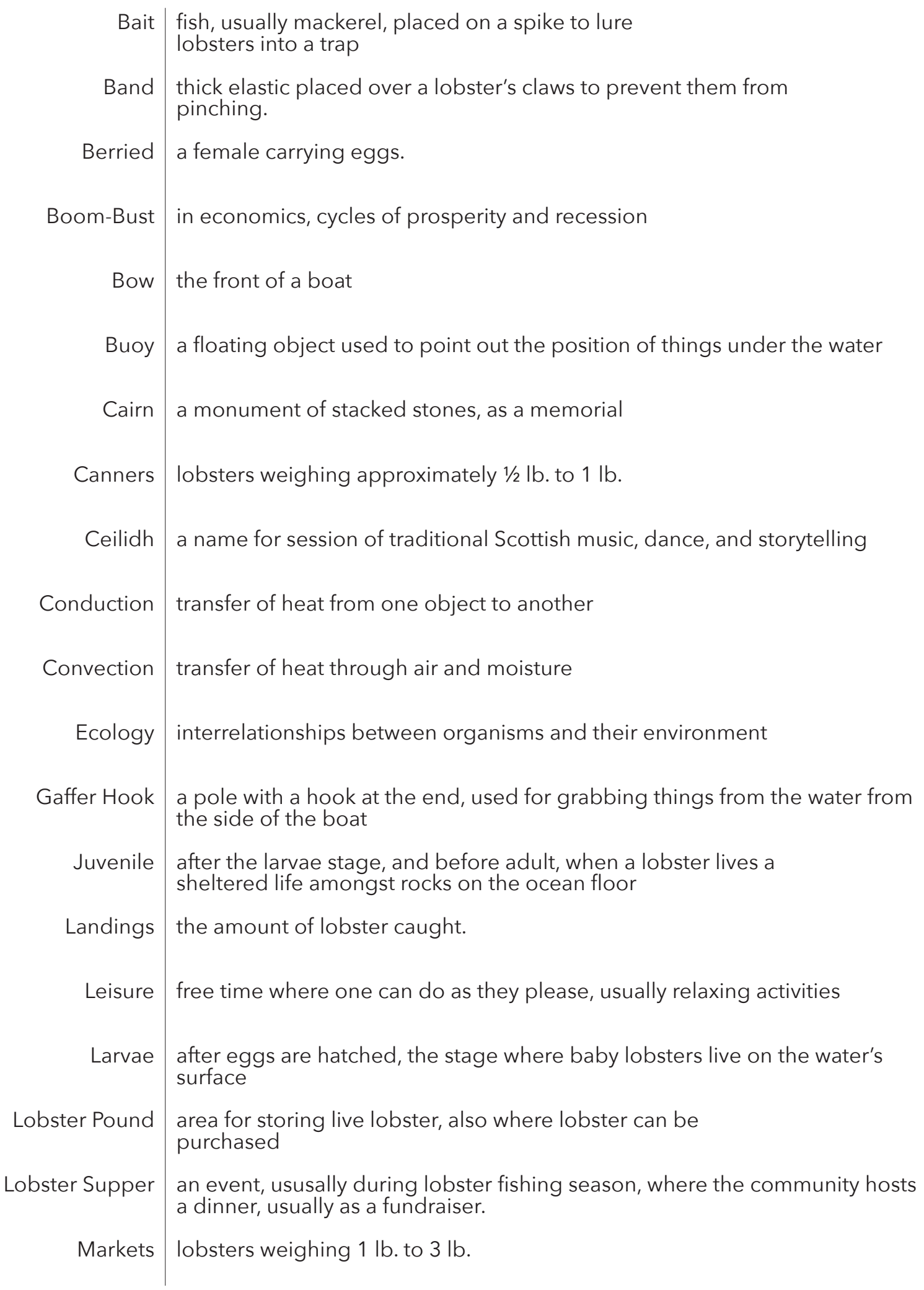




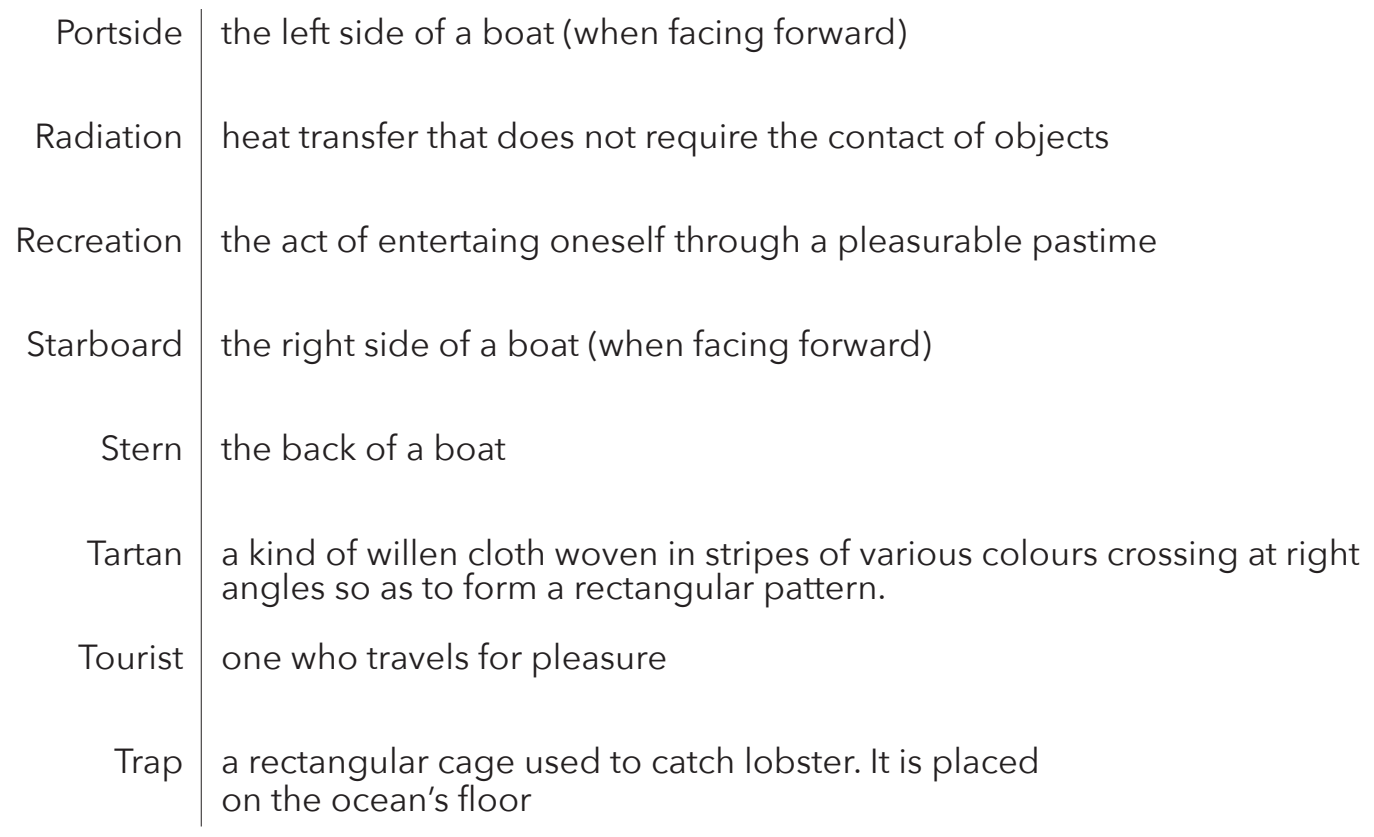


Where the land meets the ocean, there is never one definite edge. Tides ebb and flow between two concentrated extremes. ${ }^{1}$ But high tide and low tide are not the only oppositions that happen at the coast. In the province of Nova Scotia, one is never more than $60 \mathrm{~km}$ from the ocean. Fortythree percent of the population lives in rural areas, many in small coastal communities that derive both sustenance and relaxation from the sea. One of these communities is Arisaig, located in Antigonish County.

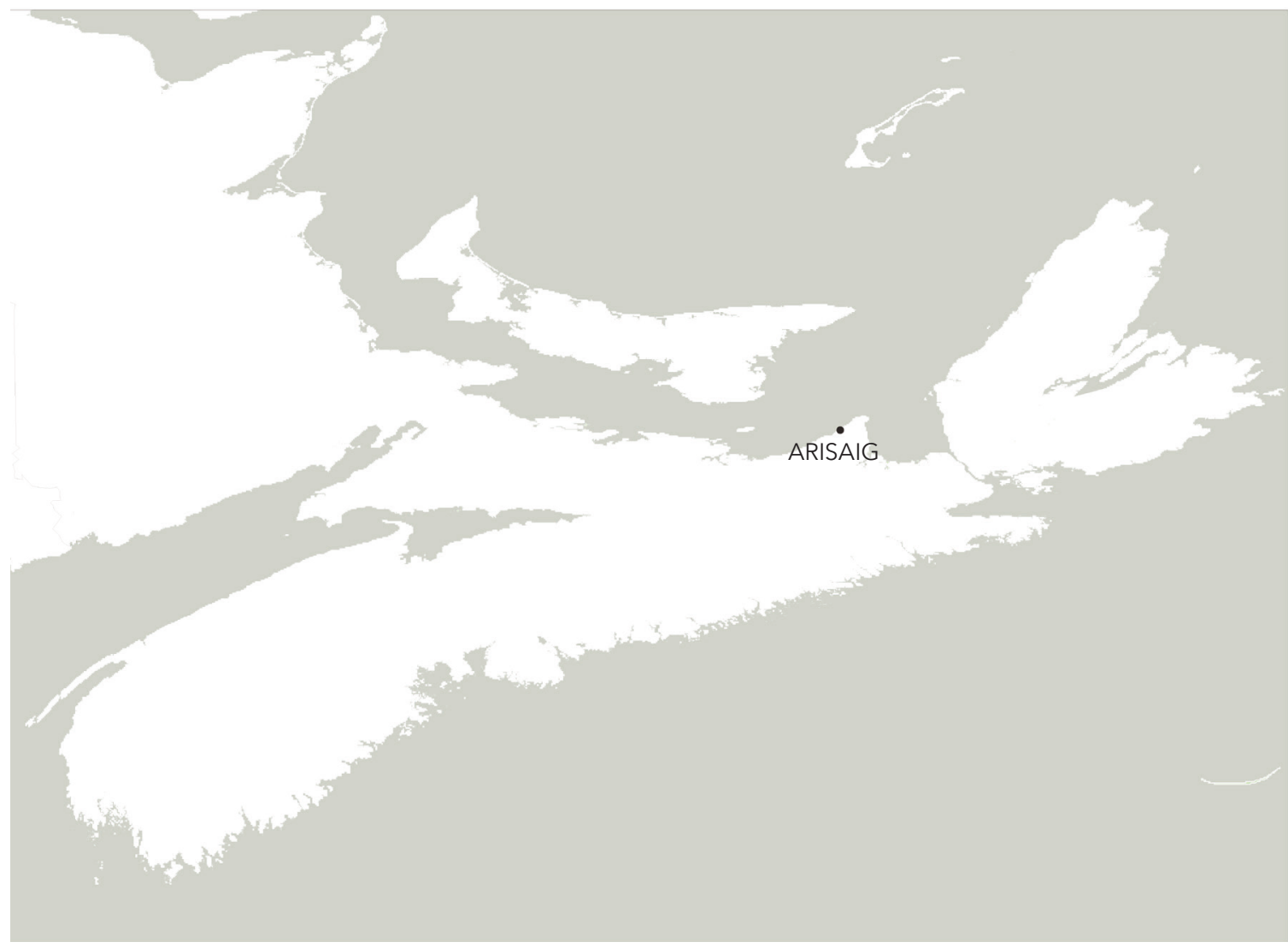

${ }^{1}$ Hoare, Philip. "The Ocean's Skin." The Architectural Review, April 2019, 6-15. 
Arisaig, Nova Scotia, like many coastal communities along the Northumberland Shore, revolves around the lobster fishing industry. The Arisaig Community Development Association has a slogan; "Arisaig: where Community, the Fishery, and Tourism Connect". This thesis aims to integrate these three entities, and design intriguing spatial associations between locals and tourists, humans and lobsters, fishing and recreation. It is a speculation of the future of an industry that is threatened by climate change, and the infrastructure needed to support it. How would this look in the existing rural, coastal landscape, while maintaining community identity, and promoting tourism in the area? How can the built environment interact with the changing edge of where land meets water?
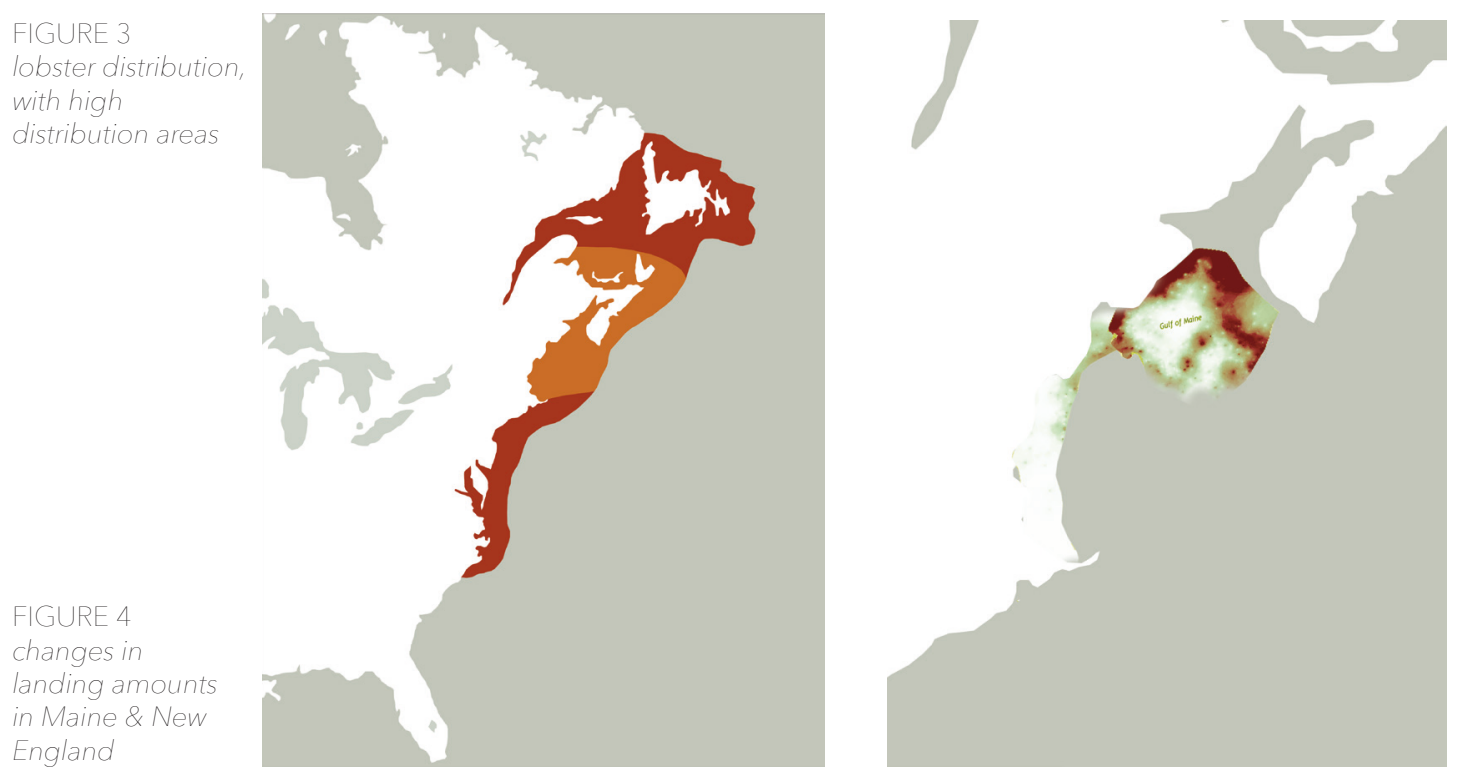

Lobster is Canada's most valuable seafood export, and trends are showing that lobsters are migrating north, with landings in New England diminishing and in Maine increasing. It is not that they are physically migrating, but that not enough larvae are surviving to adulthood due to rising sea surface temperatures. ${ }^{2}$ There is a critical temperature threshold of 25 degrees Celsius ${ }^{3}$ at which larvae will no longer survive. For the Northumberland Strait, the waters

\footnotetext{
${ }^{2}$ Ryan, Haley. "The Lobster Trap." thestar.com, June 10, 2019. https://projects.thestar.com/climate-change-canada/nova-scotia/.

${ }^{3}$ Fisheries. "Integrated Fisheries Management Plan - Lobster in the Southern Gulf of St. Lawrence." Department of Fisheries and Oceans. January 20, 2015. Accessed April 23, 2019. http:// www.glf.dfo-mpo.gc.ca/Gulf/FAM/IMFP/2014-Lobster-Gulf-Region.
} 
are already the warmest in eastern North America. This critical temperature threshold will be reached sooner, and could have disastrous effects on not only the economy, but also the quality of life of people who rely on the industry.

This thesis is a speculation of a future where contrasts and opposing conditions are active on site. The contrasts within environmental factors, programmatic activity, and symbols of cultural identity are explored. This thesis is divided into four sections: Vernacular and Vacation, Temperature and Tides, Lobsters and Leisure, and Intervention and Interdependence. In Vernacular and Vacation, the history of the region and the site are introduced through a regional building tradition, examining how the province of Nova Scotia has been marketed to tourists as a land of quaint fishing villages and anti-modern fisher folk. In this chapter, vernacular architecture is understood through critical regionalism theories of Alexander Tzonis and Liane Lefaive, along with the tectonic from Kenneth Frampton. Chapter Two describes the implications of climate change to the water and to the lobster. This chapter also explores methods of graphically depicting shifting thermal and spatial relationships, drawing on the work of Phillipe Rahm. Labour and Leisure, Chapter Three, describes the immersive fieldwork conducted as research for this project, and looks at The National Lobster Hatchery of the United Kingdom as an industrial case study for lobster larvae containment, a practice that is rare. Finally, chapter four, Intervention and Interdependence, delves into the design of this shoreline intervention, with support of emerging theories of landscape architecture relating to aquaculture. Together, this research and design work forms this speculation of a future of human-lobster coexistence in rural Nova Scotia. 
Together, New Brunswick, Nova Scotia, and Prince Edward Island make up Canada's Maritime region. They all are defined by adjacency to the Atlantic Ocean, highly rural populations, and primarily natural resource based economies, yet these three small provinces are comprised of a complex network of cultural and economic landscapes, each reflecting an ethnographic

FIGURE 5

maritimes map with indication of

location of

antigonish and

pictou counties. origin of settlers to the area, creating distinct sub-regions. ${ }^{4}$ One such subregion is the northeastern Nova Scotia counties of Pictou and Antigonish, settled by Highland Scottish immigrants the late eighteenth century.

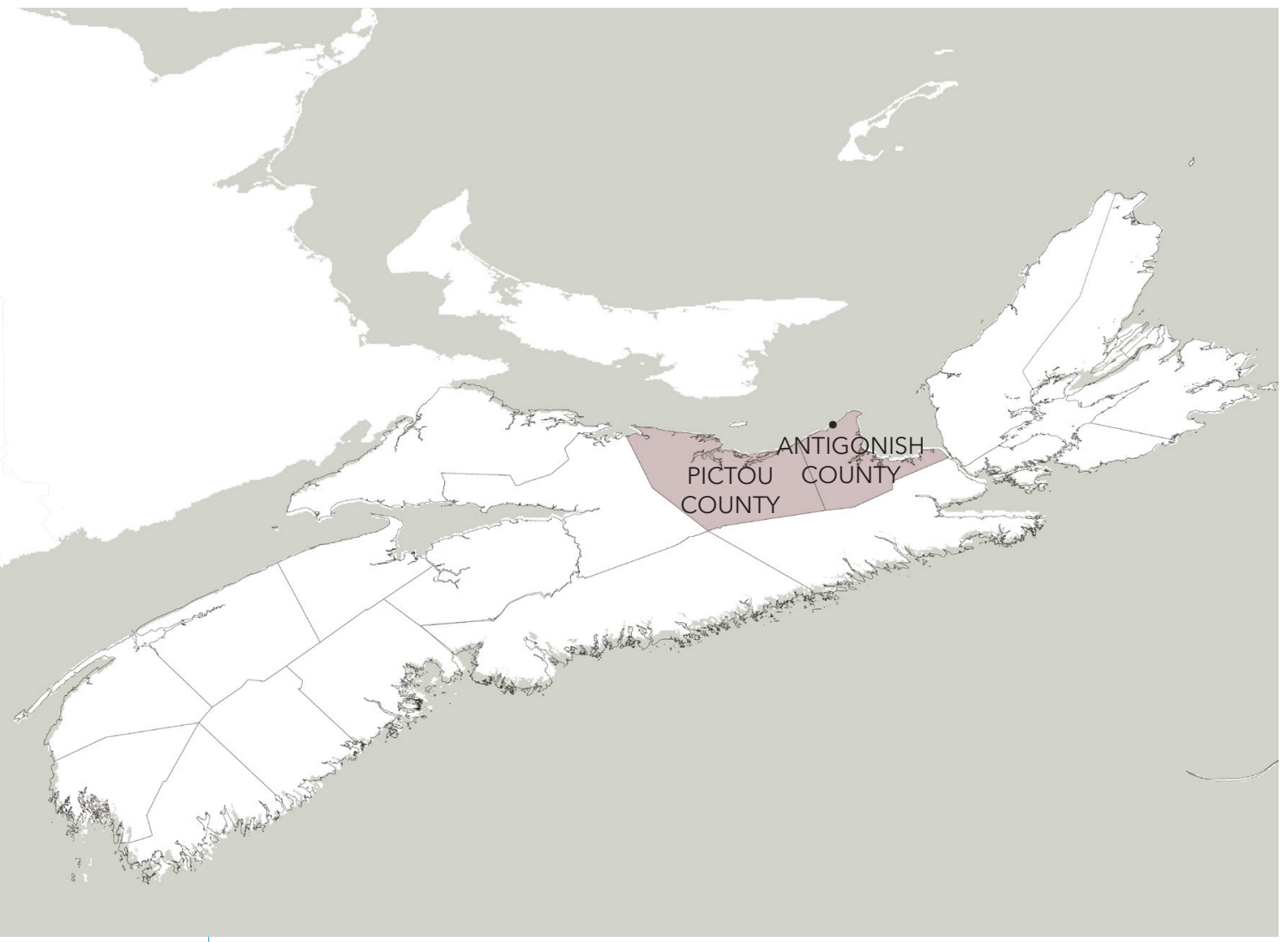

${ }^{4}$ Ennals, Peter, and Deryck Holdsworth. 1981. "Vernacular Architecture and the Cultural Landscape of the Maritime Provinces - A Reconnaisance". Acadiensis 10 (2), 104. 
The Highland Scots brought with them their culture of Gaelic language, song, and dance, but what was not transplanted was a building tradition. ${ }^{5} \mathrm{~A}$ reason for this could have been the availability of building material; the stone and turf house of the Scottish Highlands could not be replicated in the new home, as the turf would not have been practical in the new climate. Instead, the forests of Nova Scotia were abundant with building material. Combined with the establishment of sawmills, timber was readily available. ${ }^{6}$ Light-frame timber construction would not have been familiar to immigrants from either Scotland or Ireland, and it was learned from Loyalists from New England. ${ }^{7}$ Today, what is known as Maritime vernacular architecture is derived from New England forms. ${ }^{8}$ Wooden shingles were most common cladding material, clapboard less so. ${ }^{9}$

Construction knowledge was passed down from generation to generation informally ${ }^{10}$, and by the end of the nineteenth century, one dominant form began to emerge widely throughout the Maritimes. The telling architectural element is the lower pitched roof, derived from the gable roof of the Cape Cod New England home. ${ }^{11}$ The motive for this roofline is not clear, but one theory is the relation between shipbuilding and house building. The low-pitched roof sheds water and does not create wind resistance, similar to the hatch on a sailing vessel. ${ }^{12}$ It is possible that the knowledge of shipbuilding and house building be transferred, perhaps with the same individuals participating in both.

Many of the original communities of early white settlers still exist today, in the form of rural communities, many classified as "unincorporated areas", meaning they do not have a population large enough to support a its own governing body, but are grouped together under one municipal boundary. ${ }^{13}$

\footnotetext{
${ }^{5}$ Maudlin, Daniel. "Architecture and Identity on the Edge of Empire: The Early Domestic Architecture of Scottish Settlers in Nova Scotia, Canada, 1800-1850." Architectural History 50 (2007): 95-123, 95. https://doi.org/10.1017/s0066622×00002896.

'lbid., 99.

${ }^{7}$ Ennals, Vernacular Architecture, 98.

${ }^{8}$ Ibid., 101.

${ }^{9}$ Ibid., 105.

${ }^{10}$ lbid., 86 .

11 Ibid., 101.

${ }^{12}$ Ibid., 101

${ }^{13}$ Chisholm, Kassie. "Districts." Municipality of the County of Antigonish. Accessed March 8, 2020. https://www.antigonishcounty.ns.ca/.
} 
One of these communities is Arisaig, located in Antigonish County. Located $29 \mathrm{~km}$ northwest of the town of Antigonish, and $42 \mathrm{~km}$ northeast of the town of New Glasgow, many people commute to either of these towns for work or school. As Peter Ennals and Deryck Holdsworth describe in Vernacular Architecture and the Cultural Landscape of the Maritime Provinces - $A$ Reconnaisance,

The existence of these settlements is a testament to past population expansion and to a once vigorous economic life related to ...the sea, and the fact that people remain, perhaps commuting many miles to a job, is a poignant reminder of the tenacity and sense of place that many Maritimes have. ${ }^{14}$ Scottish immigrants settled Arisaig, Nova Scotia, in 1785, during the Highland Clearances. Named after their home village in Scotland, Arisaig is Gaelic for after in 1811.

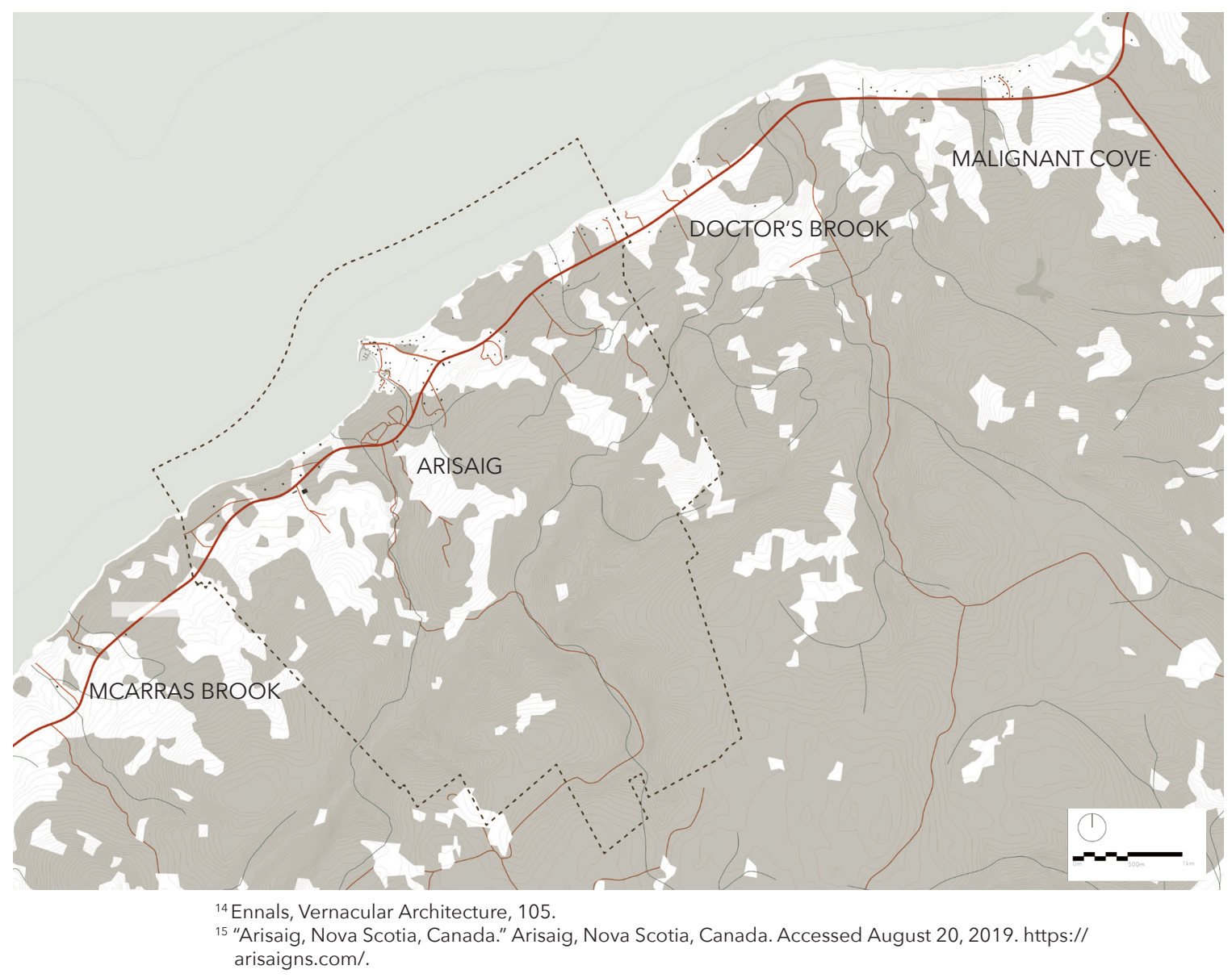


For over two hundred years, the people here have been making a living from the ocean. At present, twenty-three boats fish lobster out of the Arisaig harbour in May and June. Throughout its history, a school, grist mill, and post office were all built in the community ${ }_{1}^{16}$ however these are now gone. The fishing industry, and the infrastructure to support it, has been a constant for the past two hundred years, progressing to adapt to changing technologies. Boats have gone from being made of wood to fiberglass, hydraulic lifts help raise traps from the water where a pulley system was once used. A fish processing plant was once on site $^{17}$, and the building was later used as a lobster pound, but currently sits empty.

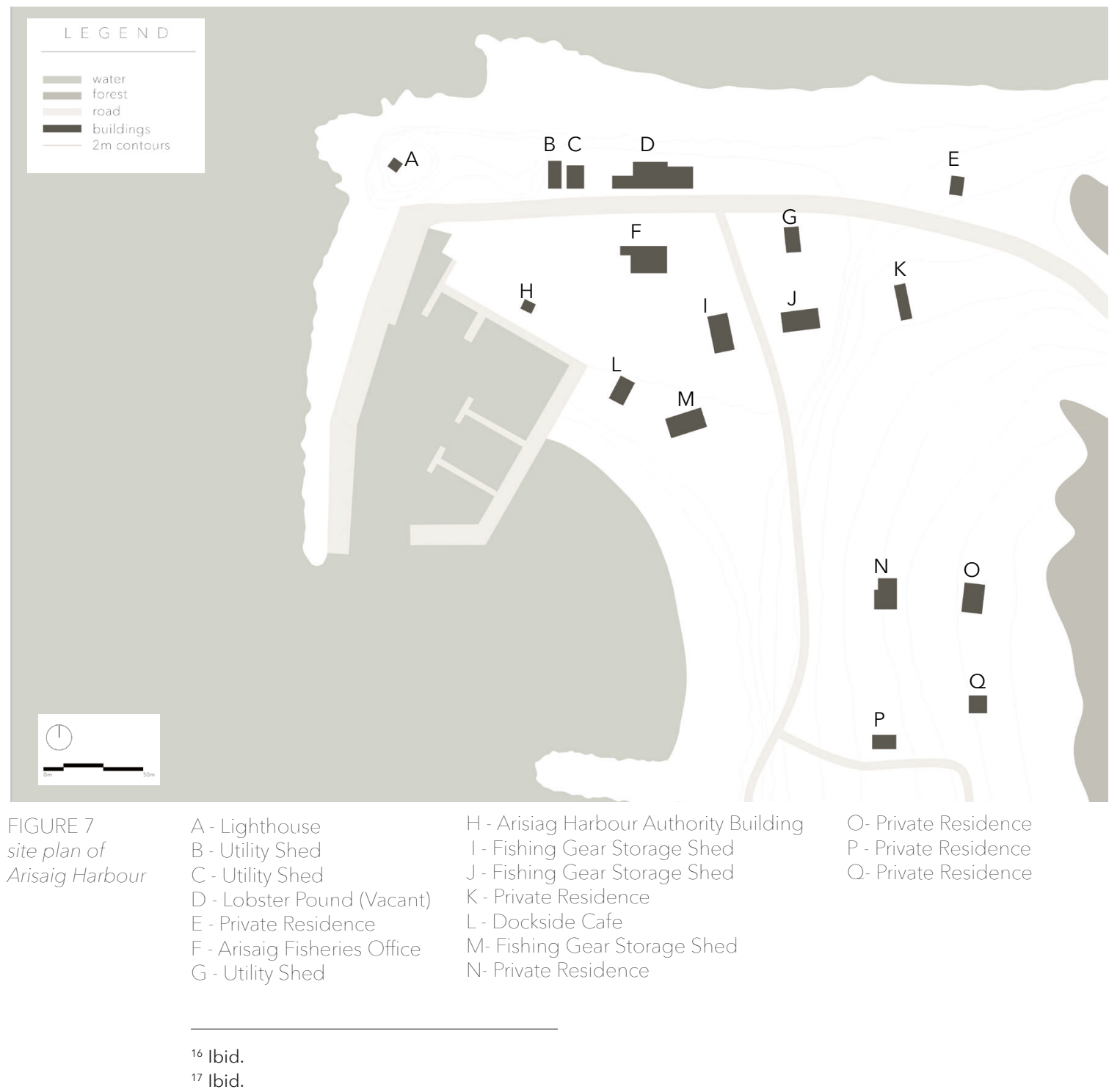


The buildings on site contain similar if not identical construction to the description of studies of maritime vernacular dwellings, iterating the point that building practices were done without the skill of master builders, but with construction knowledge passed on from generations past. The buildings at the site of Arisaig wharf are primarily industrial buildings, of a vernacular shed typology, with some variety of newer buildings built for the purposes of leisure and recreation activities, like the lighthouse and the café, continue to be built in light frame wooden structures.

As part of this thesis investigation, documentation of the variety of buildings and wharves on site was undertaken, as well as documentation of cladding materials and their state of weathering.

FIGURE 8 building typology documentation
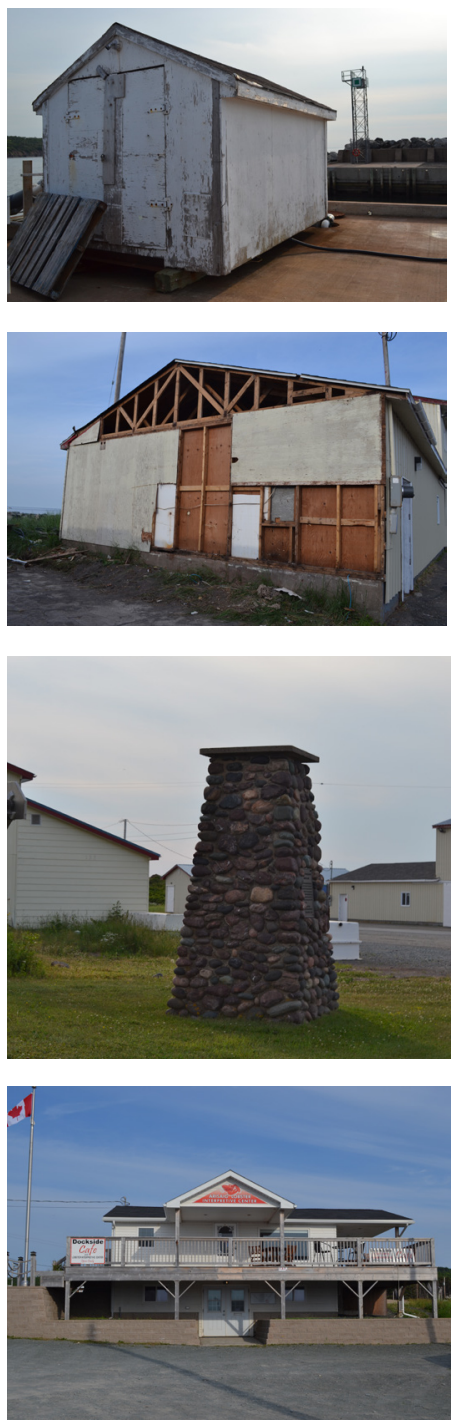

\section{Shed}

Site Plan Reference: not marked. on wharf. notes: painted plywood, peeling. rusted metal connections.

\section{Lobster Pound}

Site Plan Reference: D

notes: west wall cladding removed. (reason unknown)

\section{Cairn}

Site Plan Reference: not marked.

notes: commemoration location of first log cabin church, build 1792 .

\section{Dockside Cafe}

Site Plan Reference: L

notes: lower level sits empty. initial plan for the space was Lobster Interpretive Centre 


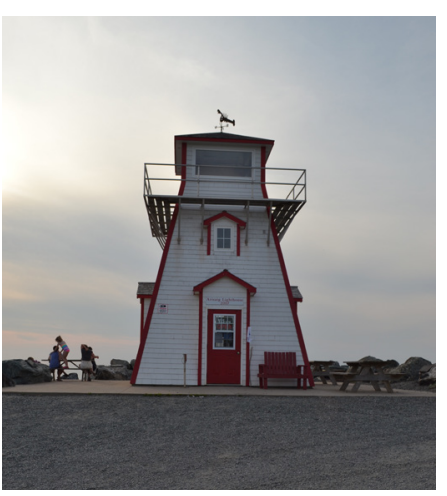

Lighthouse

Site Plan Reference: A

notes: built 2007. Open from Canada Day to

Labour Day as a canteen selling snacks, most popular is ice cream.

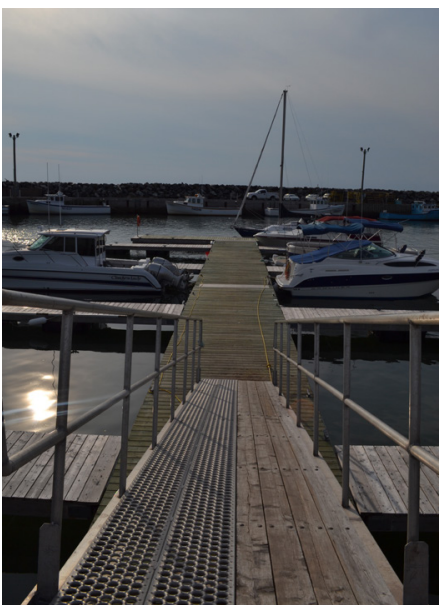

\section{Floating Docks}

Site Plan Reference: Wharf

notes: added 2012. First instance of recreational

boats in the Arisaig Harbour. Seasonal, added

after fishing season, and removed in autumn.

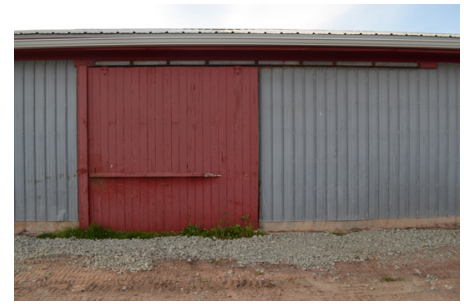

\section{Gear Shed}

Site Plan Reference: J

notes: 3 sliding barn doors on long sides of the building.

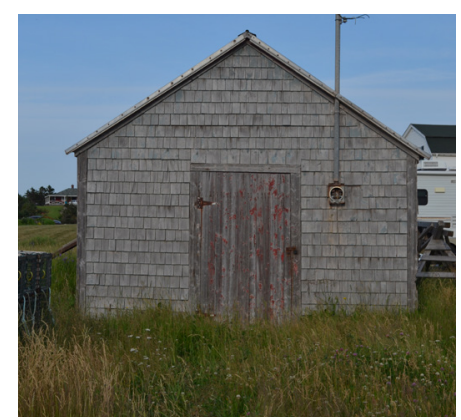

\section{Gear Shed}

Site Plan Reference: $\mathrm{G}$

notes: power lines once were connected to this shed.

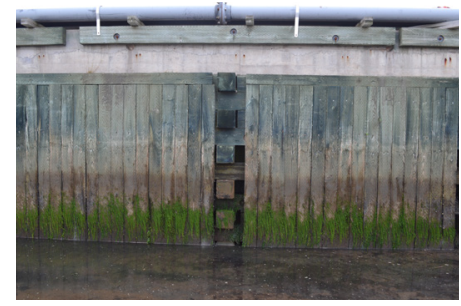

\section{Wharf}

Site Plan Reference: Wharf.

notes: photo at low tide. 
FIGURE 9

cladding

documentation
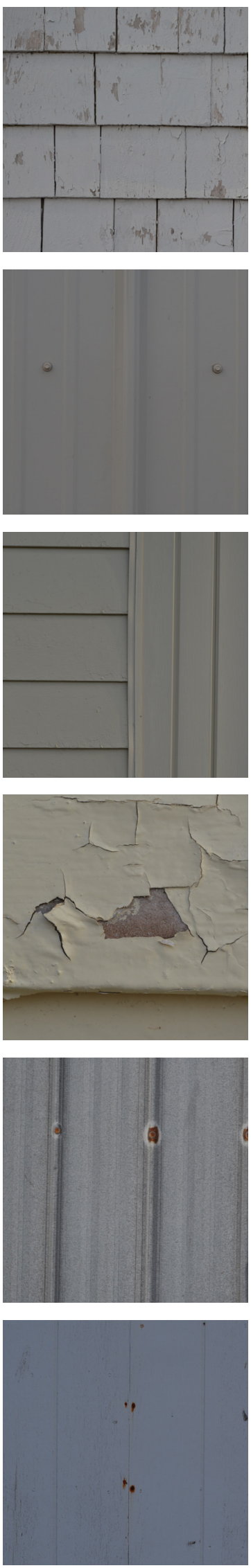

Wooden Shingles

Found on: Lighthouse

Condition: painted white, paint peeling due to

weathering. (could be combination of salt water and sun exposure)

\section{Metal Siding}

Found on: Lobster Pound

Condition: little to no signs of weathering, painted yellow, bolted in place.

\section{Wooden Clapboard}

Found on: Office

Condition: vertical boards and horizontal boards, suggests addition built at later time.

\section{Wooden Clapboard}

Found on: Office

Condition: painted yellow, some peeling. Paint very thick. (many layers)

\section{Metal Siding}

Found on: Gear Shed

Condition: unpainted. nailed in place, nails rusting. (not galvanized)

\section{Wooden Boards}

Found on: Shed

Condition: nailed in place, nails rusting. (not galvanized) 


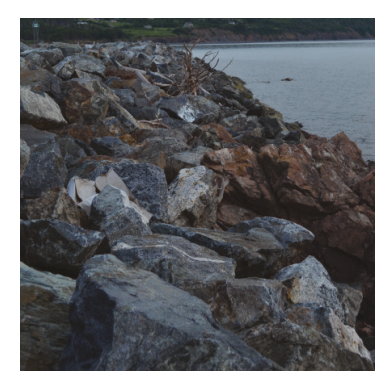

Rock

Found on: Wharf

Condition: collecting debris, driftwood, etc. Entire tree got caught amongst the rocks.

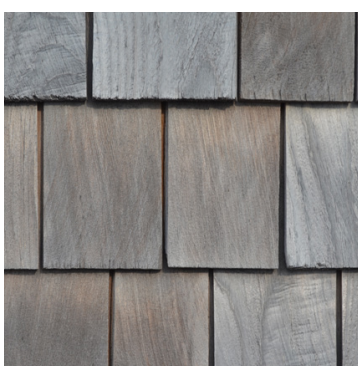

Wooden Shingles

Found on: Shed

Condition: unpainted, dry.

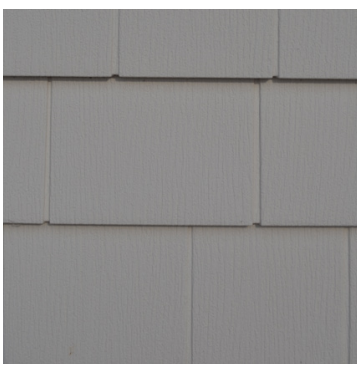

\section{Vinyl Siding}

Found on: Dockside Cafe

Condition: white. In the shape of wooden shingles.

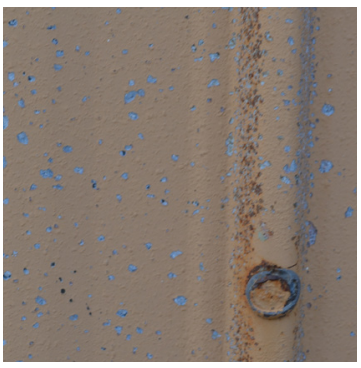

\section{Metal Siding}

Found on: Gear Shed

Condition: painted yellow. paint chipping. bolted on place, some rusting.

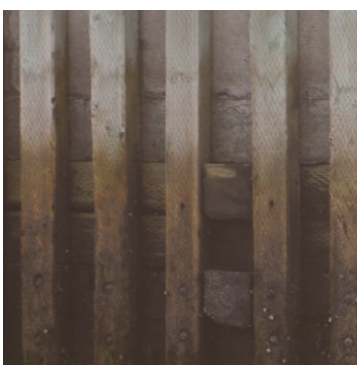

\section{$\underline{\text { Cribs }}$}

Found on: Wharf

Condition: photographed at low tide. Evidence of

high tide, where material was wet vs. dry. Combination of rock, wood, concrete.

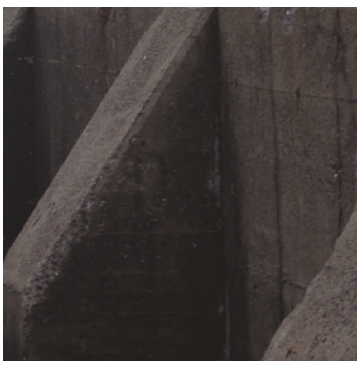

\section{Retaining Wall}

Found on: Wharf

Condition: support buttresses. Exposed rebar where concrete has deteriorated. 
The lighthouse, built in 2007, is a replica of the working lighthouse that stood at the site from 1898 until it burned in the late 1930s. It is not a working lighthouse, but acts as a canteen. It is a popular spot with locals and tourists to get an ice cream cone and sit amongst the rocks of the breakwater to enjoy the view of the sunset over the water. The completion of the replica lighthouse was done completely through volunteers. Labour and material were donated and the original drawings were used a guide. Just like the builders of the past, the lighthouse was constructed without architects, without skilled labour, an example of how vernacular building practice continues today. A building in the form of a lighthouse that is transposed onto a canteen is what Gottfried Semper would classify as using the architectonic attributes of one mode expressed in another for the sake of retaining traditional symbolic value. ${ }^{18}$ It is this 'traditional symbolic value' that acts as an attraction to tourists, to experience the constructed landscape that is portrayed in tourism literature.

FIGURE 10

on-site sketch of the Arisaig Lighthouse

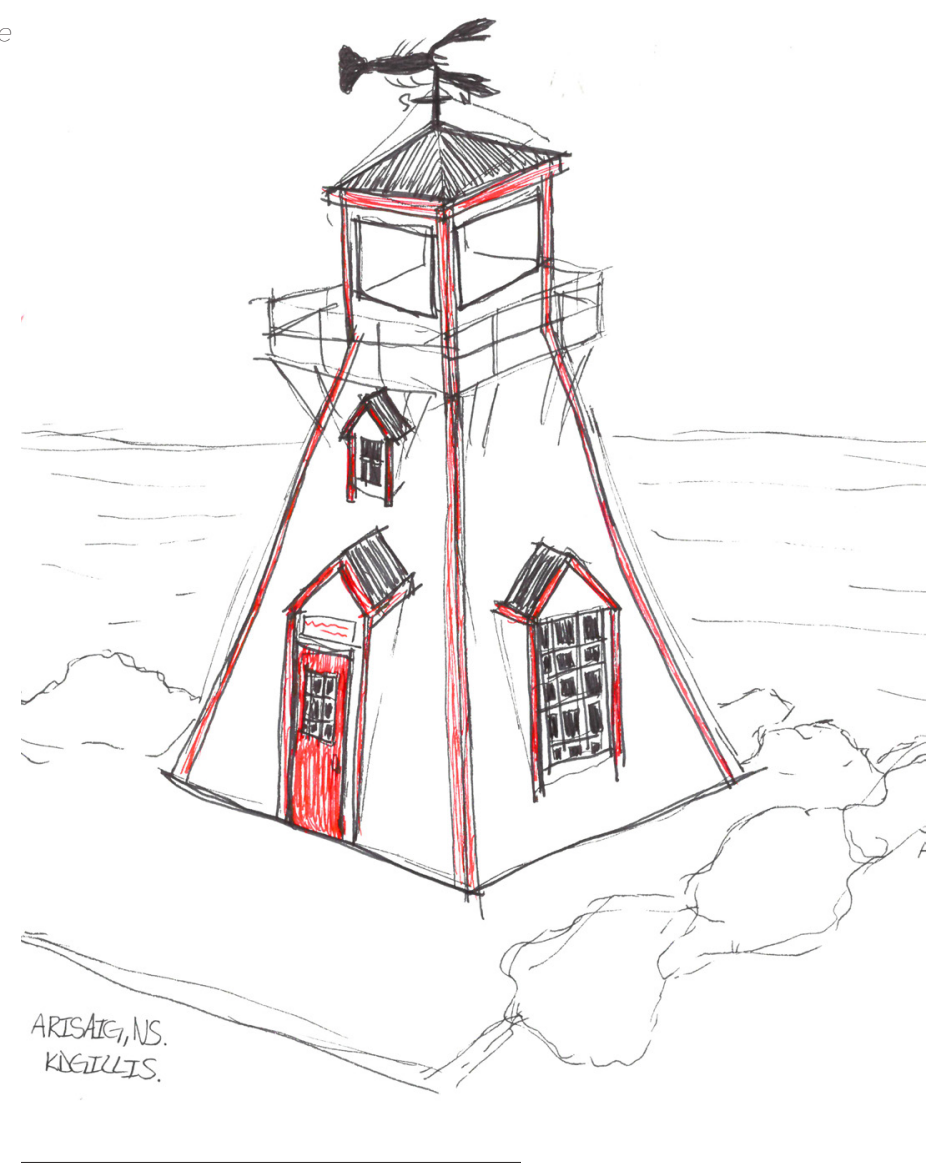

${ }^{18}$ Ennals, Vernacular Architecture, 105. 
Since the tourism industry began in the province, marketing Nova Scotia to outside visitors has been about exploiting the cultural landscape of the rural coastal life. This has contributed to a perception of the rural as a quaint, anti-modern oasis through which visitors can consume an "authentic" folk experience, a romanticized version of a place, ${ }^{19}$ where visiting the 'fisherfolk' was a quaint sight where middle-class visitors could be temporally displaced to a simpler time..$^{20}$ The reality is, lobster fishing as an occupation supports a middle class lifestyle, and there is little to no class divide between locals and tourists.

"Ciad Mille Failte" or "One Hundred Thousand Welcomes" is a slogan for Nova Scotia tourism. This Gaelic welcome emphasizes the friendly nature of Nova Scotians, who are welcoming to those who 'Come From Away' to visit Canada's Ocean Playground. In the 1950s, Nova Scotia tourism, under the direction of Premier Angus L. MacDonald, marketed "Tartanism", proving the 'Scottishness' of Nova Scotia through a series of images of nature, history, and race. ${ }^{21}$ This reconstruction of ethnicity ignored the modernity of the province, instead focusing on nostalgic affinity for the past. As McKay states in Marketing Race: Angus L. MacDonald, Tartanism, and the Cultural Politics of Whiteness, "even some early twentieth-century publications celebrating industrial progress sought to reassure visitors that [the] diverting peasant communities remained open for viewing."22 This attitude towards tourism is a commodification of constructed culture, based on a basic ethnographic analysis of a place. ${ }^{23}$ Authenticity is lost in this interpretation, because tourists are presented with a construction of an idea of a place.

\footnotetext{
19 McKay, lan, and Robin Bates. "Marketing Race: Angus L. MacDonald, Tartanism, and the Cultural Politics of Whiteness." In In the Province of History, 253-316. Montreal, QU: McGill-Queen's University Press, 2010.

20 McKay, lan. "'O, So True \& Real Like the Sea \& the Rocks': The Folk and the Pursuit of the Simple Life." In The Quest of the Folk: Antomodernism and Cultural Selection in TwentiethCentury Nova Scotia, 214-73. Montreal, QU: McGill-Queen's University Press, 2009.

21 MacKay, Tartanism, 254

22 Ibid., 263.

23 MacKay, O So True, 246.
} 


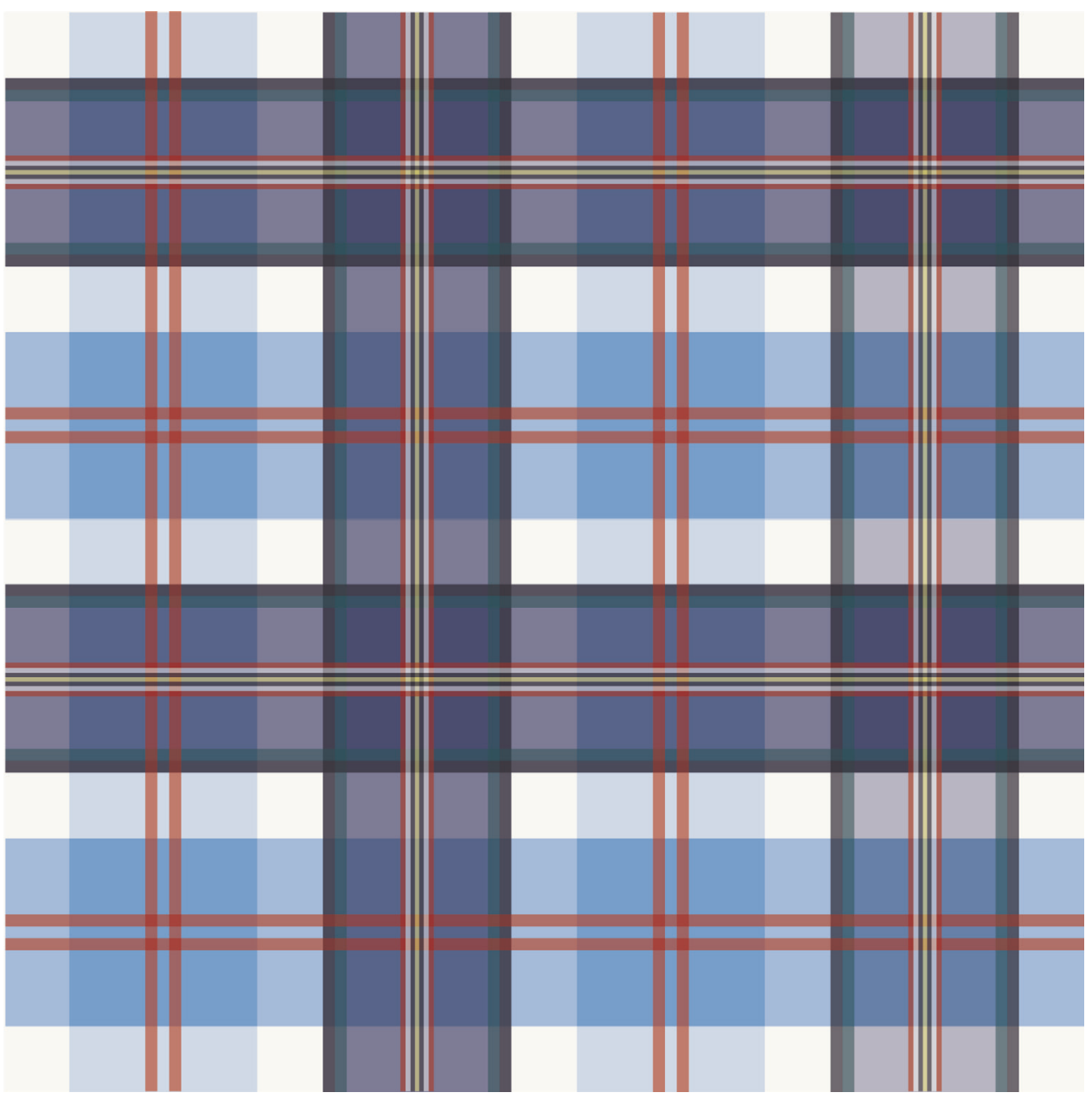

As an expression of Scottish heritage, the Arisaig tartan was registered in 2010. Each colour of the tartan represents an aspect of the natural or built environment. The colours are:

light and dark blue: the ocean, light blue for when waves are calm, dark blue for rough days when waves are churning.

white: snow and ice that covers ocean in winter.

red: sunrise and sunset, one band for each.

green: farmland, and tree-filled hills and valleys.

black: reference to traditional dark colours of Scottish tartans.

red: lobster.

white: St. Margaret of Scotland Catholic Church, the Arisaig Parish Church. black and yellow: the road of Rte. 245, part of the sunrise trail, which runs through the community. 
By examining building practices and materiality of the site, this thesis aligns itself with the theory of Critical Regionalism, first proposed by Alexander Tzonis and Liane LeFaivre in 1981. The ideas of local culture, everyday life, craft tradition, and cultural identity of a region have been incorporated into architecture for centuries, however the formal organization of Critical Regionalism is a fairly recent movement. Critical Regionalism provides a framework for instilling a sense of place in architecture, not simply a return to regional vernacular building style. ${ }^{24}$ Traditional craft is incorporated with modern technologies. The importance of place is emphasized, for sustaining local economies and promoting community culture. Place is not simply abstract space, but a place has a "genius loci", ${ }^{25}$ a spirit of a place, with a relationship to environmental character, materials, shapes, textures, and colours. Maritime Canada is a perfect place to execute architecture under the semblance of critical regionalism, as previously quoted by Ennals and Holdsworth, Maritimers have a strong sense of place. In Kenneth Frampton's definition of Critical Regionalism, value should be placed on the geographical context of the building. Emphasis is placed on topography, climate, light, and tectonic form. ${ }^{26}$ One must be careful not to focus on scenography, or constructing an image of a place. This understanding of Critical Regionalism is relevant to this thesis, where a sense of place is instilled in the people, however changes in climate need to be addressed in challenging vernacular forms. Authenticity demands place-making that is not only tailored to tourists' expectations and experiences, but that also builds upon an accurate and careful understanding of a place and its people.

\footnotetext{
${ }^{24}$ Lefaivre, Laine, and Alexander Tzonis. Architecture of Regionalism in the Age of Globalization : Peaks and Valleys in the Flat World. (Abingdon:Routledge, 2012)

${ }^{25}$ Norberg-Schulz, Christian. Genius Loci : Towards a Phenomenology of Architecture (Rizzoli, 1996), 7.

${ }^{26}$ Frampton, Kenneth. "Towards a Critical Regionalism: Six Points for an Architecture of Resistance." In Postmodern Culture, 16-30. London: Pluto Press, 1985.
} 
In 1923, the Nova Scotia Provincial government began marketing the province to outside visitors, to promote tourism in the province. The slogan "Canada's Ocean Playground" was created to describe the Nova Scotia. ${ }^{27}$ The slogan remains relevant today, as it is still used in marketing material, and is on all Nova Scotia license plates as an emblem of the province.

Nova Scotia is comprised of a peninsula and an island; with $13,000 \mathrm{~km}$ of coastline. ${ }^{28}$ There are many different ocean conditions surrounding the province, from the high tides of the Bay of Fundy, to the icy Atlantic Ocean on the South Shore, to the Northumberland Strait on the North Shore.

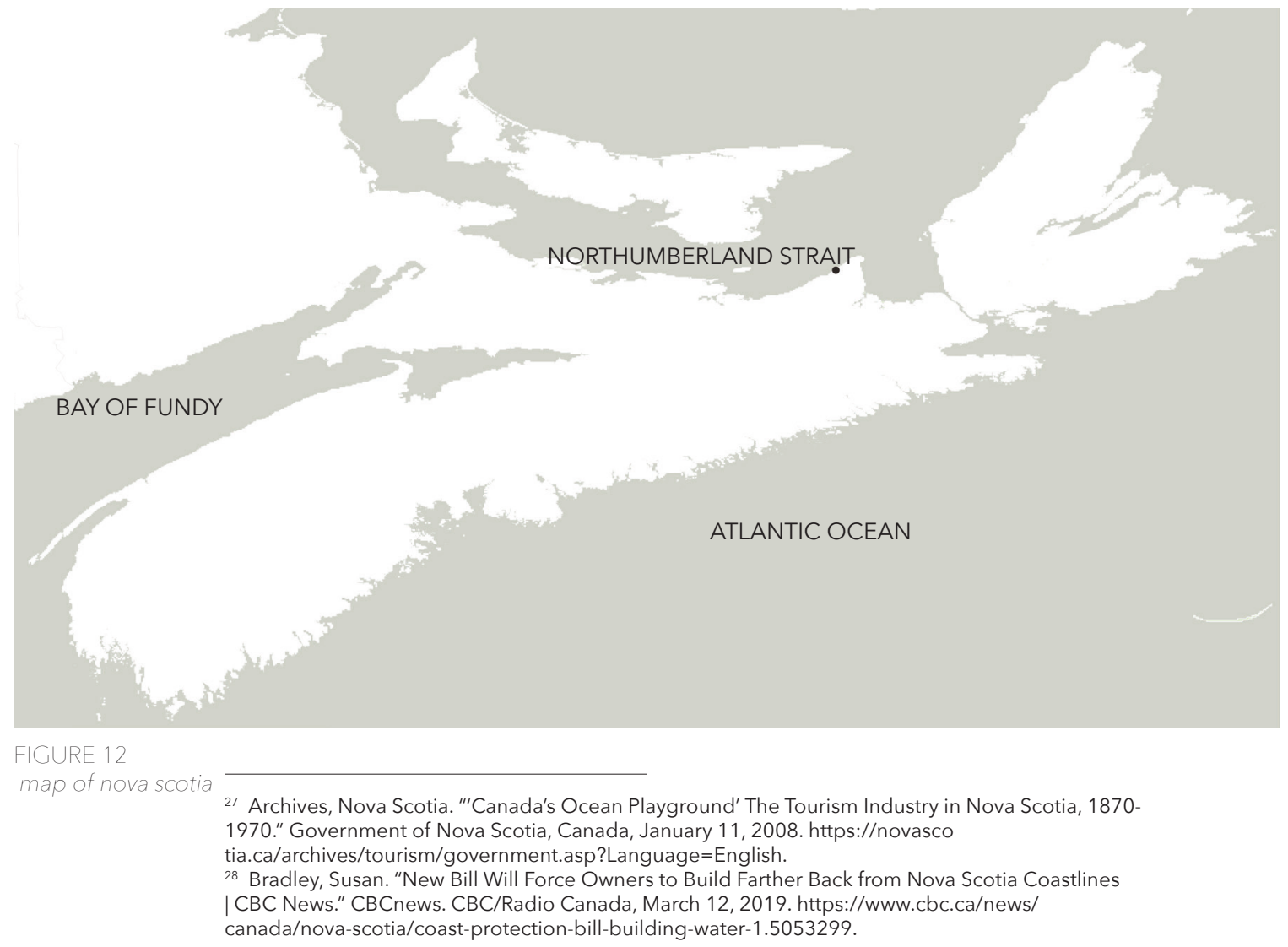




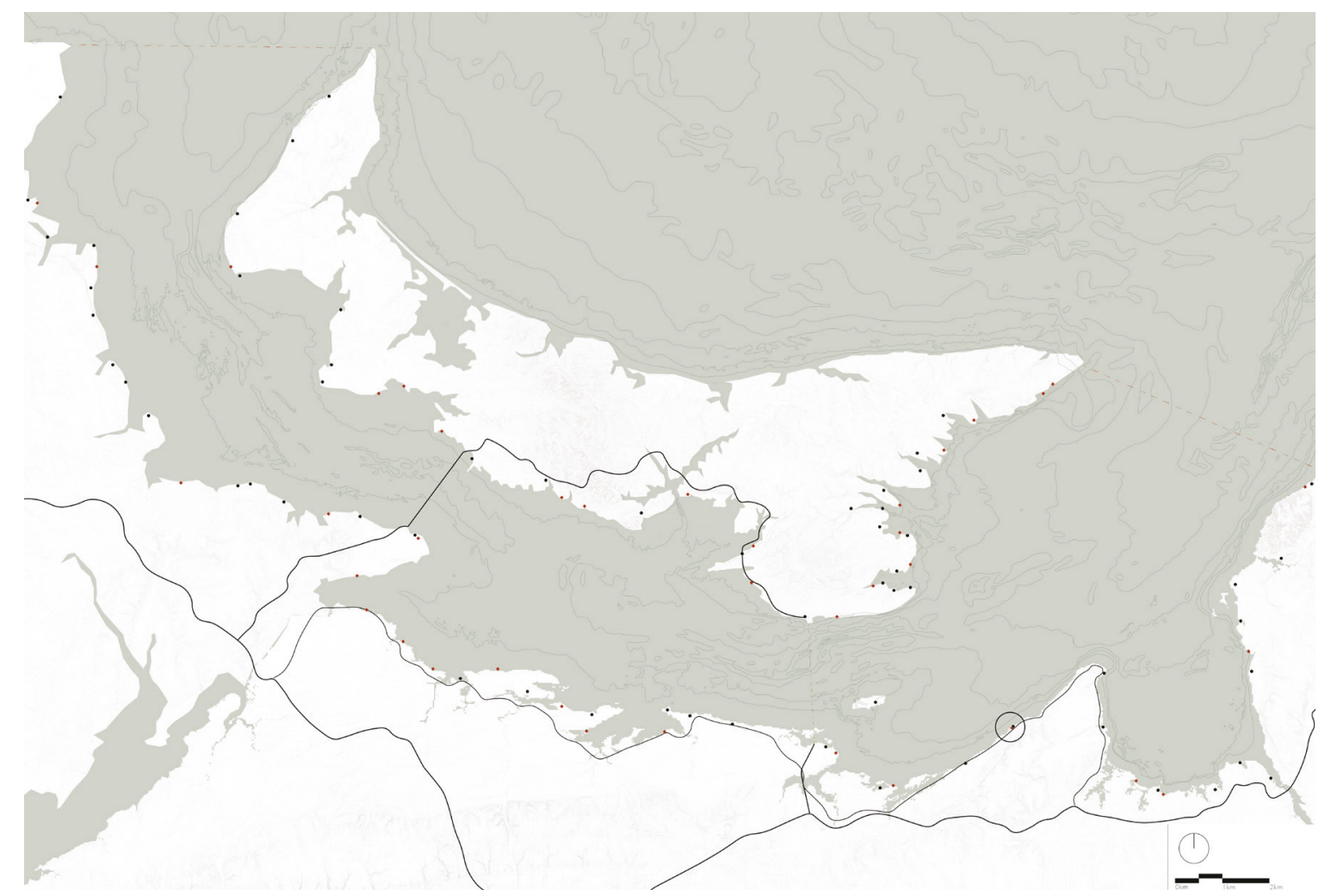

FIGURE 13 map of the northumberland strait

The Northumberland Strait is a narrow body of water in the Southern Gulf of St. Lawrence that is know for its shallow depths, warm waters, and freezing over in the winter. ${ }^{29}$ For the months of January, February, and March, the strait is covered in a mixture of grey-white ice and first-year ice, $0.3 \mathrm{~m}$ to $1.7 \mathrm{~m}$ thick. ${ }^{30}$ At its deepest, the Northumberland Strait is only $60 \mathrm{~m}$ deep, but is primarily between twenty and thirty meters deep. In the summer months, it has the warmest waters north of North Carolina, on the Atlantic Coast of North America.

The Strait borders all three Maritime Provinces, and on a clear day, you can see across to land on the other side, a faint blue line on the horizon, which separates the sky from the ocean, a gradient of air, land, and water. As expressed in the two shades of blue in the Arisaig tartan, the ocean has two moods: calm and angry. But the dichotomy of the ocean is not limited to the churning of the waves; the tides create two extremes at the land's end, at high

\footnotetext{
${ }^{29}$ Brookes, L. A. "Northumberland Strait." Northumberland Strait | The Canadian Encyclopedia. February 7, 2006. Accessed April 23, 2019. https://www.thecanadianencyclopedia.ca/en/article/northumberland-strait.

${ }^{30}$ Climate Change Canada. "Government of Canada." Canada.ca. Government of Canada, January 15, 2016. https://www.canada.ca/en/environment-climate-change/services/ice-forecasts-observations/latest-conditions/ glossary.html.
} 


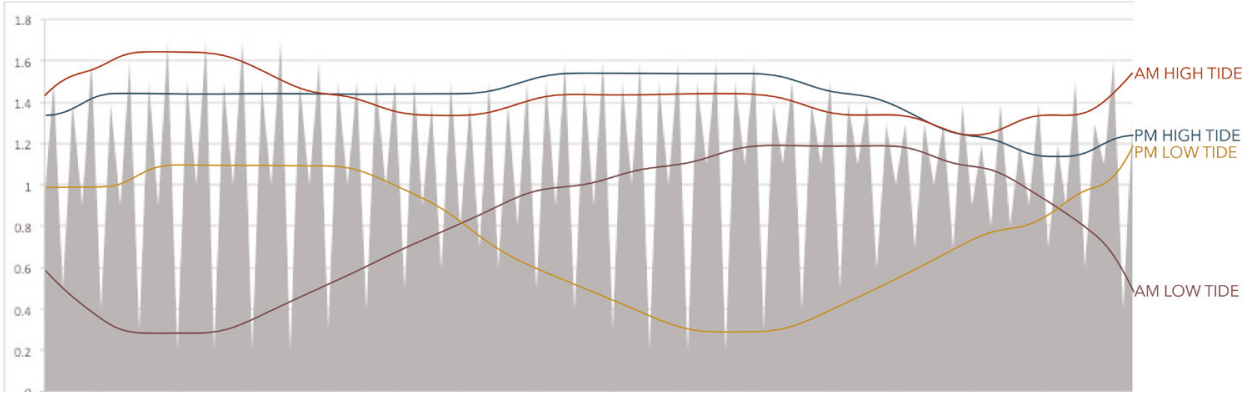

tide and low tide. Arisaig Harbour has a diurnal tide, two highs and two lows per twenty-four hour period. ${ }^{31}$ Figure 14 shows the tide chart for the month of June 2019, along with a graph of the daily highs and lows for that month. The average difference between high and low tide is around $0.7 \mathrm{~m}$, but can be as much as $1.5 \mathrm{~m}$ difference in as little as a few hours. $1.5 \mathrm{~m}$ is about the height of the average adult female, so while these changes in tides are not as impressive as the more famous Bay of Fundy tides, their impact can still be felt at the human scale on the coast. The ebb and flow of the tides expand and compress the land's edge, two extremities ${ }^{32}$ that make the boundary between land and water constantly shift, and the coast is never one fixed, defined line.

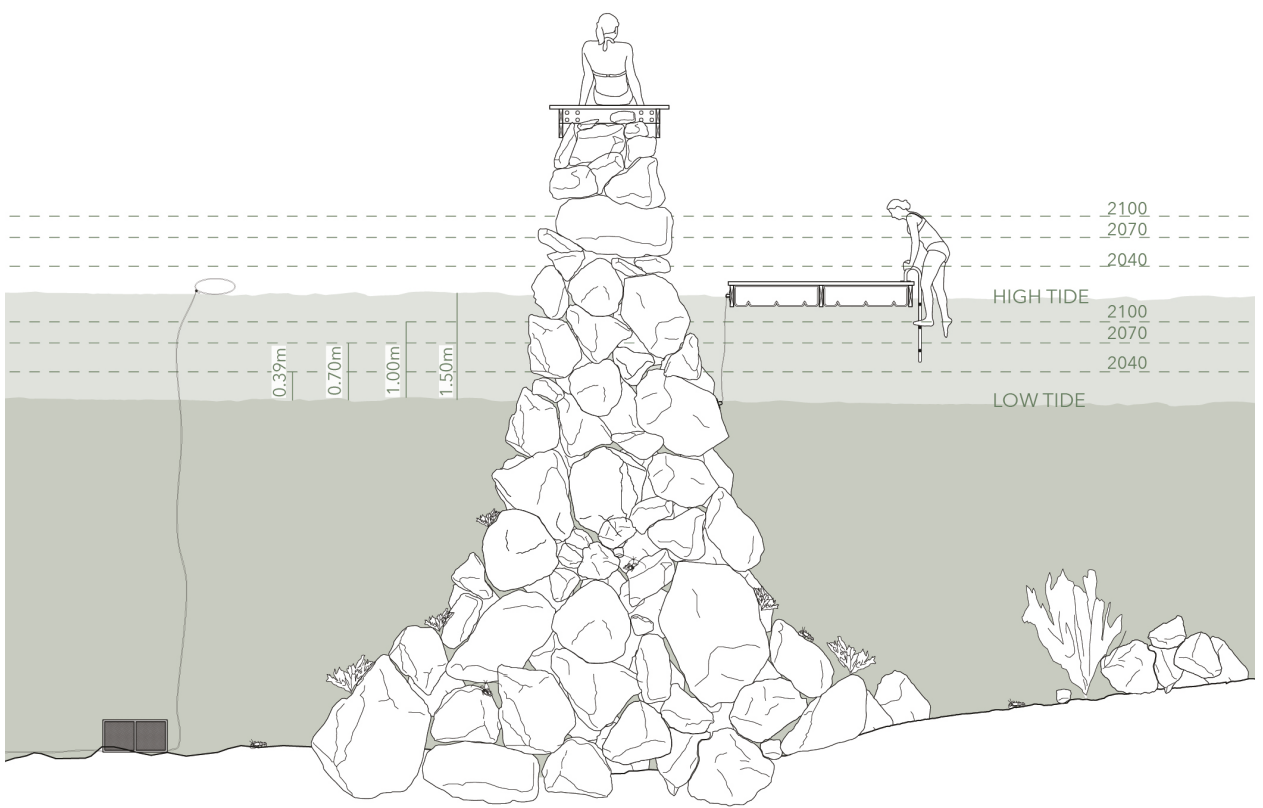

\footnotetext{
31 "Tides, Currents, and Water Levels." Department of Fisheries and Oceans, May 1, 2019. https://www.waterlevels.gc.ca/eng/data/predictions/2019.

32 Hoare, Skin, 7.
} 
One concern when inhabiting the coast is how you are to protect yourself and the built environment from the rough waves and storm surges that crash upon the shore. Figure 16 shows how the wind direction affects the surface waves at the site. From this information, a breakwater design was constructed to shelter the coast. (See figure 17)

FIGURE 16 wind and waves

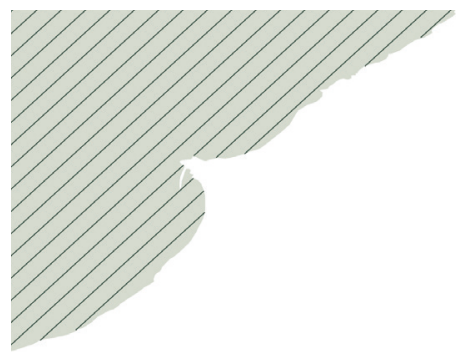

winter

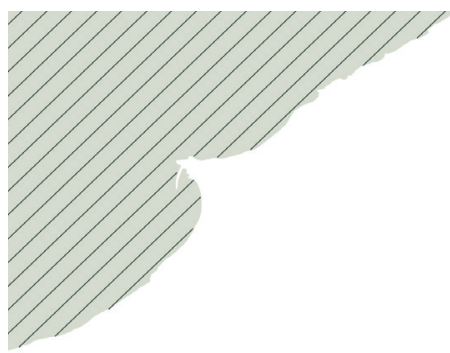

spring

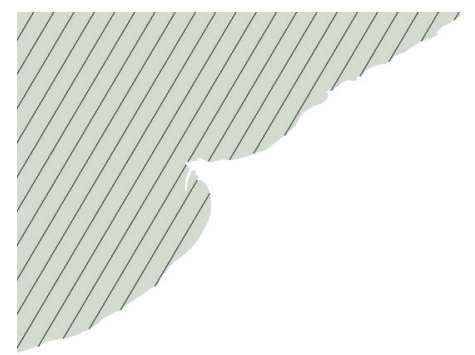

summer

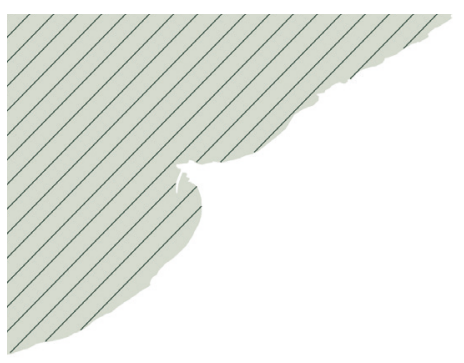

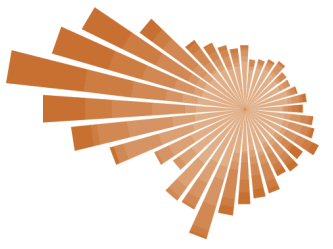
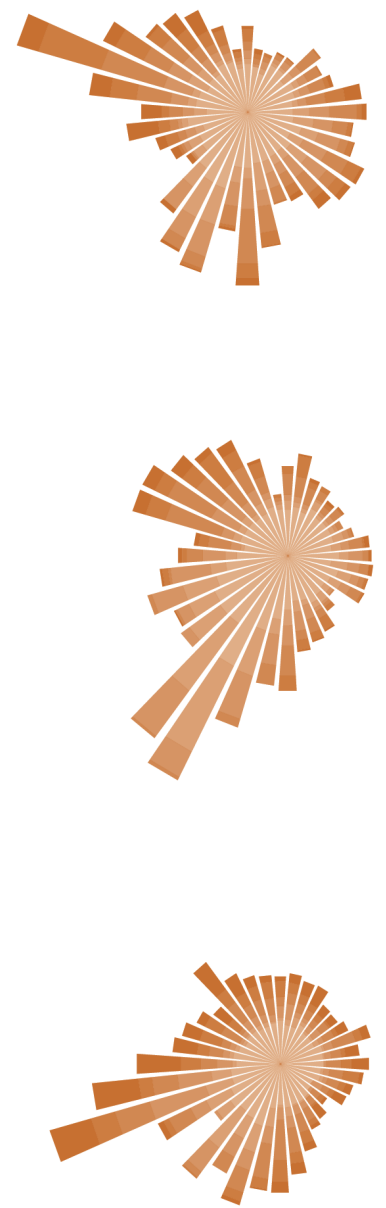
FIGURE 17

breakwater

iterations
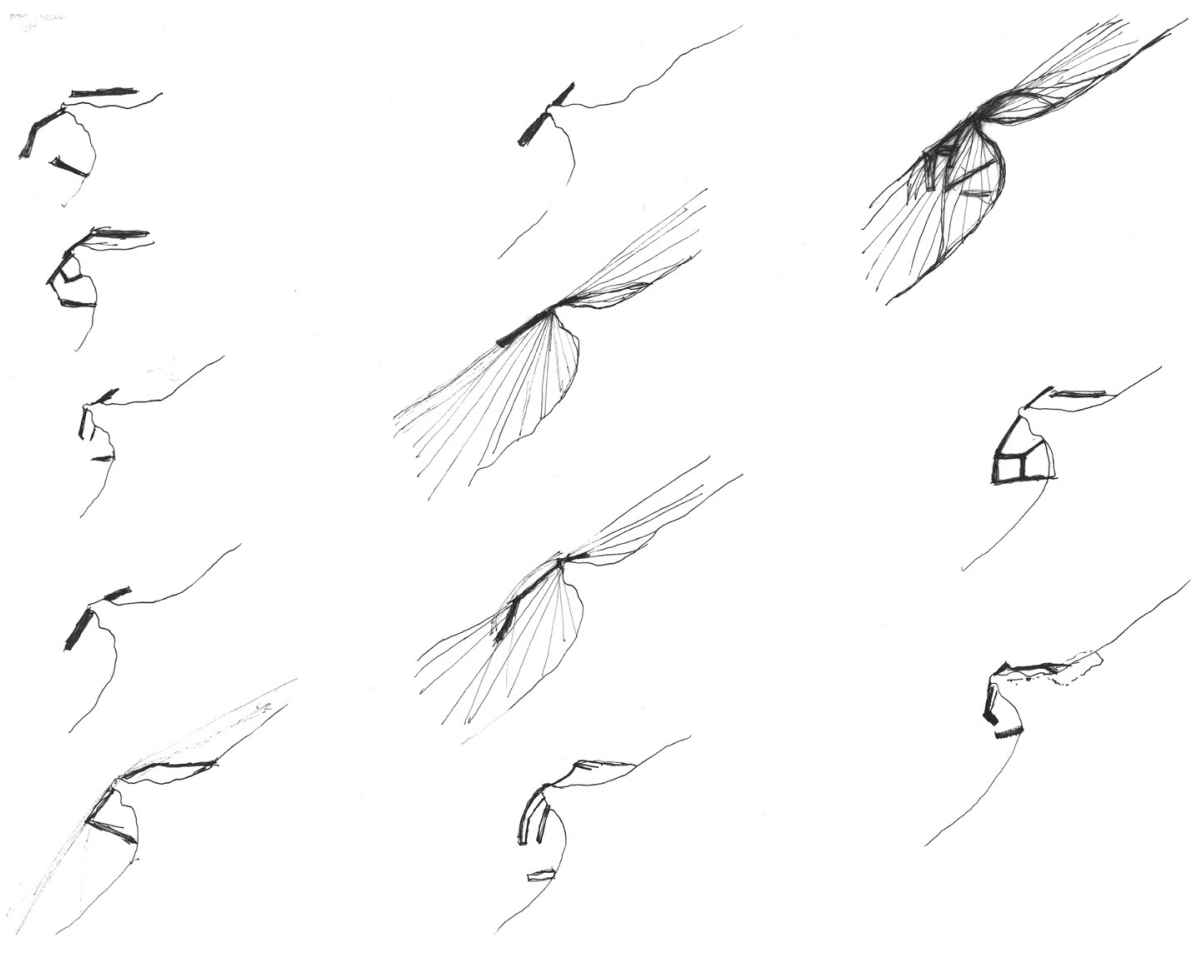

On a global scale, the oceans are rising in both height and temperature as a result of a warming climate, and melting polar ice caps. ${ }^{33}$ In the

Northumberland Strait, the ocean level is projected to rise by $1 \mathrm{~m}$ by the year $2100 .{ }^{34}$ (See figure 18). Between the everyday tides and the long-term ocean level rises, there are two temporal scales to consider the in the design of a coastal intervention.

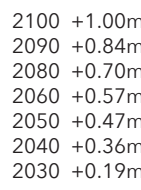

$2030+0.19 m$

MAX HIGH TIDE

AVG HIGH TIDE -

AVG LOW TIDE

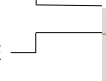

MAX LOW TIDE

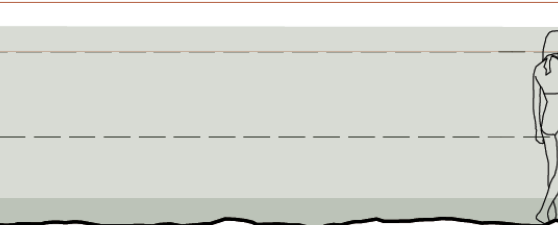

FIGURE 18

rising water levels

${ }^{33}$ Auld, Alison. "The Big Picture: The Looming Threat of Rising Sea Levels - and What We Can Do about It." Dalhousie News, December 12, 2019. https://www.dal.ca/news/2019/12/12/the-big-picture--the-looming-threatof-rising-sea-levels---and-w.html.

34 Ibed. 
The water of the Northumberland Strait is estimated to rise by one degree Celsius per decade at the surface, and 0.25 degrees Celsius at the bottom..$^{35}$ The maps of figure 23 show the rising water levels and temperatures together, using colour to diagrammatically represent average seasonal water temperature, and new edges of coastline where rising water will result in flooding. In Figure 19, the rising water temperatures are illustrated in section through time. Each month is represented by one block, and throughout the seasons, the temperature of the water cycles from nearly freezing temperatures in the winter, to warm-enough-for-swimming temperatures in the summer. At the bottom of the ocean, the range of temperature of the water is not as pronounced as it is at the surface. As time progresses, the difference between surface temperature and bottom temperature increases, as illustrated in figure $19,20,21$, and 22.

FIGURE 19

surface and bottom water temperature pattern 2020 - 2100
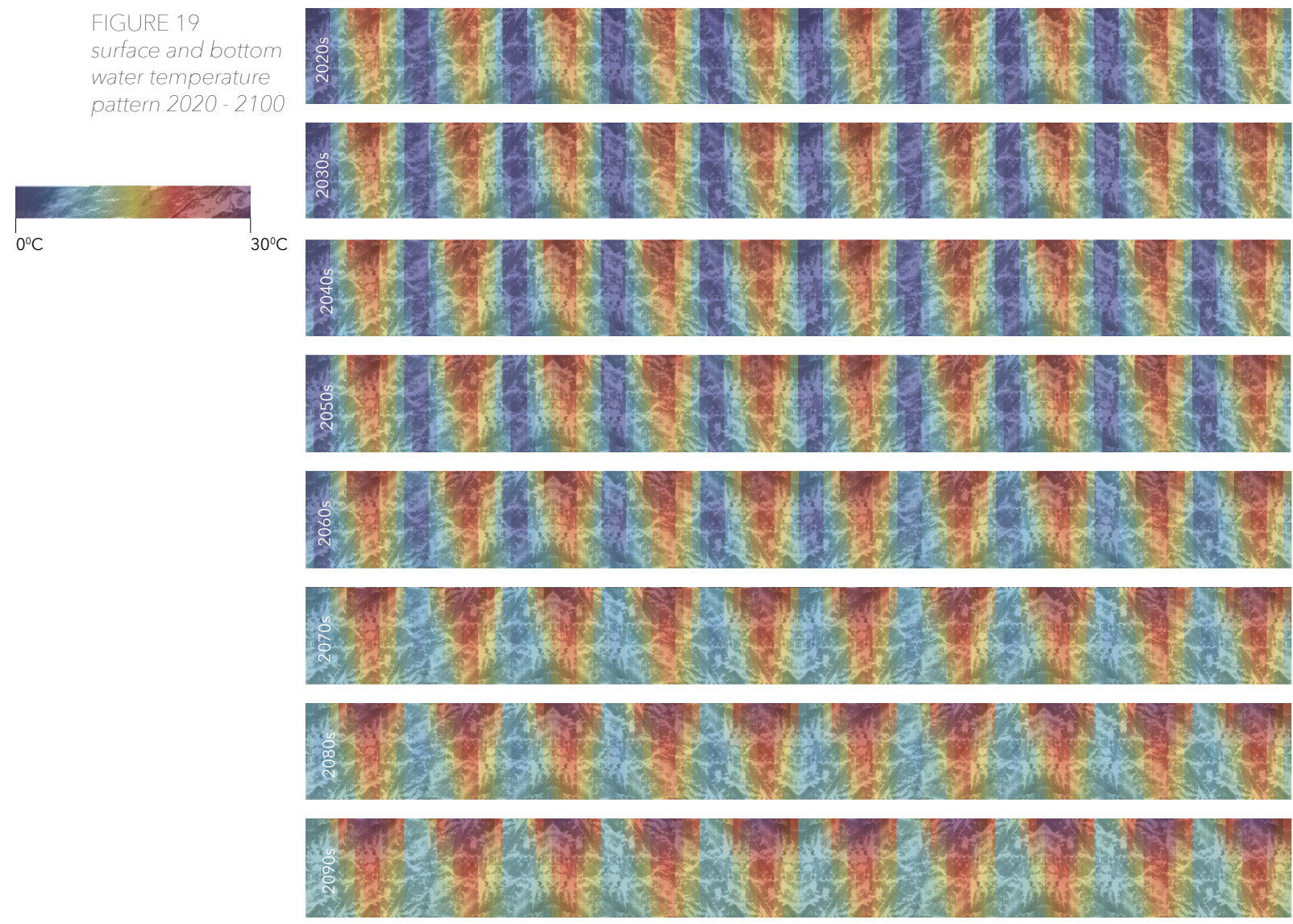

35 Fisheries and Oceans Canada, Communications Branch. "Canada's Oceans Now: Atlantic Ecosys tems, 2018." Government of Canada, Fisheries and Oceans Canada, Communications Branch, June 7, 2019. http://dfo-mpo.gc.ca/oceans/publications/soto-rceo/2018/atlan tic-ecosystems-ecosystemes-atlantiques/index-eng.html. 
tourism

fisheries prep

fishing season

hatchery $\sqrt{6} \sqrt{6} \sqrt{6} \sqrt{6}$

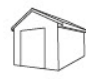

回

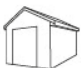

$$
\square
$$

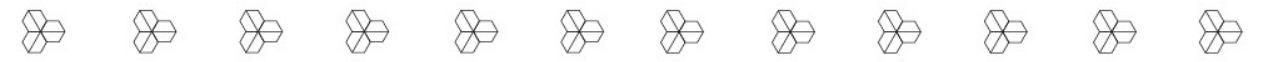

$\operatorname{depth}(\mathrm{m})$

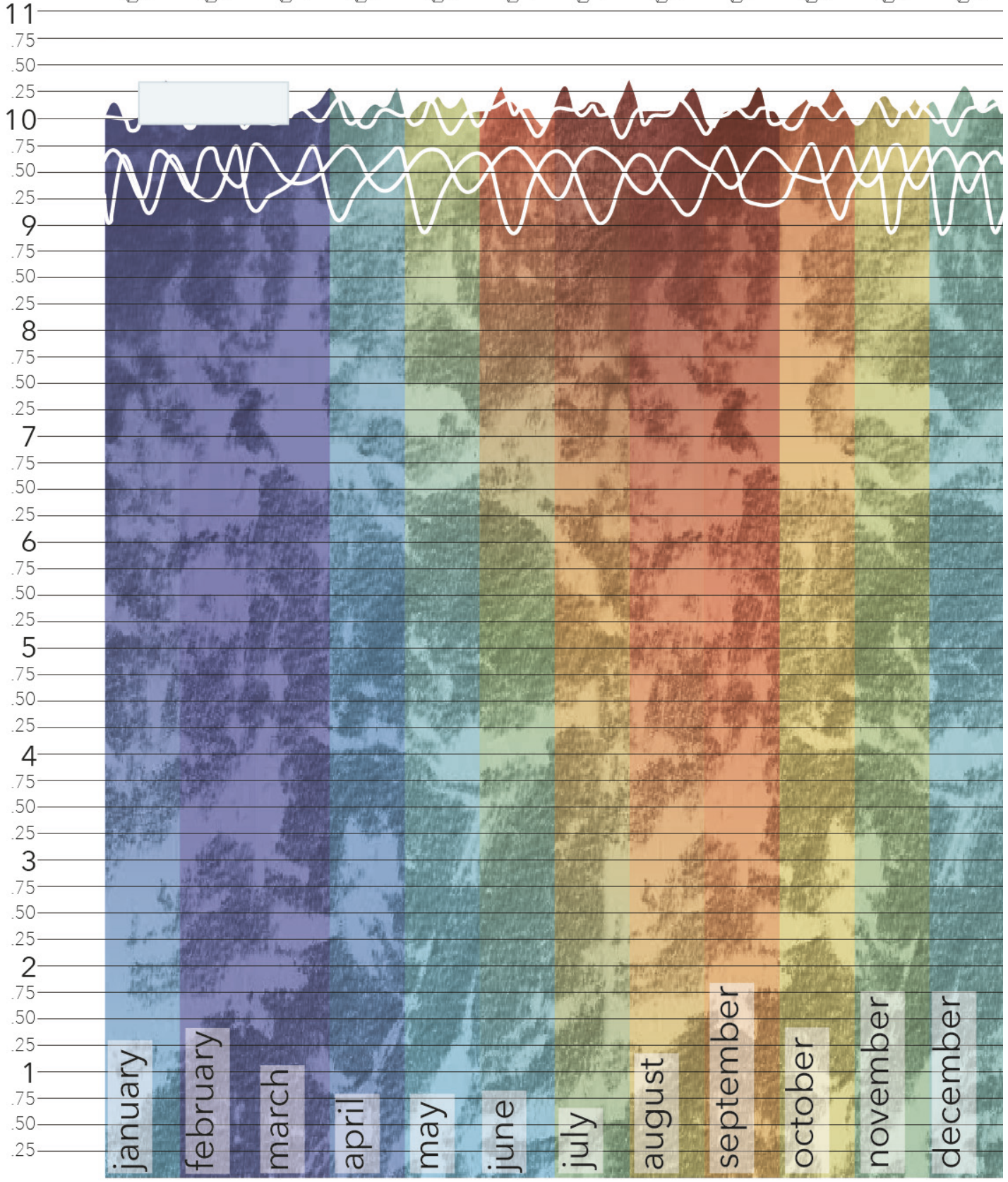

FIGURE 20

surface and bottom water temperatures 2040 
tourism

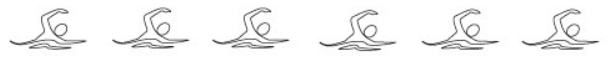
fisheries prep $\widehat{\mathbb{D}} \widehat{\mathbb{D}}$ $\widehat{\square} \mathrm{D}$

fishing season

$$
\longrightarrow
$$

hatchery $\& \& \& \& \& \& \& \otimes$

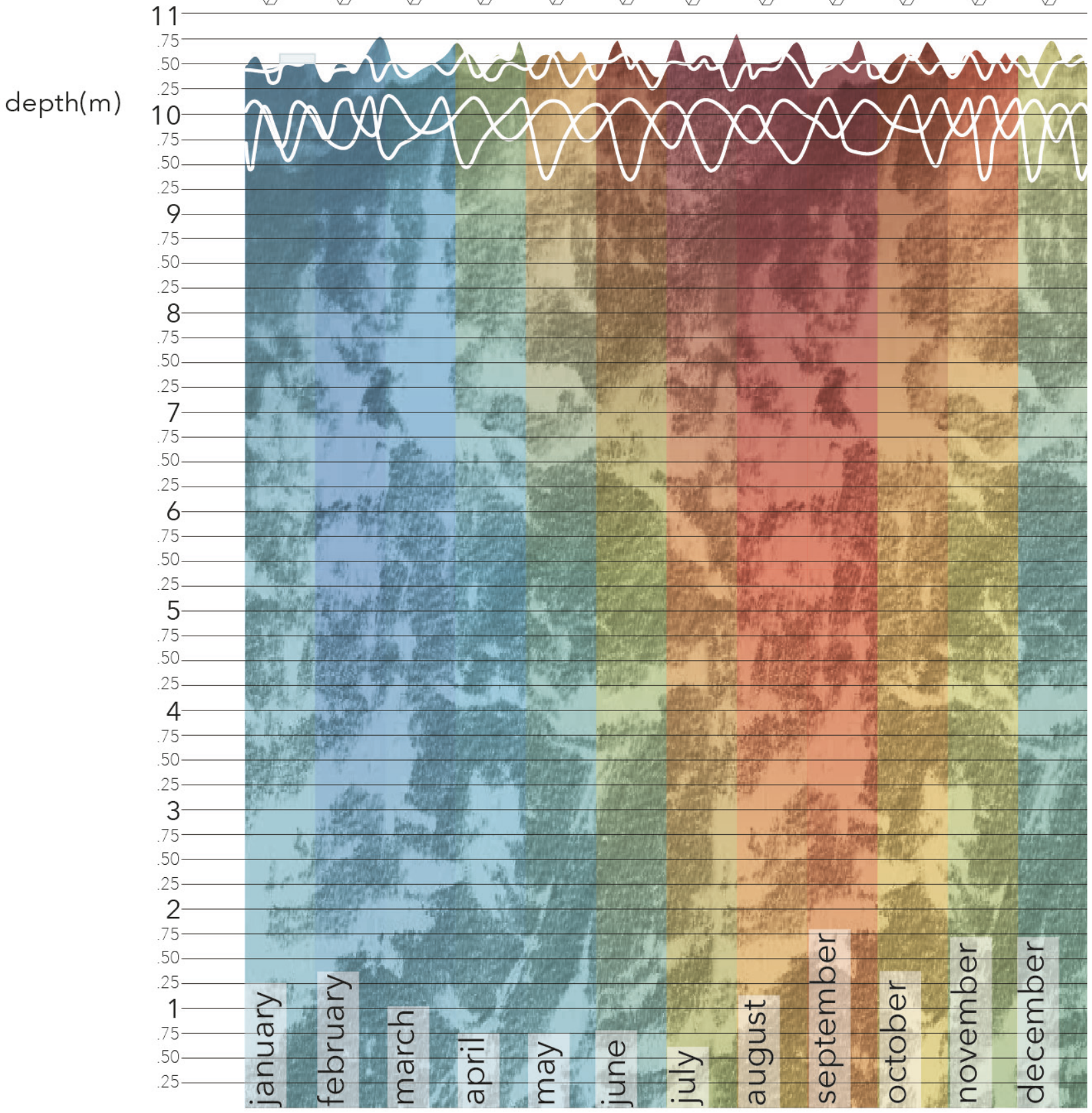

FIGURE 21

surface and bottom water temperatures 2070 
tourism

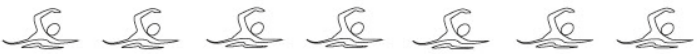

fisheries prep $\widehat{\mathbb{D}} \widehat{\mathbb{1}} \mathbb{\mathrm { C }}$

fishing season

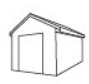

hatchery $\& \otimes \otimes \& \& \otimes \otimes \& \otimes$

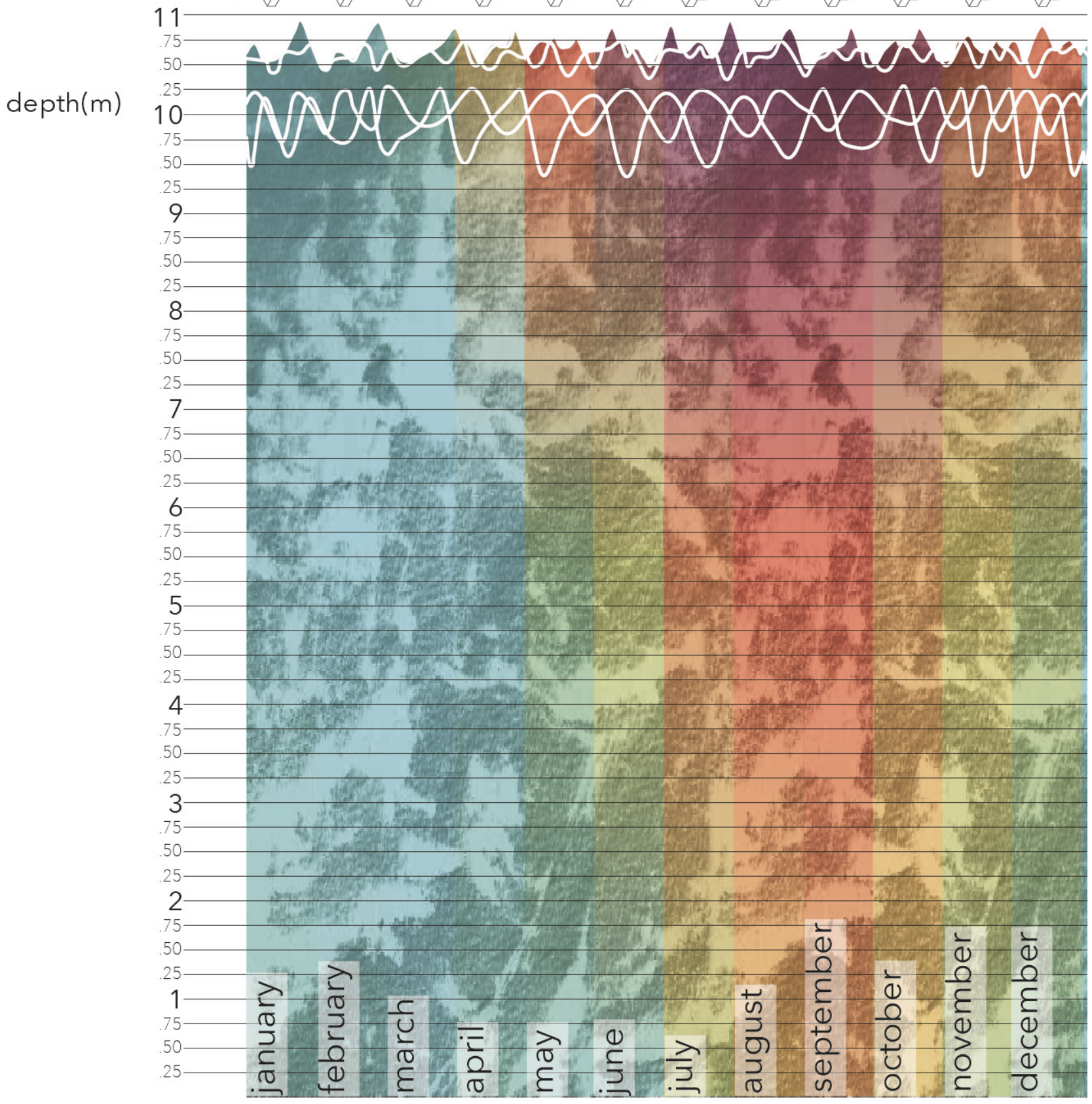

FIGURE 22

surface and bottom water temperatures 2100 
FIGURE 23

rising water levels

and temperatures

Summer 2040 is

marked as season

where $25^{\circ} \mathrm{C}$ is

average surface

temperature

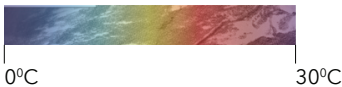

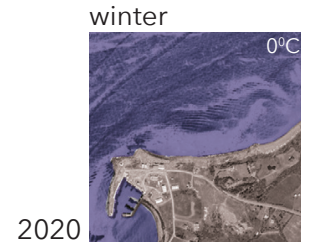
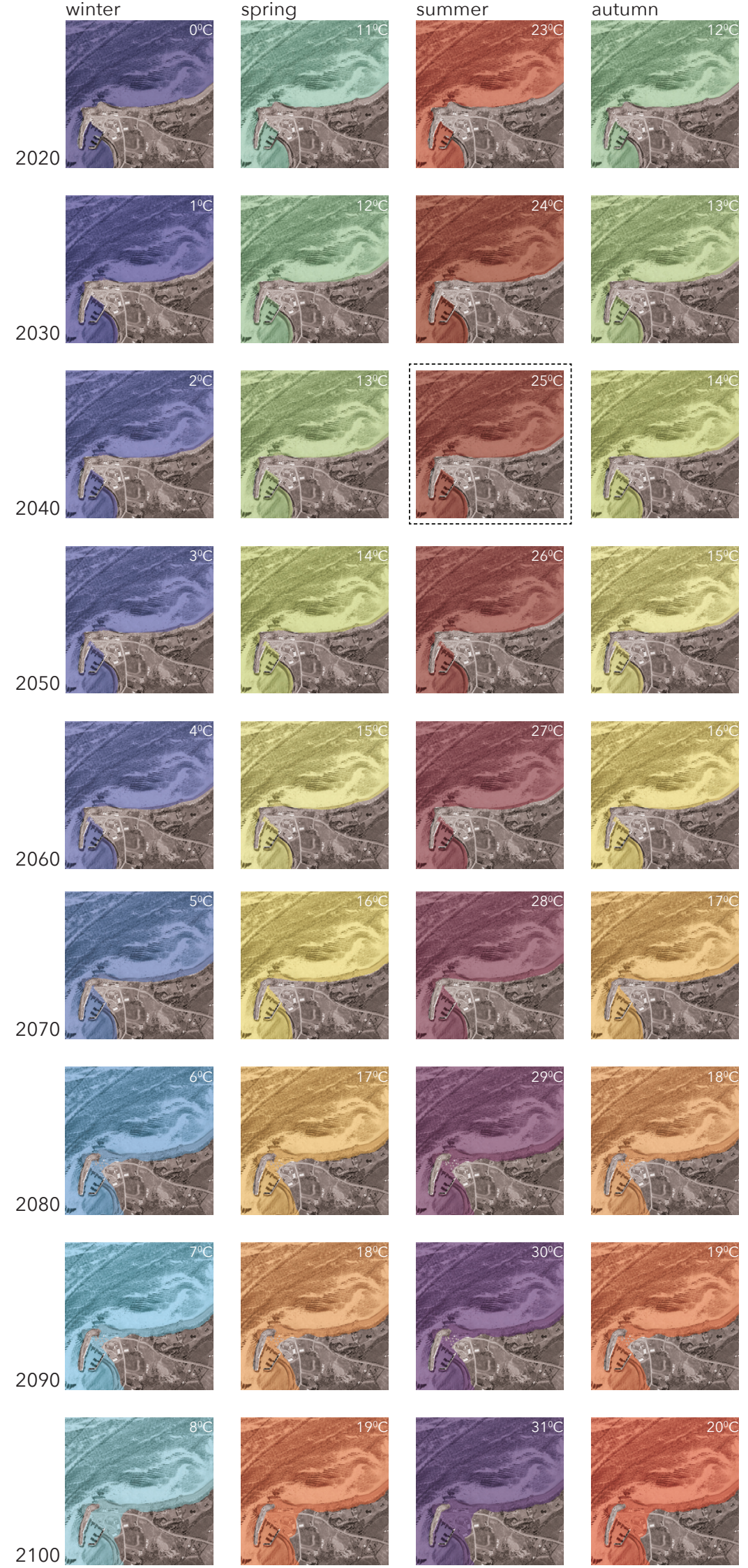
To be able to understand what we need to do to help the lobster, we first must need to understand them; their habitat, movement patterns, their own relationship with the ocean, and their position in a greater ecosystem. As cold-blooded animals, the temperature of their surroundings, the water, dictates much of what a lobster does. ${ }^{36}$ A lobster begins its life as an egg attached to the underside of its mother's tail. She carries the eggs anywhere from nine to twelve months, and when she senses that the water is warm enough, some time between July and August, she fans her tail and releases the eggs, which hatch into larvae. The larvae float to the surface of the water, where they are vulnerable to prey; easily accessible to birds and fish. A female lobster can carry approximately 10,000 eggs, and of these, only about $0.01 \%$, or 1 , survive ${ }^{37}$ The larvae phase has four phases, and can last anywhere from three to ten weeks, depending on the temperature of the water. ${ }^{38}$ Larvae grow faster in warmer temperatures. Once they are about the size of a dime, the larvae are in Stage IV, and they return to the bottom of the ocean. ${ }^{39}$ Figure 24 , from the University of Maine Lobster Institute shows the four stages of larvae. Juvenile

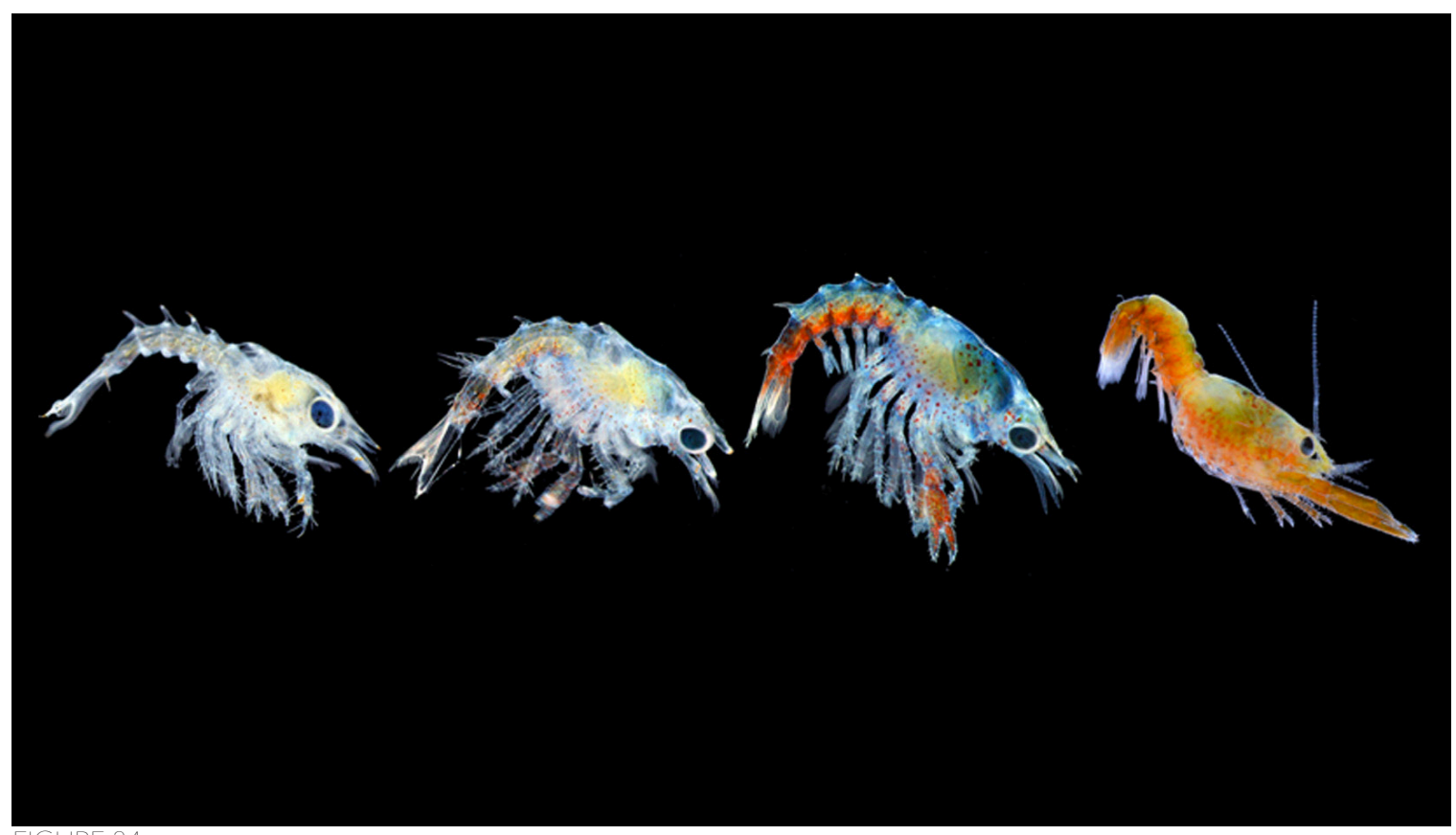

Lobster Larvae Stages.Lobster Institute. University of Maine. https://umaine.edu/lobsterinstitutel.

\footnotetext{
${ }^{36}$ McPhee, John. "Out in the Sort." The New Yorker, April 18, 2005.

37 Fisheries, Integrated Fisheries Management Plan

${ }^{38}$ Fisheries, Integrated Fisheries Management Plan

39 NOAA. "American Lobster." National Oceanic and Atmospheric Administration. Accessed March

10, 2020. https://www.fisheries.noaa.gov/species/american-lobster\#overview.
} 
lobsters remain in sheltered habitats under rock or gravel, only venturing out for food. It takes five to seven years for a lobster to reach a size where it can be harvested for human consumption. ${ }^{40}$

At both the surface and bottom of the ocean, a lobster can live in temperatures not exceeding $25^{\circ} \mathrm{C}$. As discovered through projecting the increase in water temperatures, $25^{\circ} \mathrm{C}$ will be average water surface temperature by the summer of 2040 . The larvae released this season will most likely all reach their stress threshold ${ }^{41}$ and none will survive. This will not be immediately evident, as there will still be adult lobsters at the bottom of the ocean, but eventually, the lack of larvae growing into juvenile lobsters will result in diminished lobster stocks in the Northumberland Strait. If the projection of $0.25^{\circ} \mathrm{C}$ per decade increase at the bottom of the ocean is consistent, then $25^{\circ} \mathrm{C}$ may not be realized for at least another 300 years. ${ }^{42}$ While it is more likely that the rate of temperature increase will increase itself, it is sufficient to say that the benthic layer of the Northumberland Strait will remain a comfortable environment for Homarus Americanus.

FIGURE 25

lobster life cycle.

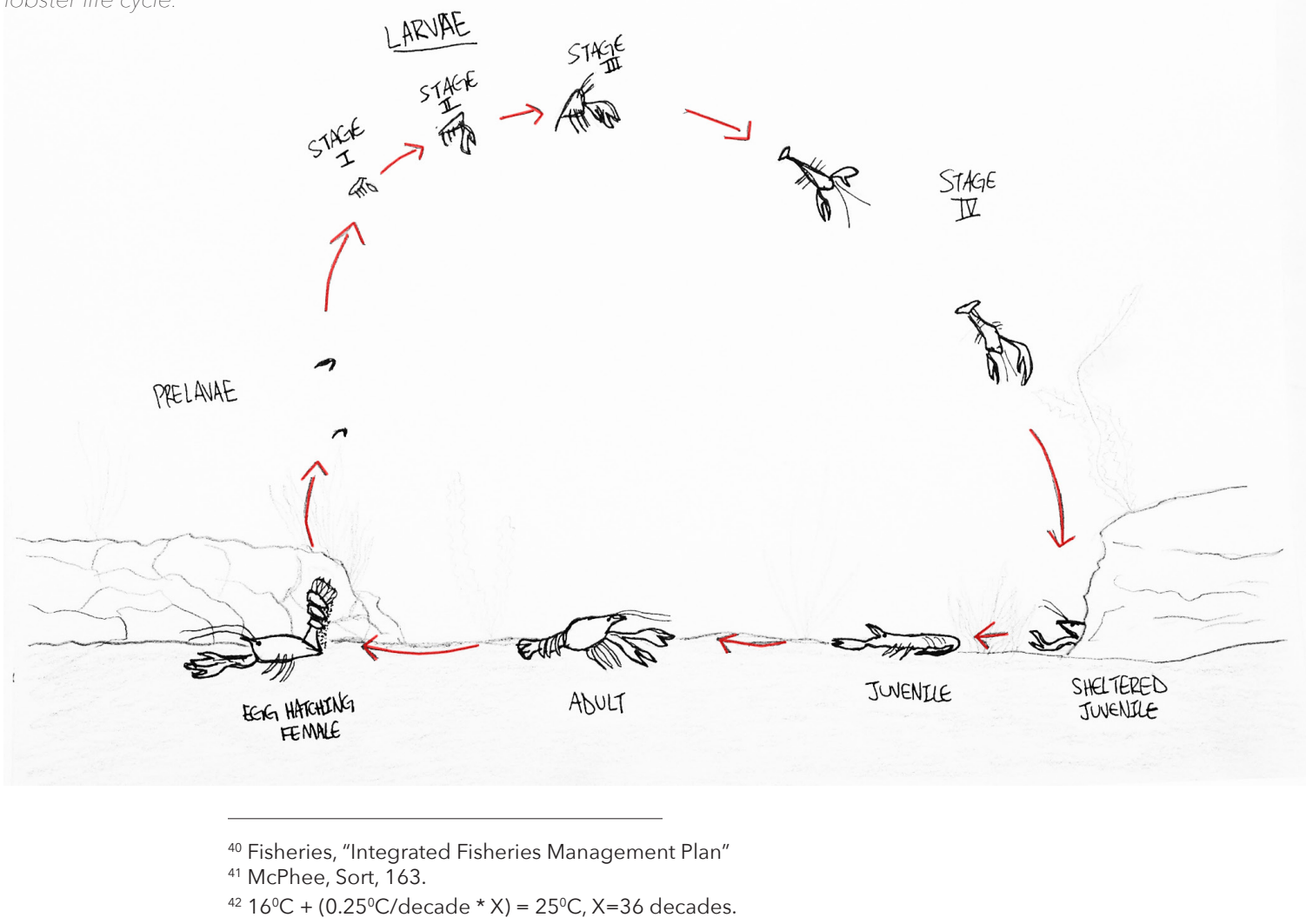


While the temperature of the lobster's environment dictates its survival and behaviors, for humans, we can manipulate the temperature of our environment for comfort. We have a greater agency than that of the lobster.

When we feel too warm, we find ways to cool down. If we are too cold, we can do different things to warm up. Thermal sense is not one of the traditional five senses, ${ }^{43}$ but we are able to sense heat flow in our bodies. Convection of heat through air and radiation of the sun's rays are the most common thermal environments, which makes our conductive thermal relationship with water that much more rare. ${ }^{44}$ As stated in Thermal Delight in Architecture, Lisa Heschong explains, "When we immerse ourselves in water, its temperature is always an important consideration because we exchange heat with it so quickly." ${ }^{45}$ This is especially relevant to the idea of this thesis. The closer a temperature is to our own body temperature of $37^{\circ} \mathrm{C}$, the less intense that quick heat exchange will be, and therefore the more comfortable the experience.

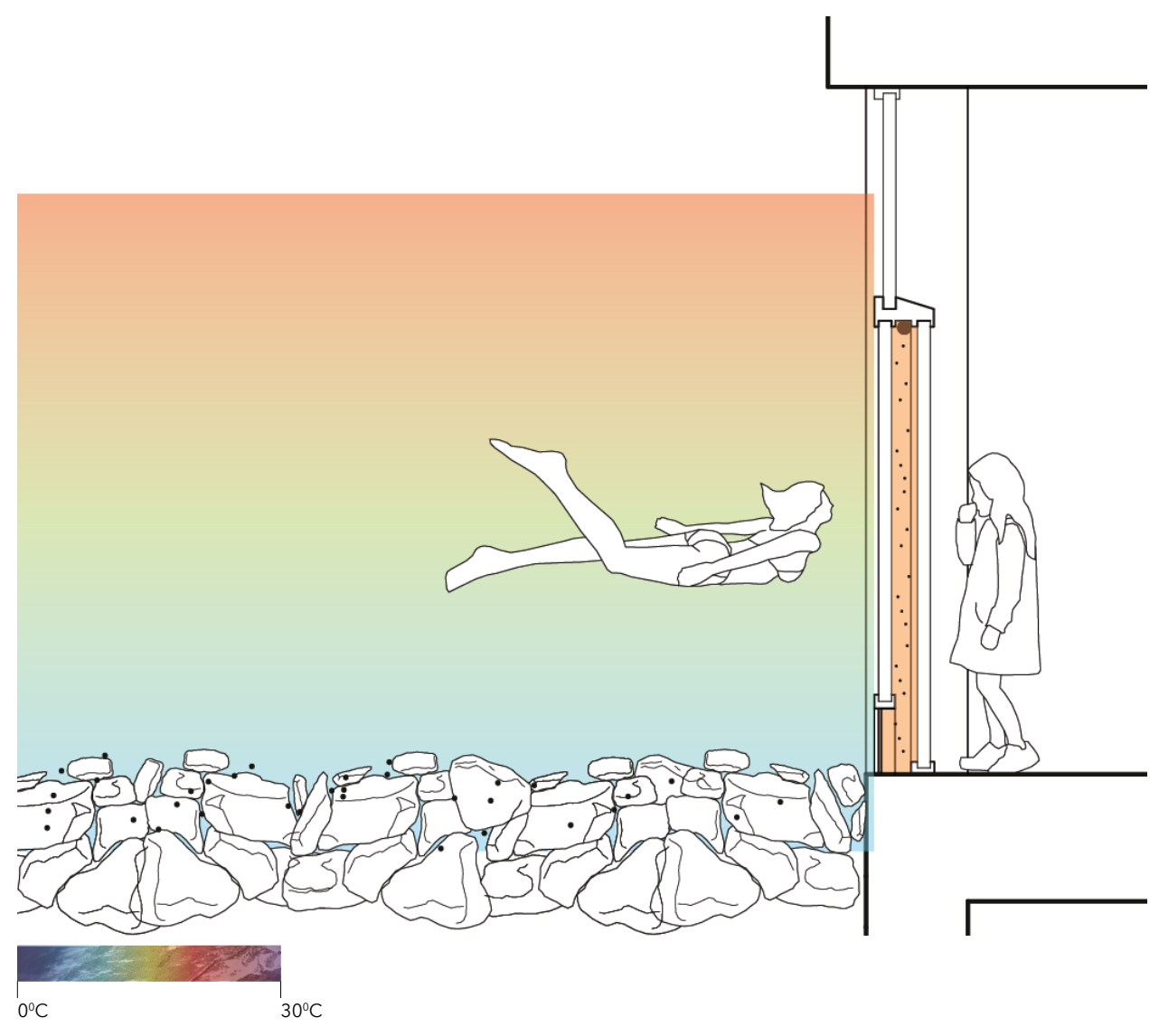

${ }^{43}$ Heschong, Lisa. Thermal Delight in Architecture. Cambridge, MA: M.I.T. Press, 1979, 18. ${ }^{45}$ Ibid., 39.

${ }^{45}$ lbid.,39. 
Architect Phillippe Rahm describes the concept of thermal comfort as acting across different scales: atmospheric, physiological, social, physical, and neurological. ${ }^{46} \mathrm{He}$ defines architecture as "a thermodynamic mediation between the macroscopic and the microscopic, between the body and space, between the visible and the invisible, between meteorological and physiological functions." ${ }^{47}$ This thesis adds another layer of mediation to consider: the thermodynamics between the leisure of human comfort and the sustenance of animal (lobster) survival.

This thesis aims to embrace, rather than resist, the looming threat of climate change. It exploits and mitigates ${ }^{48}$ the challenges of a water environment to create a dynamic network of human-lobster interaction.

\footnotetext{
46 "Digestible Gulf Stream." Philippe Rahm Architectes. Accessed March 10, 2020. http://www.philipperahm.com/ data/projects/digestiblegulfstream/index.html.

47 Ibid.

${ }^{48}$ Finch, Paul. "Water Needs an Architectural Embrace." The Architectural Review, June 2017.
} 
In the previous chapter, lobsters were understood based on their relationship to water temperature. In this chapter, the spatial extent of lobster fishing, lobsters as sustenance, and building for lobsters are examined.

On June 15, 2019, I had the opportunity to join Bernard MacInnis, John Allen MacLean and Eric Maclnnis for a day of lobster fishing on the Carrie Anne. We met at the Arisaig wharf at 4:45am, and headed out of the harbour, in search of the 34 sets of traps to be hauled that day. My expectations were to not only document the process, but also get a sense of the site as approached by way of water. Approaching a site by either land or sea gives you a completely different perspective of a place. ${ }^{49}$
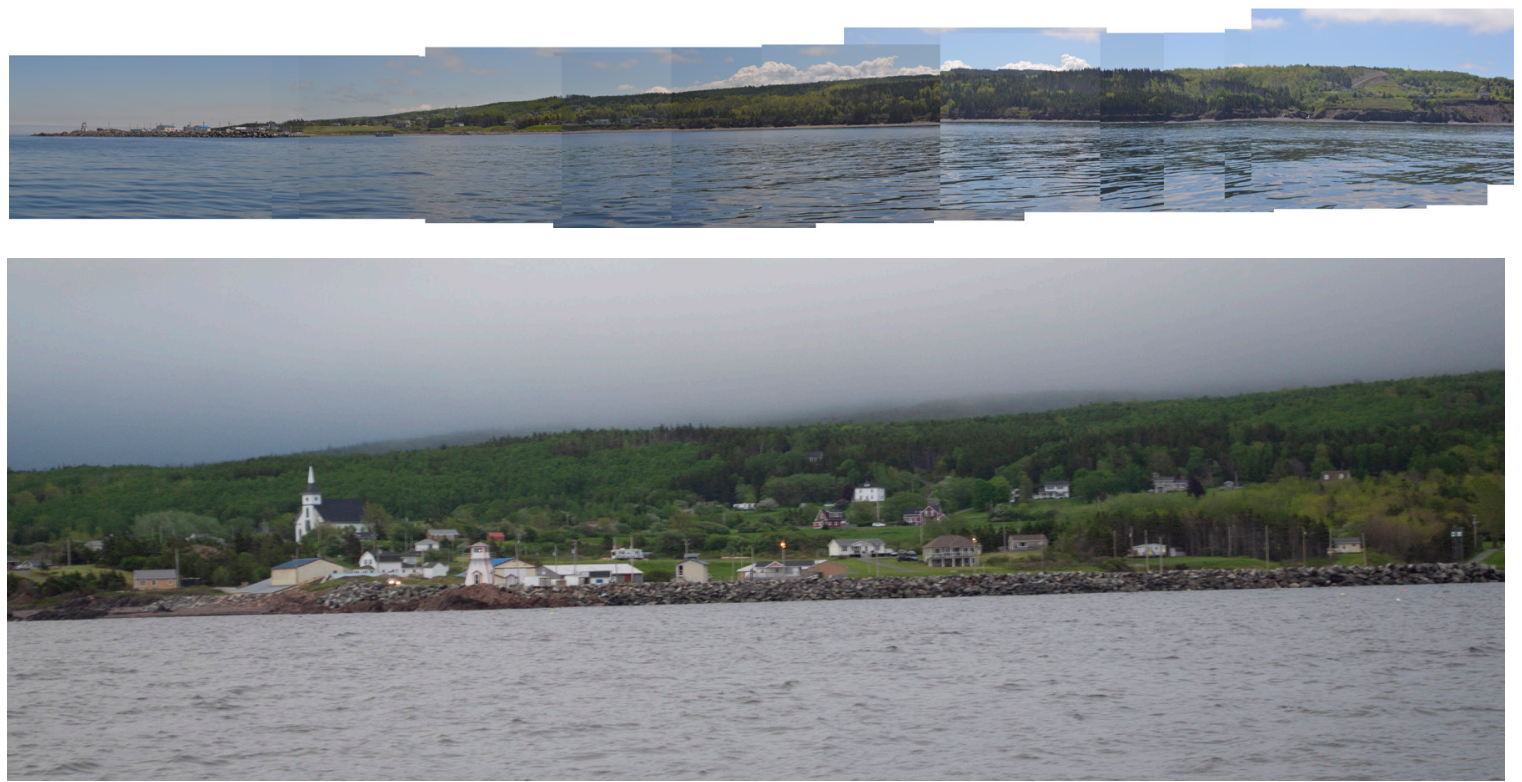

FIGURE 28

Arisaig harbour, NS

\footnotetext{
${ }^{49}$ Ibid., 11.
} 
As we headed away from land, I was introduced to the ocean in a way I had never seen before: an assortment of colourful buoys bobbing on the water's surface, acting as property markers for each fisherman. Where nearby harbours operated under a berth system ${ }^{50}$ where every fisher has his or her own delegated space to fish in, the fishermen and fisherwomen of Arisaig shared the water from the shore of Malignant Cove at the east, to McArras Brook at the west, approximately 15 kilometers of coastline. Legally, anyone with a lobster fishing license can fish anywhere in the Lobster Fishing Area, however the coastline is informally divided by harbour in LFA 26a. For approximately eight hours we drove back and forth, with all of the other boats in a choreographed exercise perfected from years of working alongside each other.

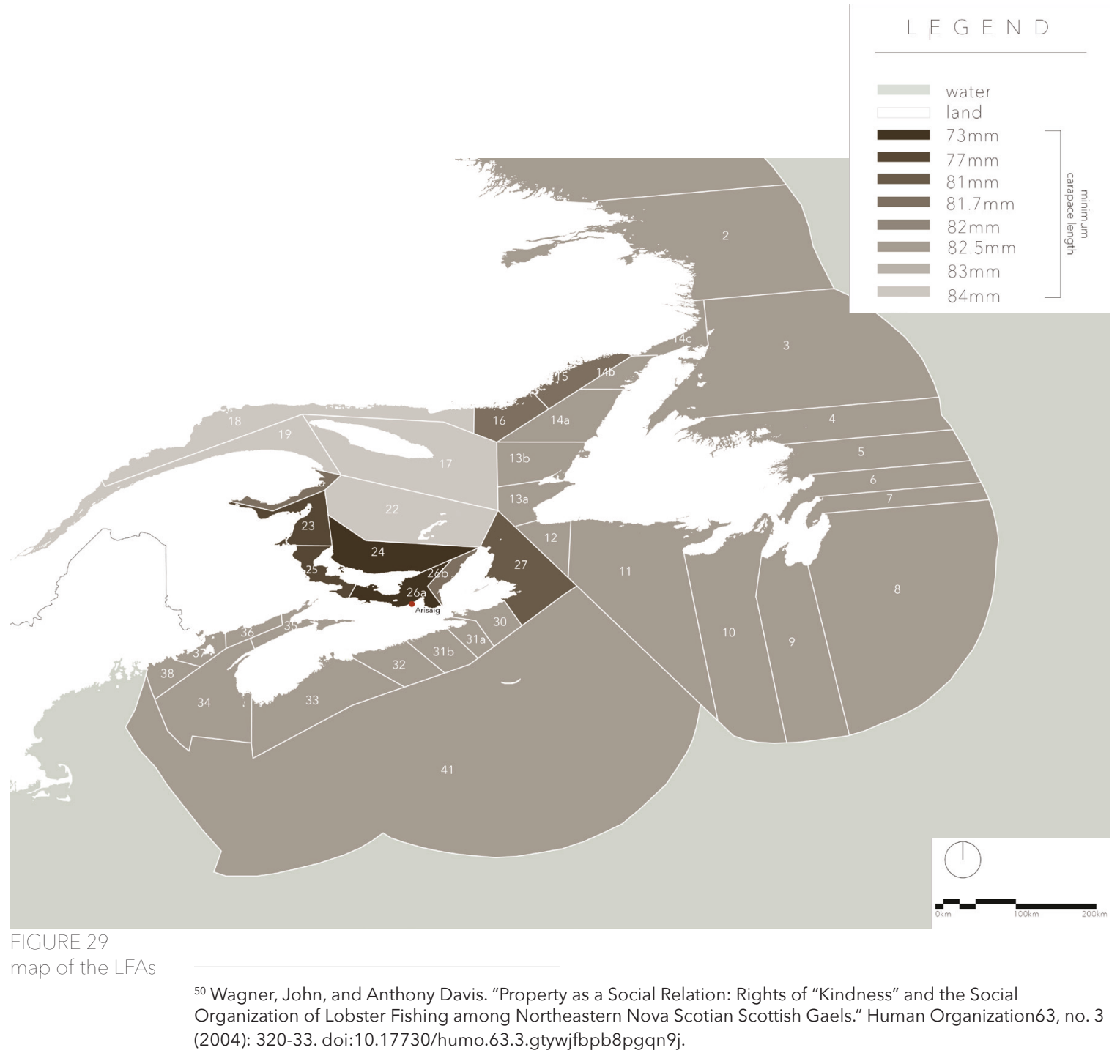




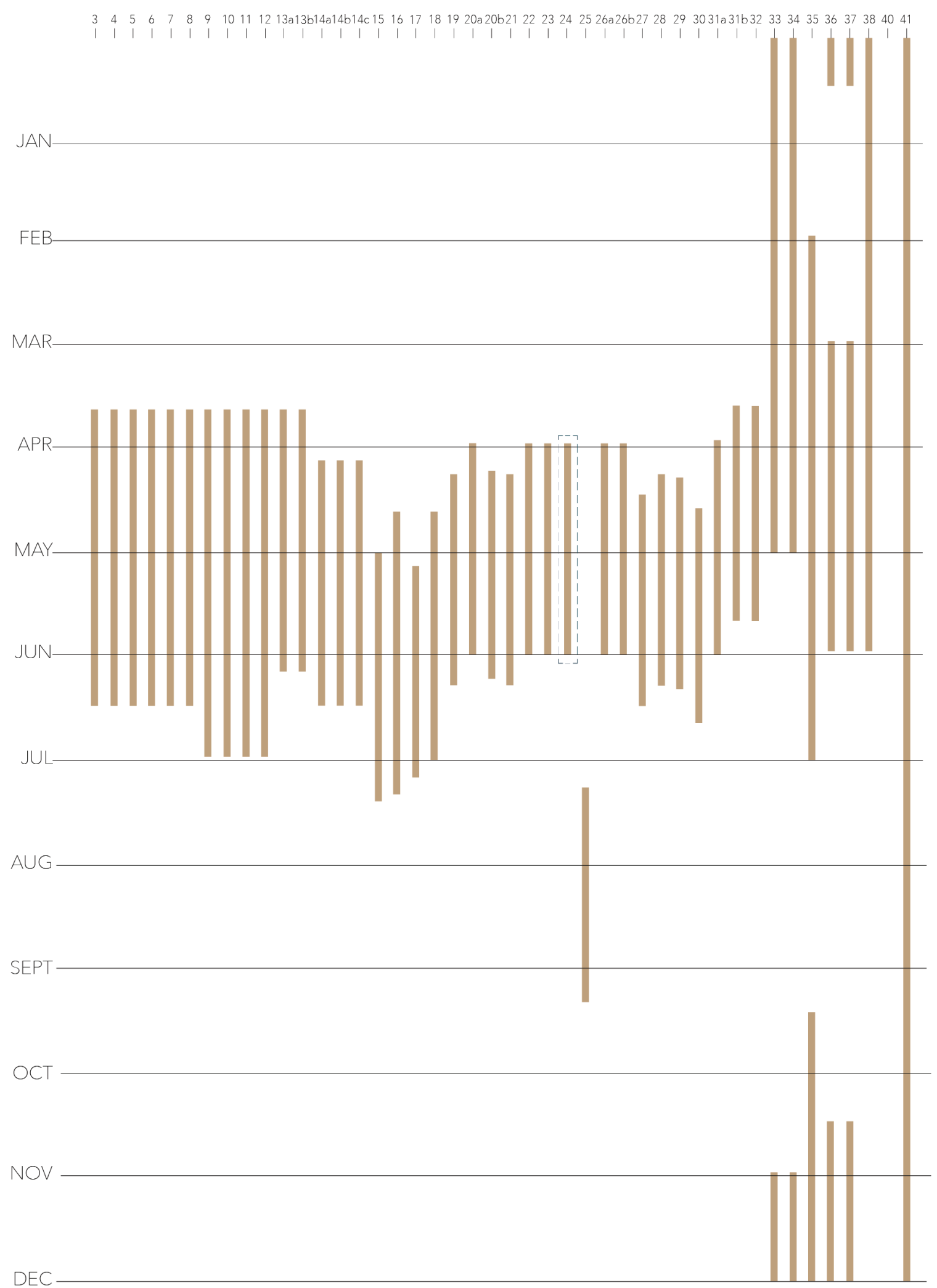

FIGURE 30

LFA fishing seasons 
Much like the choreographed exercise of the boats working together, the tasks on board were completed just as swiftly. Each boat has its own colours of buoys, pink and white buoys marked where the Carrie Anne's traps were. When the boat drove up to a buoy, the number on the buoy was checked and that number was checked off on the tackboard. (31a, 31b) This kept track of which traps were checked. The first buoy was pulled up with a gaffer hook (31c), and the rope attached was secured in a pulley, which pulled the rope until the first trap broke the water's surface. (31d, 31e) The trap was then hooked onto a hydraulic lift, and placed on the side of the boat to be opened. (31f) The bait was replaced $(31 \mathrm{~g}, 31 \mathrm{~h})$, and all lobsters in the trap were measured. (31i)

Once the lobsters were hauled on board, they were sorted and separated. The ones that were too small were thrown back in the water, (31j) and the ones big enough were tossed into a crate to be banded. (31k) Female lobsters with eggs (31l), were also thrown back, as well as those of 'breeding size' in an effort to maintain stocks. This process was repeated for all eight traps that were on the line. Empty traps with fresh bait lined the starboard side. (31 m, 31n, 310, 31p) Captain Maclnnis drove the boat, while John Allen pushed the traps back into the water. (31q, 31r) Lobsters were separated into two categories based on size; markets and canners. Bands were placed on their claws, $(31 \mathrm{~s}, 31 \mathrm{t}, 31 \mathrm{u}, 31 \mathrm{v})$ and the lobsters were then transferred into crates in a small tub of water, to keep them content until they were brought to shore. $(31 w, 31 x)$ When Lobsters are stressed they release ammonia ${ }^{51}$, so they need to be kept comfortable. Once all traps were checked, we headed back to the harbour. Before the boat was parked at the wharf, we drove up to a floating dock to drop off the lobsters at the pound, a temporary building made from a shipping container. Two hundred pounds of lobsters were brought in that day on the Carrie Anne. Shore price, or the price per pound paid, ranged from $\$ 5.00 / \mathrm{lb}$ to $\$ 6.75 / \mathrm{lb}$ for the 2019 season. ${ }^{52}$

\footnotetext{
${ }^{51}$ McPhee, Sort, 163.

${ }^{52}$ Davis, Tony. "Lobster Prices Could Be Better Says P.E.I. Marketing Group | CBC News." CBCnews. CBC/ Radio Canada, June 4, 2019. https://www.cbc.ca/news/canada/prince-edward-island/pei-lobster-prices-2019-1.5161255.
} 
FIGURE 31

fishing day

documentation
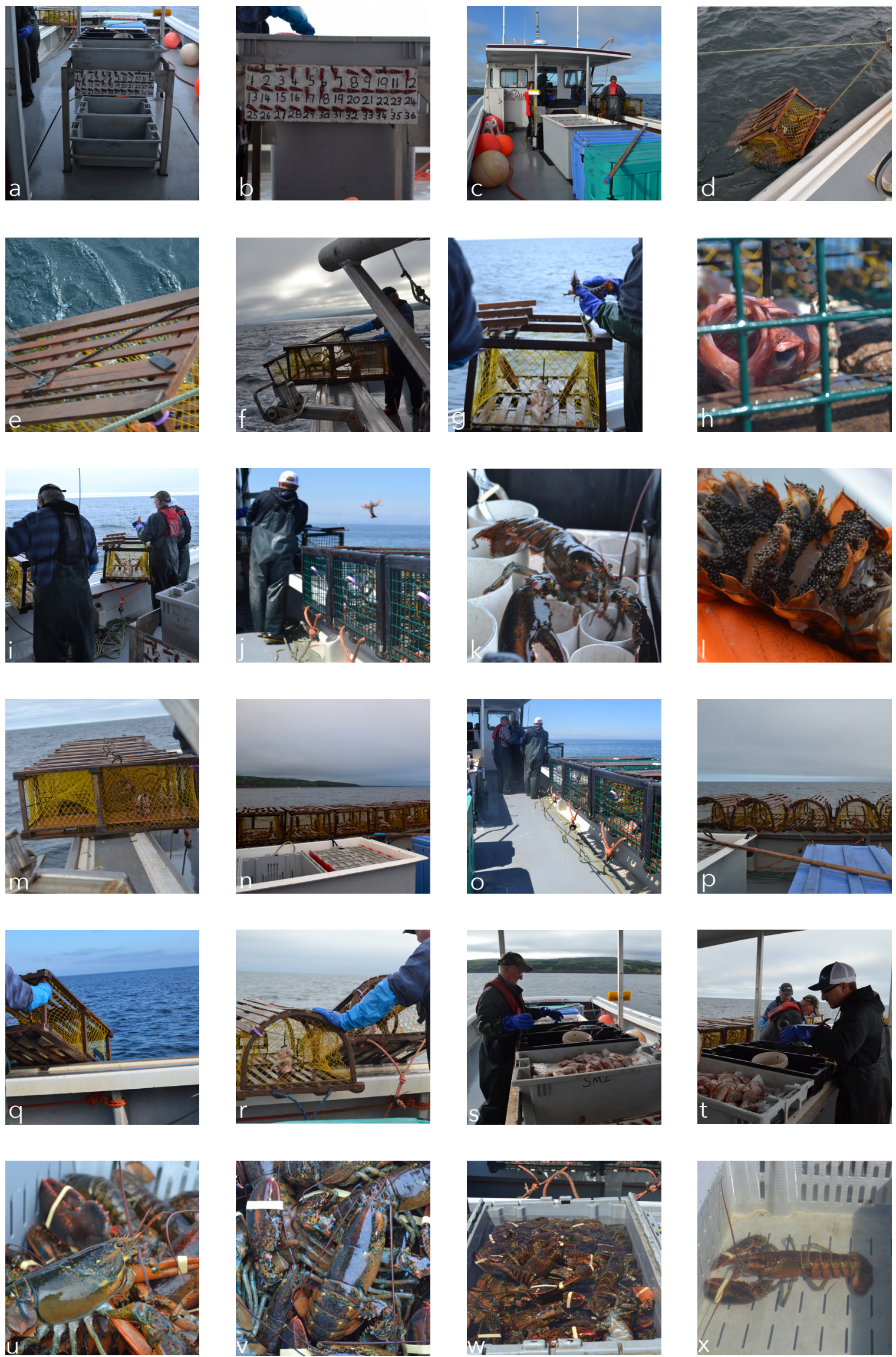
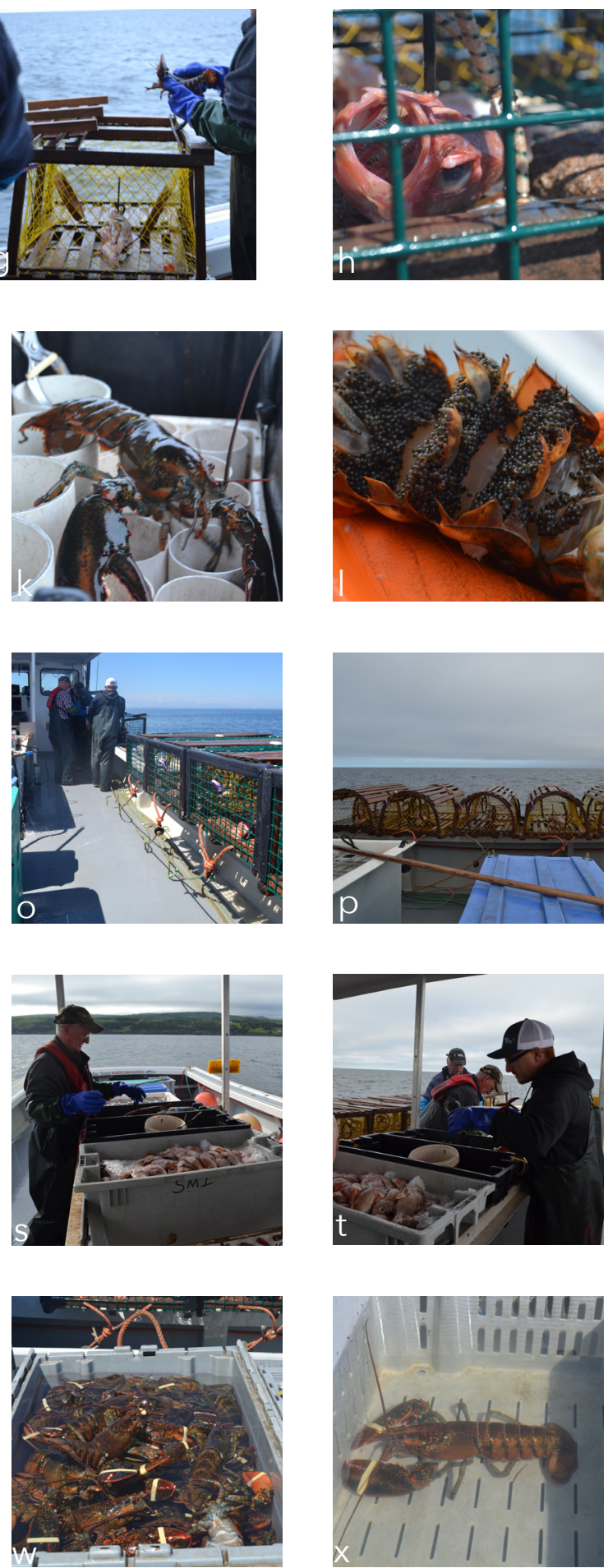
Reflecting on the day, I not only gained a better understanding through first hand knowledge of the lobster fishing process, but the experience challenged an assumption: that land is ground..$^{53}$ There are layered 'grounds' operating in tandem, where the bottom of the ocean is the 'ground' where lobsters live and humans invade with traps, and the ocean's surface, the working 'ground' of lobster fishing boat. The ocean's surface is a skin ${ }^{54}$ that conceals the realm underneath.

When building for animal captivity, whom are we really building for? ${ }^{55}$ In the case of the lobster, the trap is designed with their habits and movements in mind, but is ultimately for the benefit of people: we trap them to eat them. The two main spaces of a lobster trap are called the kitchen and the parlour. (See Figure 32).
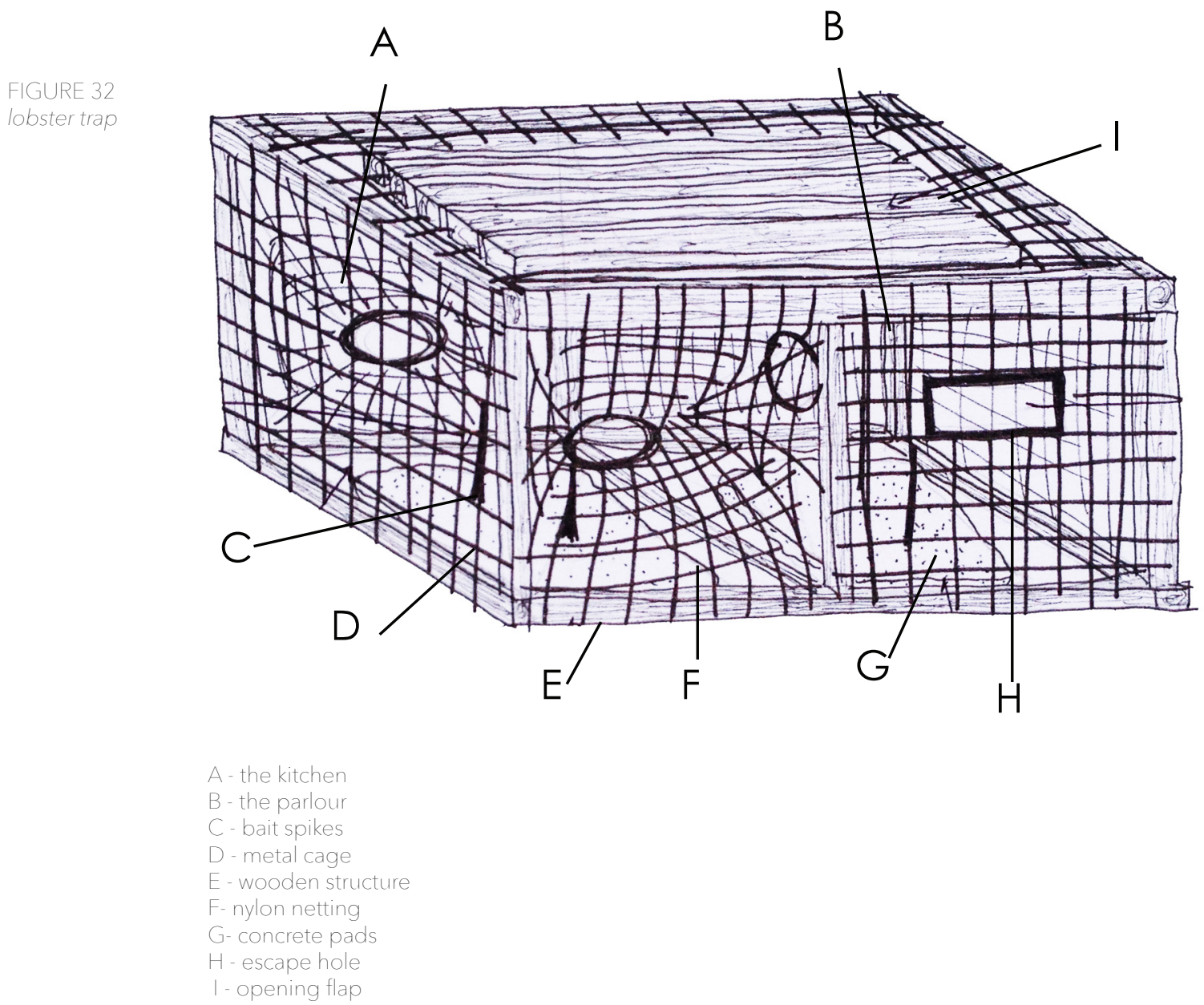

${ }^{53}$ Ashraf, Kazi Khaleed. "Fluid Space." The Architectural Review, June 2017, 8-17, 11., 11.

${ }^{54}$ Hoare, Skin, 8.

55 Wilkenson, Tom. "Typology: Buildings for Animals." The Architectural Review, April 2018, 100 
The names are derived from human household spaces, a personification of the lobster. A kitchen and a parlour were two main rooms of the nineteenth century maritime vernacular house. (See figure 33)
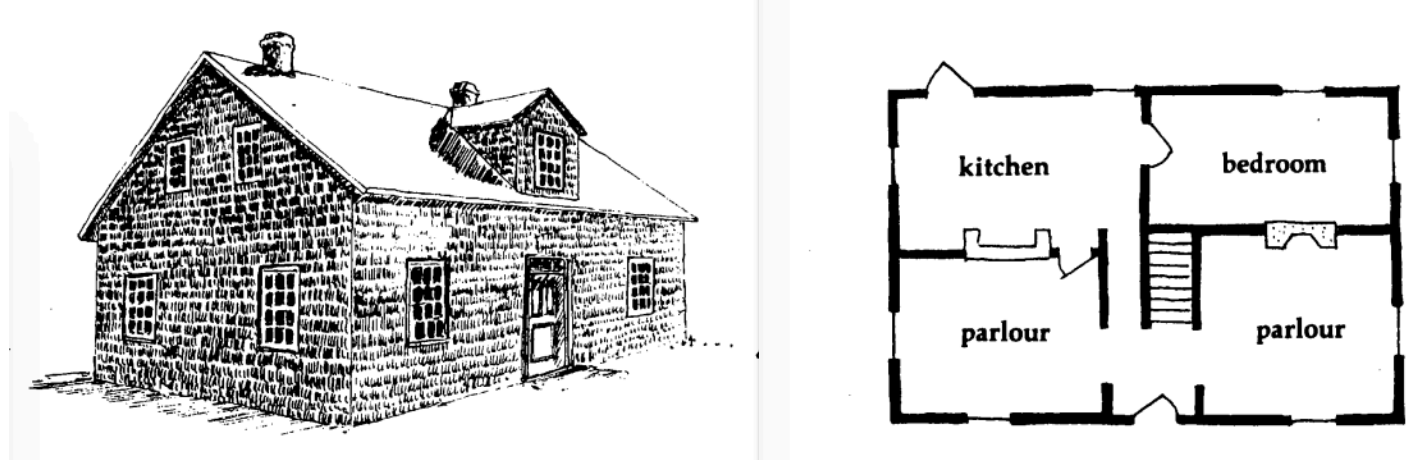

FIGURE 33

kitchen and parlour of Maritime Vernacular house (Ennals, Peter, and Deryck Holdsworth. 1981. "Vernacular Architecture and the Cultural Landscape of the Maritime Provinces - A Reconnaisance". Acadiensis 10 (2), p 93. https://journals.lib.unb.ca/index.php/Acadiensis/article/view/11174.)

Approximately the same size, these two rooms in plan look like the spatial organization of a lobster trap. There is even an entrance through the kitchen, and passage into the parlour. The lobster enters the trap through a net into the kitchen, lured by the smell of bait. Eating happens in the kitchen, just like with people. The lobsters cannot move backwards out of the trap, so their only way to move is into the parlour, where they unsuspectingly wait to be harvested.

One can think of the lobster trap architecturally not only in terms of is programmatic use, but also in its construction. Gottfried Semper's four elements of architecture ${ }^{56}$ can be analogous to the four elements of a trap. The first element is the foundation, or the earthwork. The foundation of the trap is the two concrete pads at the bottom of the trap, which give it weight to sink to the ocean floor. Second, is the framework. Either rounded or rectangular, the structure sits on a rectangular base, and is wooden. The rounded structure is more traditional, but is being phased out by rectangular structures that are easier to stack. The third element, enclosure is the wire mesh and nylon net that keeps the lobsters inside the trap. They enter through a rectangular metal ring in the netting, directed inwards, and move through a metal ring in netting when transitioning from kitchen to parlour. The last element is the hearth. For

${ }^{56}$ Frampton, Tectonic, 6. 
the purposes of this thesis's argument, the hearth is the bait spike in a lobster trap. The hearth is a place of importance, and gathering, not necessarily a component related to a place for a fire. The bait spike, and the bait, is the lure that brings the lobster to the trap.

When one thinks of Nova Scotia, the lobster is an icon that comes to mind. In fact, the cover of the 2019 Nova Scotia travel guide, Doers and Dreamers, features two people seated at a "toasting" with lobster meat on their forks, with the water in the background. The image plays a key role in the social construction of tourism spaces. ${ }^{57}$ Just as an architectural drawing conveys a perception of a space, the tourism image presents a vision of a place, to appeal to certain types of visitors. ${ }^{58}$ The same place can be revealed as a destination for adventure, relaxation, or cultural immersion, based on how the image is constructed. This has consequences for the host community, as these
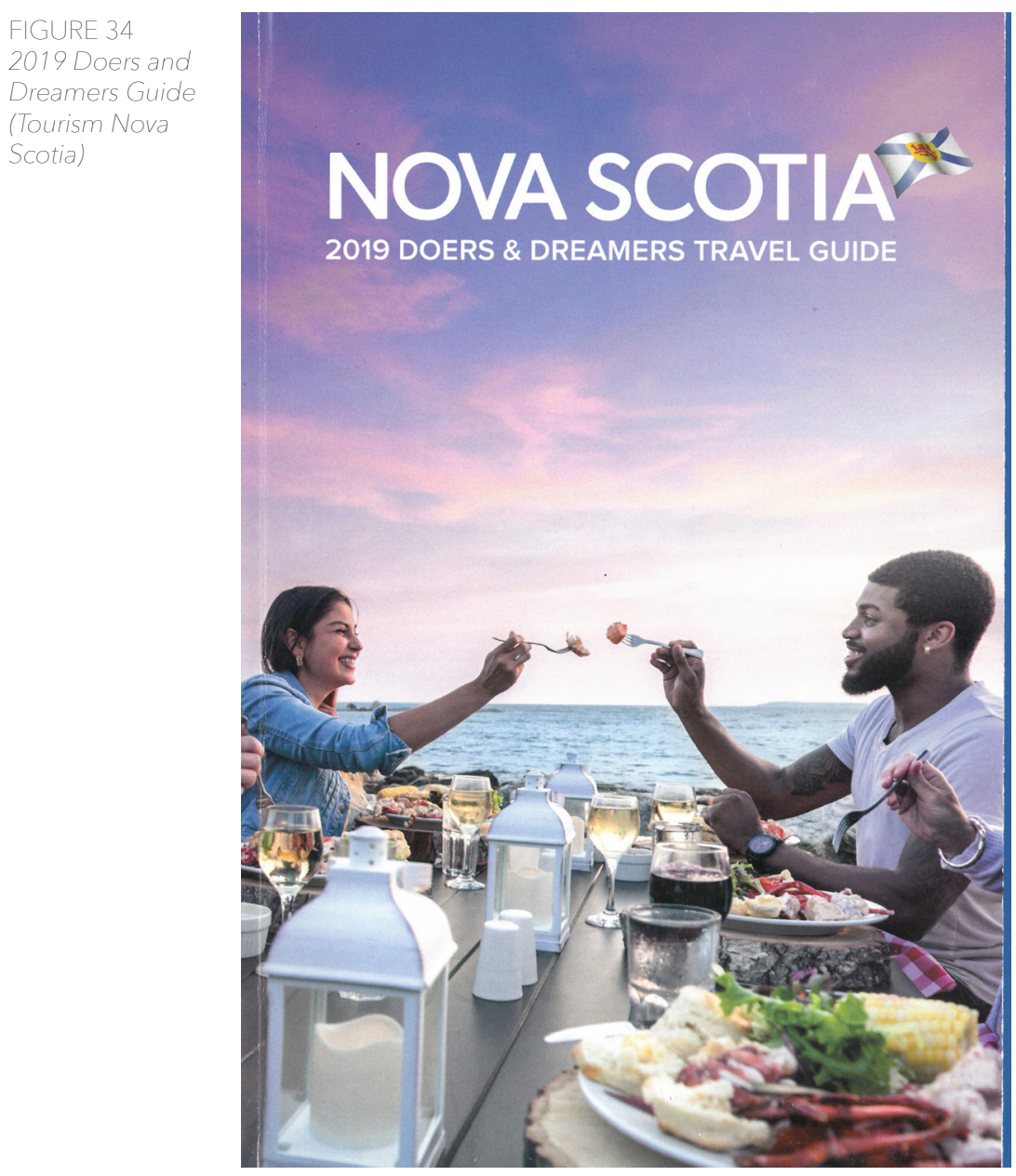

${ }^{57}$ Shaw, Gareth, and Allan M. Williams. Tourism and Tourism Spaces. Los Angeles: SAGE, 2004. 
marketing strategies identify particular sites as being places of consumption, ${ }^{59}$ separated from the everyday activities of a place. Tourism is characterized by temporality and spatiality. Tourists consume resources and experience. These experiences are ephemeral, a short-term escape from typical life. Currently, coastal leisure-based tourism is the fastest growing sector in the tourism industry. ${ }^{60}$ From a western perspective, leisure at the coast was first introduced in the mid eighteenth century, with the advent of formal spaces of piers, jetties, and promenades created for organized recreation. ${ }^{61}$

The design of this thesis does not follow a model of resort typology, where luxury architecture is created in isolation from the local community, but one where authenticity of the tourist's experience is enriched with the immersion within local activities and industry. FIGURE 35
early tourist posters
lobsterland

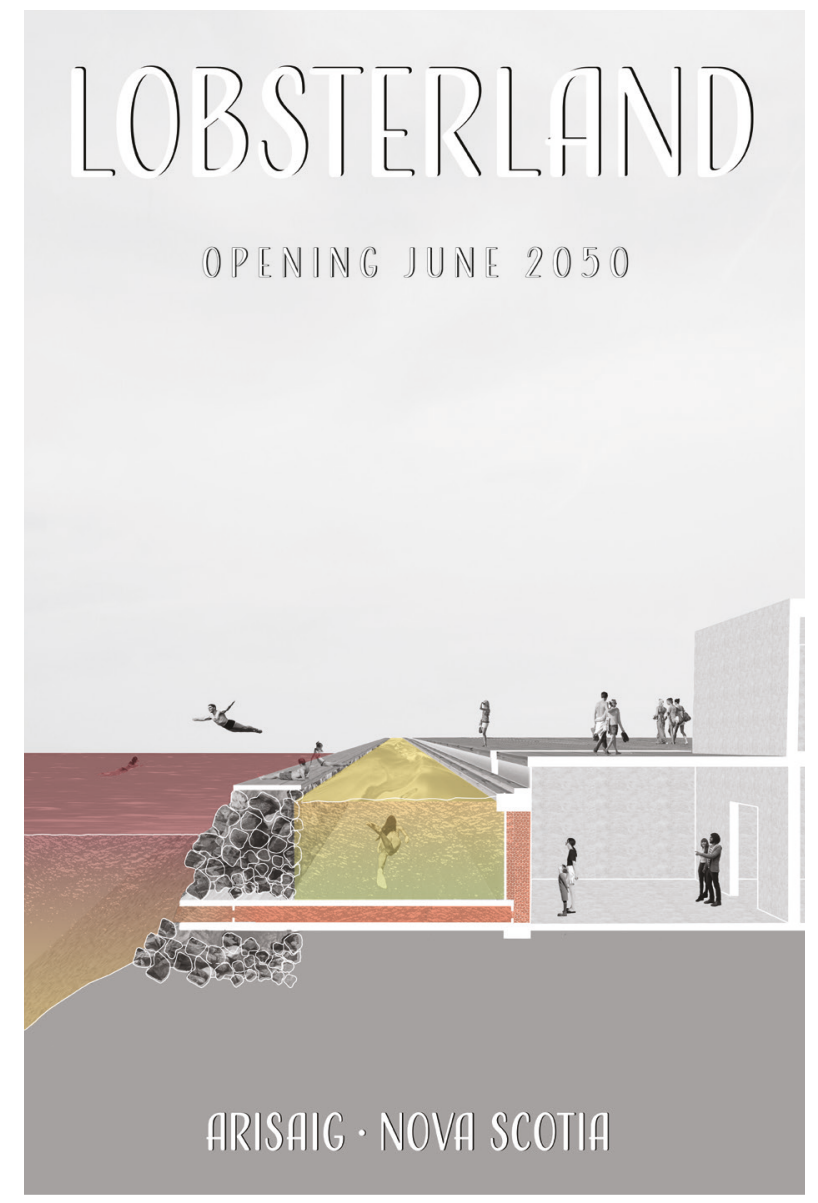

An early image of
different water

temperatures in proximity, and the human/ lobster associated activities. An infinity lap pool runs along the north shore, sheltered by a stone breakwater on the ocean side, and the hatchery's glass larvae-observation wall on the landward side. Larvae are released under the infinity pool.

\footnotetext{
${ }^{58}$ Shaw, Tourism Spaces, 167.

59 lbid., 166.

${ }^{60}$ Hall, Colin Michael, and Stephen J. Page. The Geography of Tourism and Recreation: Environment, Place and Space. London: Routledge, 2014. 283

${ }^{61}$ Hall, The geography of tourism and recreation p.285
} 
FIGURE 36

early tourist posters: crate to plate

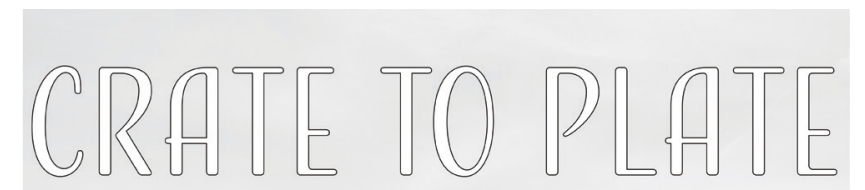

CATCH OF THE DAY!

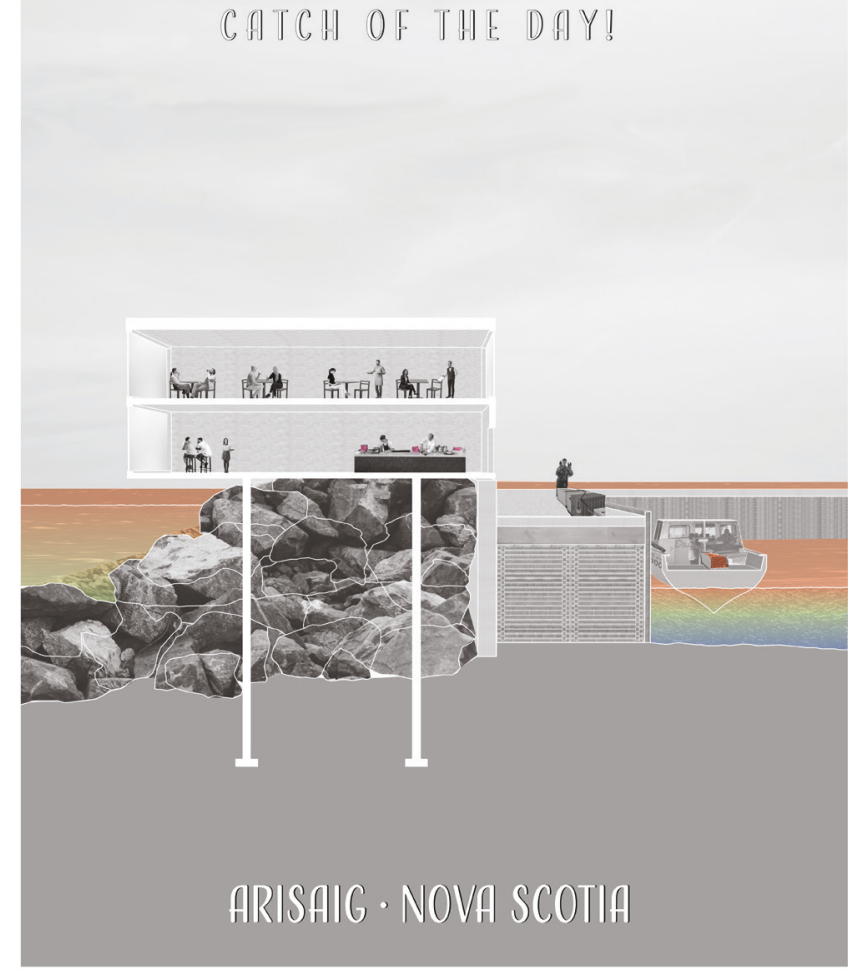

A resturant is built on top of an existing breakwater, adjacent to the harbour, where lobsters can be brought directly off the boat and into a pot of boiling water. 
In the previous chapters, both lobster and human activity on site were studied and understood. This chapter is the synthesis of this research, a design proposal that supports the symbiotic relationship between the two species on the coast, in water and on land.

Landscape designer Michael Ezban uses the term Aquaculture Landscapes to describe the sites of encounters between humans and fish. ${ }^{62}$ Aquaculture is the farming of any aquatic organisms, including fish, mollusks, crustaceans, and aquatic plants. ${ }^{63}$ Approximately half of fish production is done using some form of aquaculture, making it one of the fastest growing food sectors in the world. In many cases, the aquaculture sites are in rural, coastal areas. The workers are local, with a minimal commute from home to work. But the idea that food production occurs in remote, rural areas, hidden from the public gaze ${ }^{64}$ is outdated. Rural areas are far more complex than a series of farms, both agricultural and aquacultural; rather they can be a "random collection of resources that, together, provide a rich collection of material you can do almost anything with." 65 Integrating this random collection of resources, including food production, but also elements that are recreation and wellbeing oriented, is the intent of this design. The result is a series of buildings, coastal infrastructure, and pools in a master plan of the Arisaig Harbour. The composition is informed by the varying relationships between humans and lobsters, as they both seasonally inhabit the site, with a goal of becoming less singularly production oriented, and firmly rooted in ecology, community, and culture. ${ }^{66}$

\footnotetext{
62 Ezban, Michael. Aquaculture Landscapes: Fish Farms and the Public Realm. Milton Park, Abingdon, Oxon: Routledge, 2020.

63 "Environment Index." Canadian Aquaculture Industry Alliance. Accessed March 27, 2020. https://www.aquaculture.ca/environment-index.

${ }^{64}$ Sutherland, Adam. "Reinventing the Rural- Our Skewed Perception of the Countryside." The Architectural Review, April 2018, 10.

${ }^{65}$ Sutherland, Reinventing, 9.

${ }^{66}$ Ezban, Aquaculture Landscapes, 4.
} 
As mentioned in Chapter 2, twenty-five degrees Celsius is the maximum temperature at which lobsters can thrive, and this temperature could be realized as the seasonal average at the surface in the summer of 2040 .

Due to this, lobster larvae would not survive in their natural habitat. As a way to help support the species, larvae can be hatched and raised in a controlled environment in a hatchery. A hatchery is a commercial fisheries operation where eggs are hatched under controlled conditions. As a precedent, the systems of the National Lobster Hatchery in Padstow, UK were studied. The National Lobster Hatchery is a non-profit organization focused on marine conservation, education and research, specifically in regards to the European Lobster, Homarus Gammarus. ${ }^{67}$ The European Lobster is the closest relative to the American Lobster, with similar physical characteristics, including growth habits and environmental tolerances. ${ }^{68}$ Due to their similarities, one can imply that the methods used for rearing European Lobsters could also apply to the American Lobster.

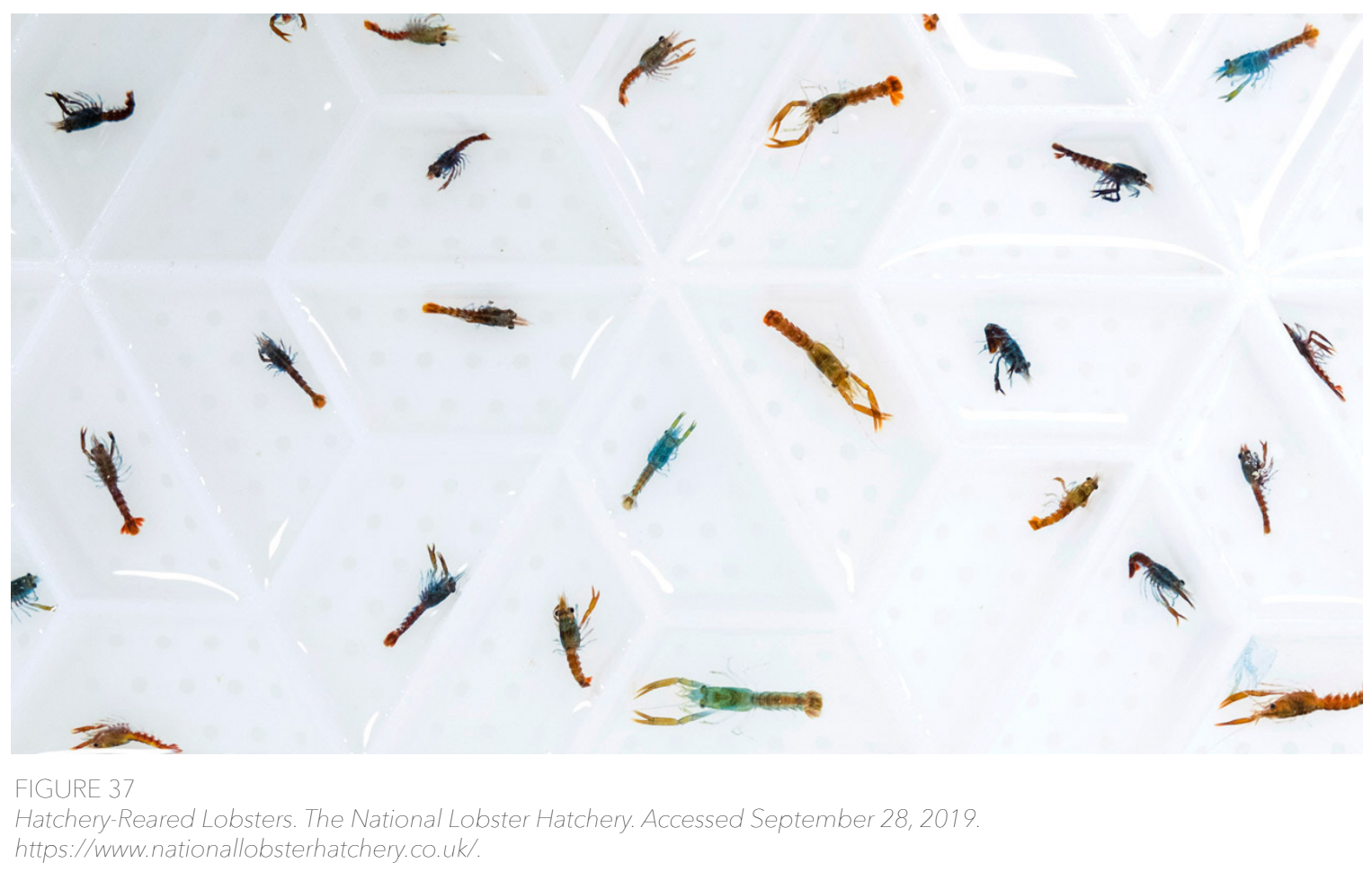

67 "Lobster Conservation Charity." The National Lobster Hatchery. Accessed March 27, 2020. https://www.nationallobsterhatchery.co.uk/whats-it-all-about/.

68 "European Lobster Biology: Biology of the Homarus Gammarus." The National Lobster Hatchery. Accessed March 27, 2020. https://www.nationallobsterhatchery.co.uk/lobster-biology/. 
Lobster larvae have to be kept separated. Lobsters are very aggressive, even as larvae. Keeping them separated keeps them from killing each other. The spatial strategy employed in the hatchery is keeping larvae in individual, trapezoidal shaped pods. The pods are attached to each other, in a disk with a perforated bottom to allow for water flow. (See fig 37) The larvae are raised through all stages, and once they reach stage 4, they are ready to be released into the ocean. The disks are then brought from the hatchery building to a location near the shore, to deposit the young lobsters into the wild. The intention of this project is to improve on current methods, and let the building do the work of releasing the lobsters. This creates a physical threshold between the natural and controlled environments of the ocean and hatchery.
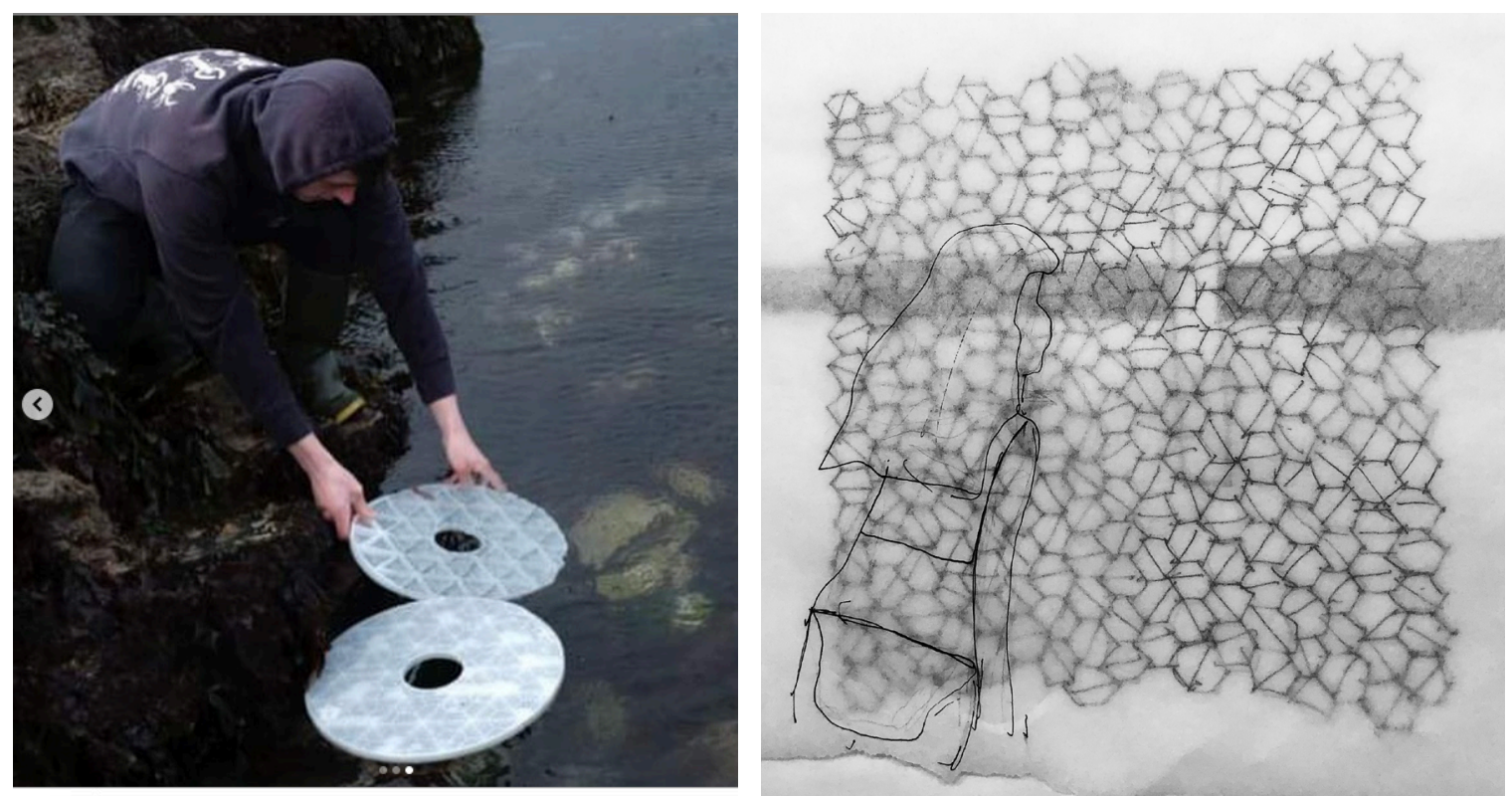

FIGURE 38

FIGURE 39

releasing the larvae The National Lobster Hatchery. Accessed early diagram sketch of the wall releasing larvae September 28, 2019. https://www. nationallobsterhatchery. co.uk/. 
In this shoreline intervention, the lobsters are not simply a commodity. Humans and lobsters are co-workers in their multifunctional activities. Humans provide food, shelter, and healthcare, while lobsters are mothers, foragers, and food providers. There is agency, collaboration, and interdependency between the species. Cohabiting with other species requires the local knowledge of animal life required to grasp their ways of being, interact accordingly in specific contexts, and protect their autonomy in their own spaces, as theorized by urbanist and geographer Jennifer Wolch. ${ }^{69}$

It is this idea of interdependence that is the driving force behind the design of the shoreline intervention. The master planning of the site began through zoning based on three programmatic areas: related to fishing (Work), relating to tourism/recreation (Play). The intermediate zone, where work and play meet, is a flexible zone that can change programmatically with season. (See Fig 39) The breakwater is extended, comprised of armored stone, to protect the coastline. At the same time, the breakwater is habitable for both humans and lobsters, as explained and illustrated further in this chapter. Sightlines of the ocean and lighthouse are maintained. The design of this intervention was largely developed through section. As mentioned in chapter three, there are multiple grounds on site to consider. The section allows for the relationships between the grounds and their activities to be illustrated and explored. In Aquaculture Landscapes, Ezban discloses the characteristics for a successful aquaculture landscape:

Exemplary aquaculture landscapes can be characterized as sites where fish have agency and freedom to express species-specific behaviors in bio diverse habitats, novel aesthetic experiences and recreational activities are enabled, collocated programming and infrastructural functions produce diversified economies, and mutualistic relations between humans, fish, and plants are constructed. ${ }^{70}$

\footnotetext{
${ }^{69}$ Ezban, Aquaculture Landscapes, 7.

${ }^{70}$ Ezban, Aquaculture Landscapes, 2.
} 

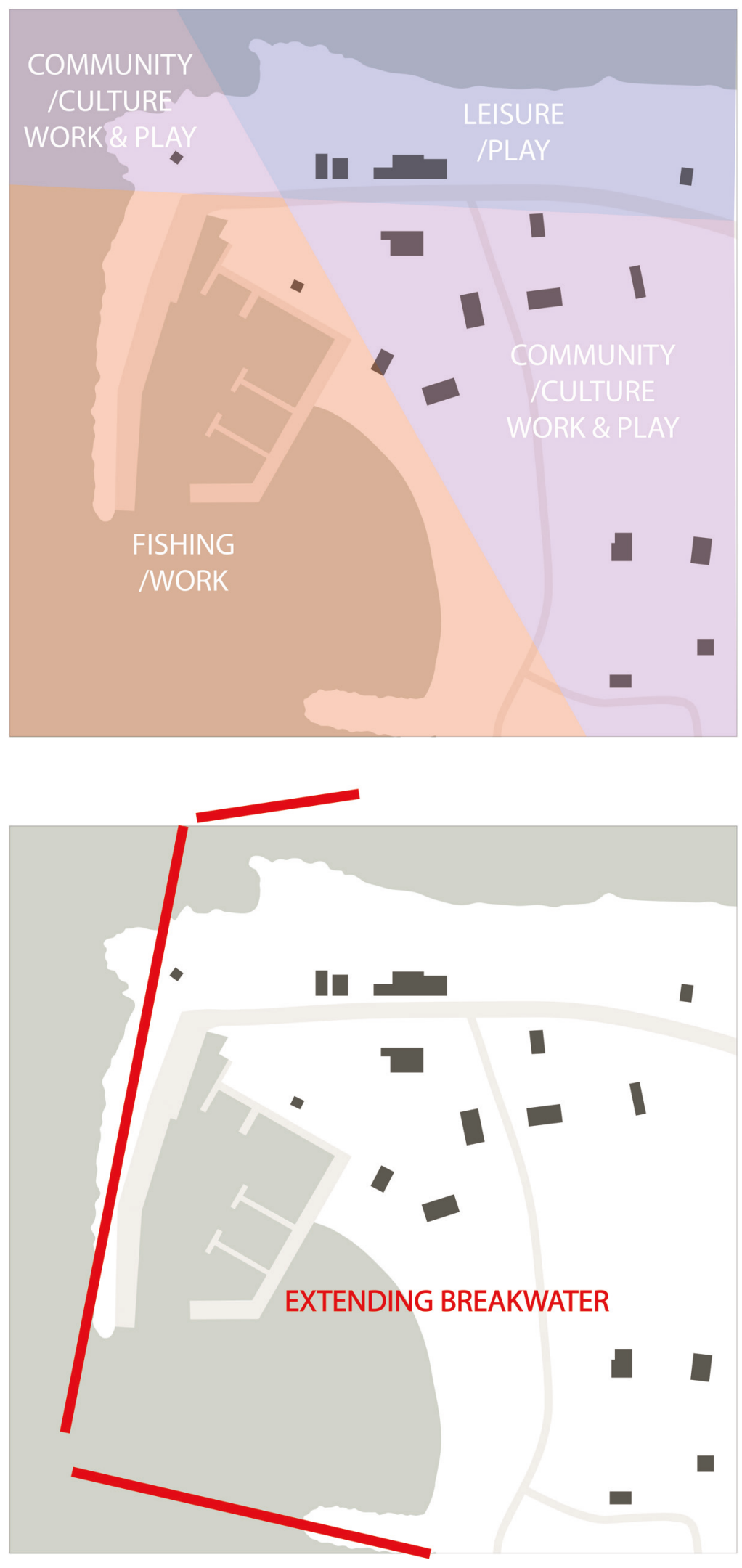
On site, rituals of activity change with the seasons. There is a relationship between the thermal quality of the season, and the activities, such as swimming in the warm months of July and August, and empty, vacant site in the dead of winter. The seasonal cycles are an interconnected network of dependence, lobsters generally molt in the summer, so the fishing season happens before that takes place. On a daily cycle, fishing boats usually head out before sunrise, so they return to the harbour to avoid being out during the warmest part of the day. As Herschong explains, "The thermal conditions that coincide with these cycles are inextricably associated with the activities and rituals and serve to reinforce their importance." ${ }^{\prime 71}$

From the studies of increasing water temperature from chapter 2 , it is inferred that these seasonal cycles of activity will change as the temperatures increase. For example, the ocean will be warm enough for swimming from June to October by 2060. From this, the idea for a design for ocean pools to accommodate recreational swimmers was created. As a precedent, the Leca Swimming Pools by Alvaro Siza were studied. (See Appendix) Combining knowledge of local materials, building practices, and climate with the aesthetics of the global modernism influenced the development of the pools and circulation of the shoreline.

Landscape architect Kate Orff urges designers to think "beyond a built environment conceived exclusively for human consumption and comfort" in order to "address the wider global ecosystem as a shared space for species." ${ }^{172}$ This master plan and building intervention for Arisaig is based on considerations that extend beyond human use, also taking into account how lobsters will inhabit new spaces. The juvenile lobsters will spend most of their time hiding in rock, away from predators. Another time in their life they seek shelter is after a molt, where they lose their hard shell, while their soft shell hardens. A lobster seeking out a crevice in a rock is seeking out a favourable microclimate, ${ }^{73}$ while their regular environmental barrier, their shell, has changed. The rock provides a lifetime cycle of shelter for the young stage of life, as well as a season cycle of shelter for the molting phase of adult life.

\footnotetext{
${ }^{71}$ Heschong, Lisa. Thermal Delight in Architecture. Cambridge, MA: M.I.T. Press, 1979, 32.

72 Ezban, Aquaculture Landscapes, 4.

${ }^{73}$ Heschong, Delight, 7.
} 
The architecture in this proposal is designed with the principles of Critical Regionalism introduced by Kenneth Frampton: that architecture must considered in terms of topography, light, climate, and tectonic form, and not simply a replication of vernacular architecture. ${ }^{1}$ While the vernacular form and materiality are referenced in the design of the buildings in this master plan, it is so the construction of the building can be done with local labour and materials. Wooden light frame timer construction and low pitched gable roofs already present on site are also incorporated in the form and materiality of the architecture of this intervention. The topography of the site, a flat landscape surrounded by ocean, requires that fortification against the force ocean waves and storms. This barrier is achieved through introducing heavy stone breakwater walls both off and along the coast. This heavy construction is introduced and gradually expanded throughout the site through time, as resistance against rising water levels and temperatures are required. The long timeline of this phased intervention is a response to the changing ocean temperatures due to climate change. The 60-year length of the timeline slows the rate of expansion of other development that may occur as a result of this intervention. Any large scale changes not included in this intervention, such as an increase in the number of dwellings, or the introduction of a hotel, would occur gradually, to give people a chance to acclimate to the changes on site, as we gradually acclimate to our new climate.

The first phase in this intervention begins in the year 2040. This is the year where the ocean temperature reaches the critical temperature of $25^{\circ} \mathrm{C}$. (See figure 23) A lobster hatchery is located on the North side of the site, along with public pools and access to the ocean. (building D, figure 42) This is to activate the north side of site, and populate it with people looking for water recreation. On the ground level, the hatchery is a long rectangular building with a low pitched gable roof. The structure is light framed timber, clad in wooden shingles. While this materiality is cohesive with the existing

\footnotetext{
${ }^{74}$ Frampton, Kenneth. "Towards a Critical Regionalism: Six Points for an Architecture of Resistance." In Postmodern Culture, 16-30. London: Pluto Press, 1985.
} 


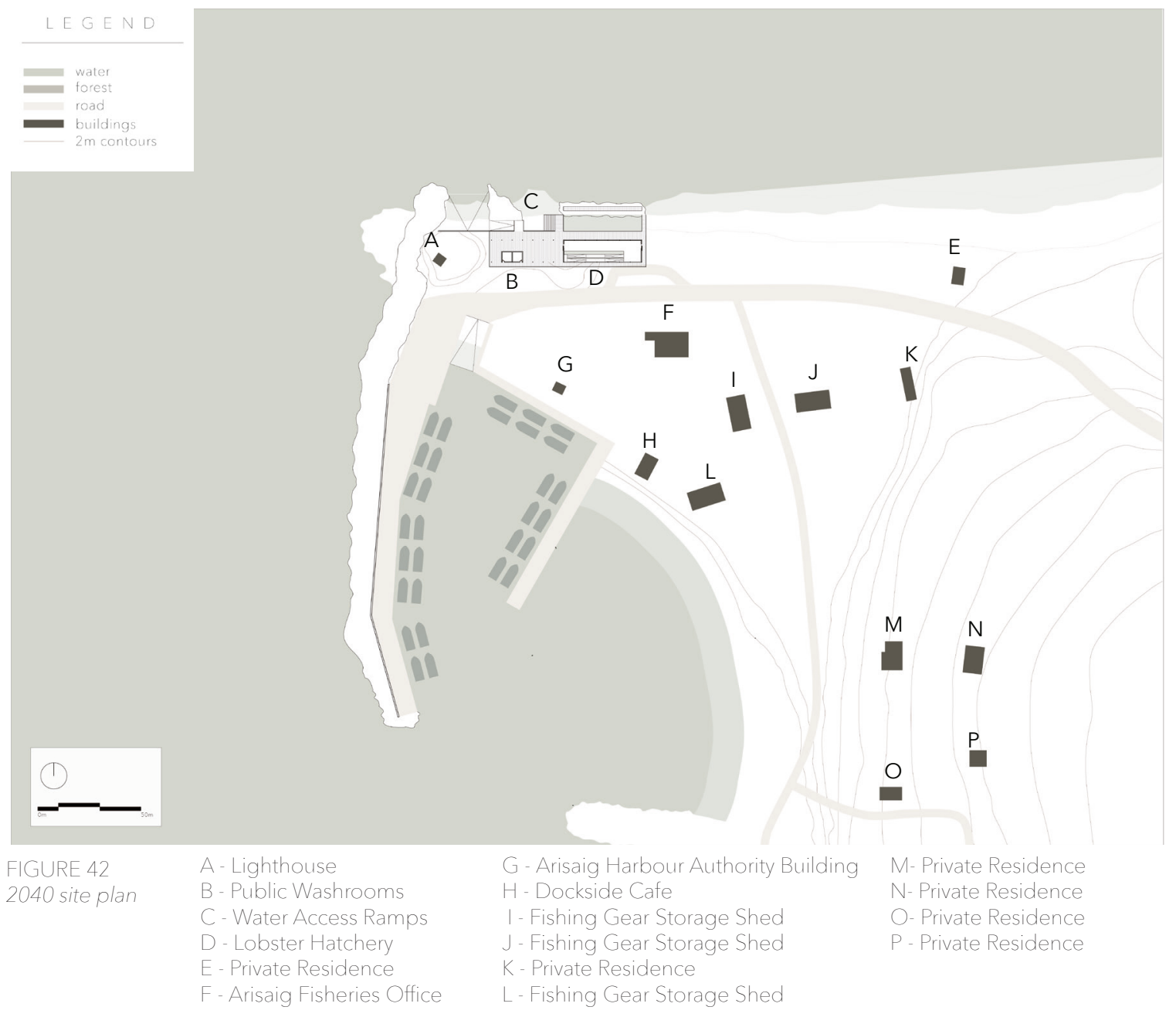

buildings on site, the reason is not only for replicating the vernacular style.

The low pitched roof sheds water and does not create wind resistance. (See figure 43) Sliding barn doors on either end of the building allow for visitors to pass through, from an entrance on the east side, through a visitors centre / interpretive centre, and back out to the recreational pool area, where visitors can either continue to walk towards the lighthouse, or take the ramp or stairs into the water. On the lower level, the wall between interior and exterior is a thick, double glass wall, bracing the impact of the ocean on the exterior side. Between the panes of glass live small lobsters, in individual trapezoidal shaped pods, which are released at the bottom of the wall. Figure 65 shows the view of this wall from the perspective of a swimmer underwater. 


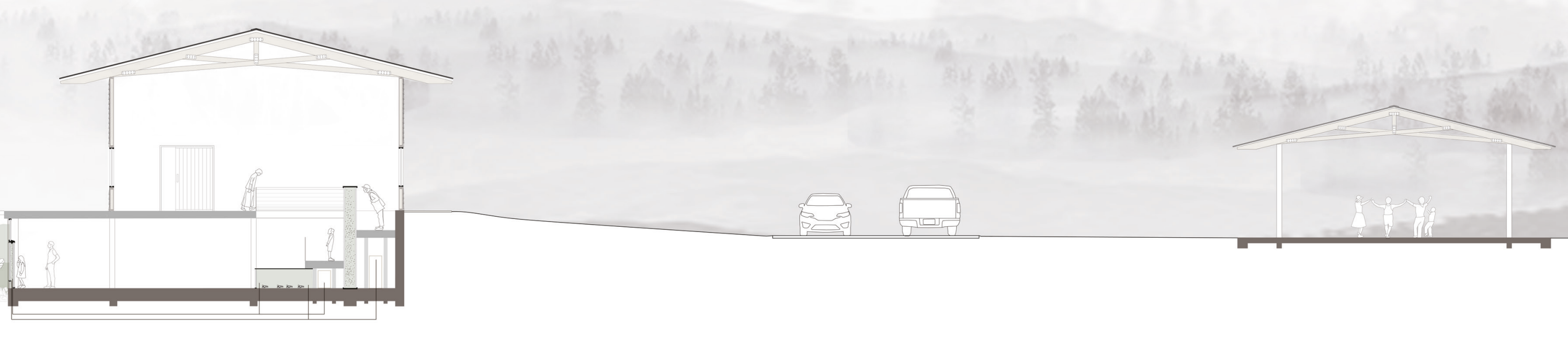

FIGURE 43
2040 hatchen

${ }^{2} \mathbf{n}=$

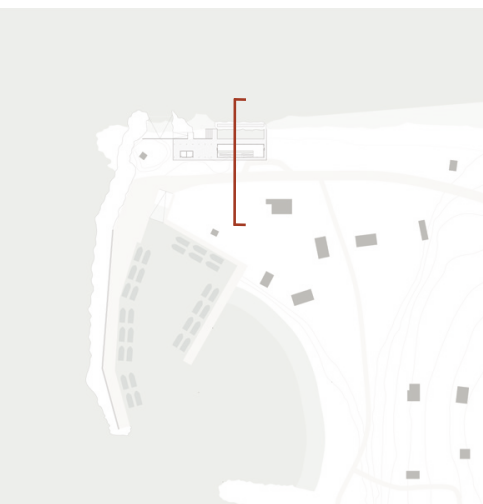




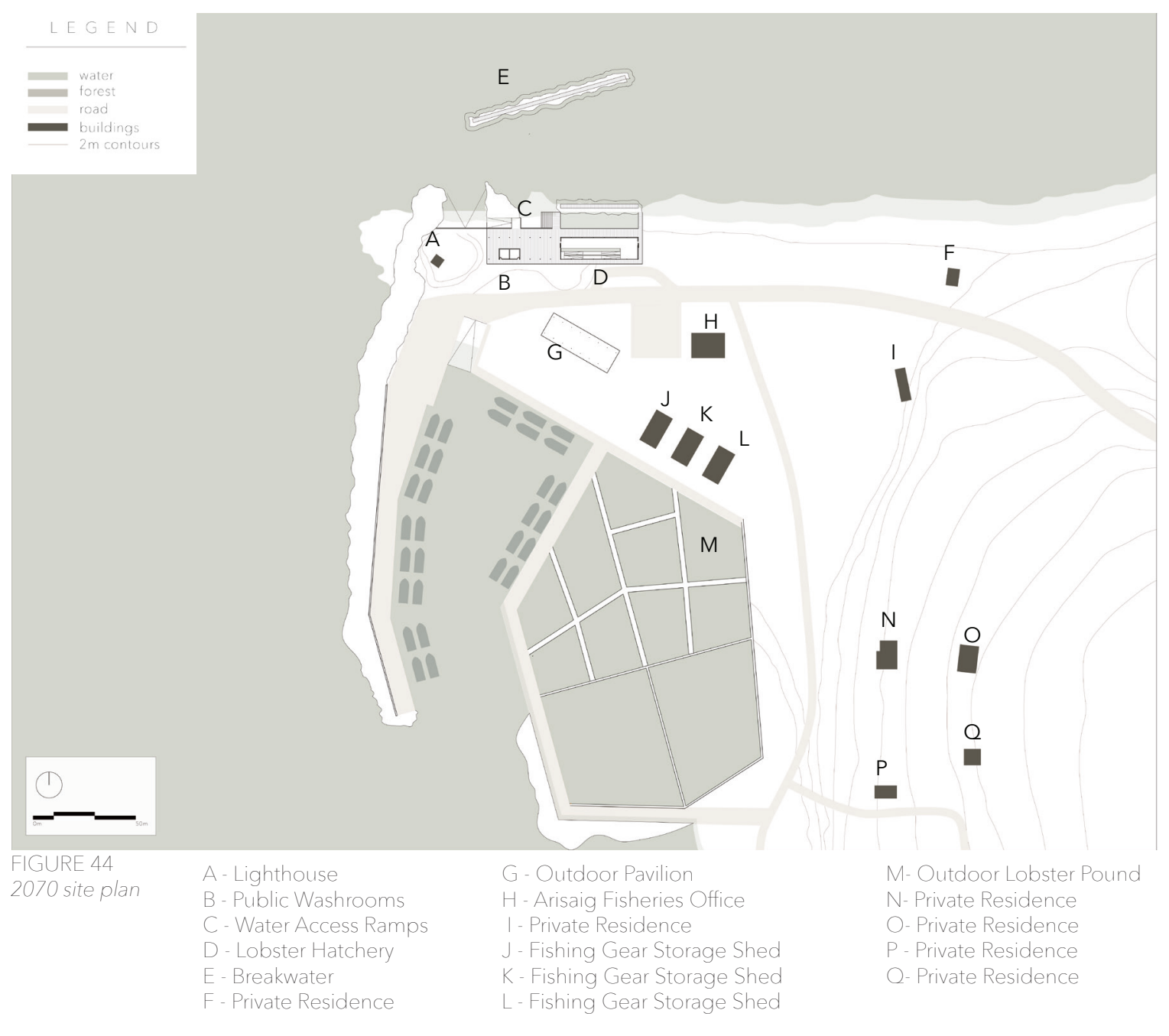

The next phase of the intervention occurs in the year 2070, thirty years after phase one. As a result of the prosperous lobster fishing industry, thanks in part to the work of the lobster hatchery, a new outdoor holding pool is added. ( $M$, figure 44) Half of the pound is dedicated to lobster available to purchase on site, and the other half is dedicated to crates to be shipped internationally. As illustrated in the section in figure 45, boats drive up to the wharf, and unload the catch of the day, while visitors can walk along floating docks and pick out their lobsters. The water of this pool is controlled at $10^{\circ} \mathrm{C}$, to prevent lobster molting. Figure 46 shows that this controlled environment's temperature is very similar to the lobster's natural habitat, the ocean floor. In figure 55, the ocean floor temperatures of the spring of 2100 will still be a cool 
and comfortable habitat for the lobsters. This stresses the importance of human intervention for the surface phase of the lobster life cycle only.

Offshore, a stone breakwater (figure 44E, figure 48) is a place for people to swim to, rest on, jump off of, and enjoy water recreation. A floating dock rises and falls with the tides, while a wooden platform at the top provides a vertical distance from the water. Figures 49-52 illustrate that this dock and platform are usable for three seasons, and are removed in the winter months. As well as human leisure, the breakwater acts as an artificial reef, providing a home and shelter for lobsters.

The last addition the 2070 phase is an open, rectangular structure with a gable roof. (figure 44G) The form is derived from the industrial gear sheds, and is oriented so that the lighthouse is framed on the northwest side. In the summer, people can gather for ceilidhs, and in the winter, this building can be used for boat storage. The foundation is a concrete slab, and wooden columns and trusses hold up a low pitch gable roof. As shown in figure 47, this building does not interact with the water, but the form resembles that of the hatchery. 


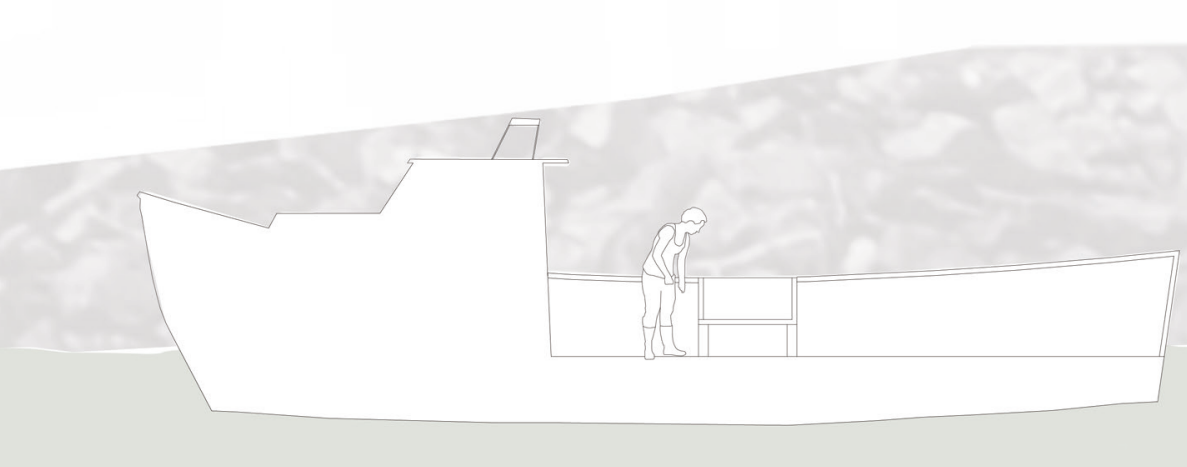

FIGURE 45
2070 wharfand

2070 wharf and

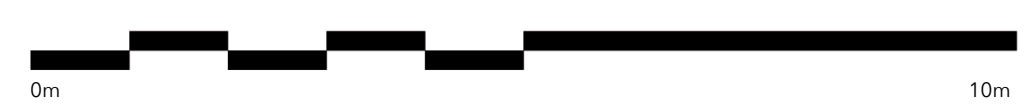

*

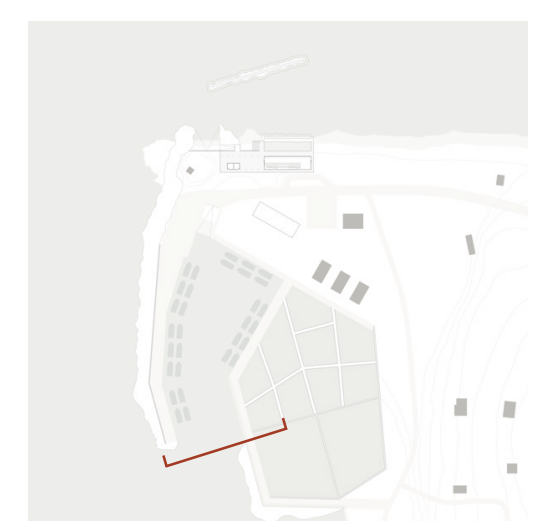



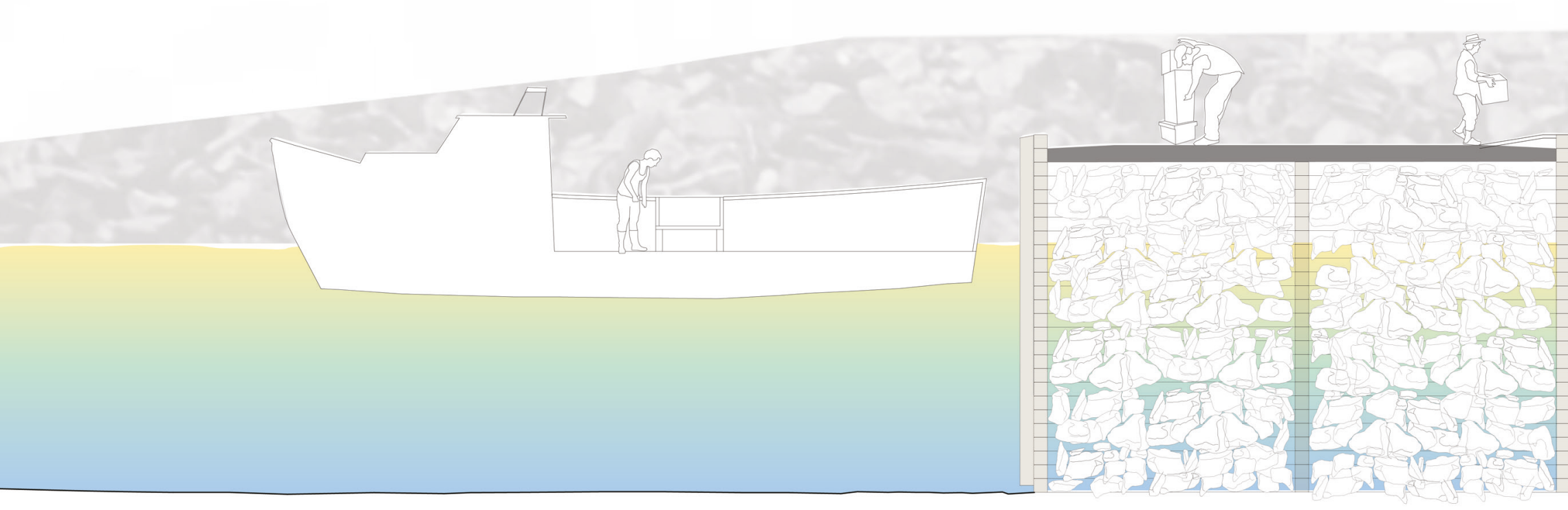

* 


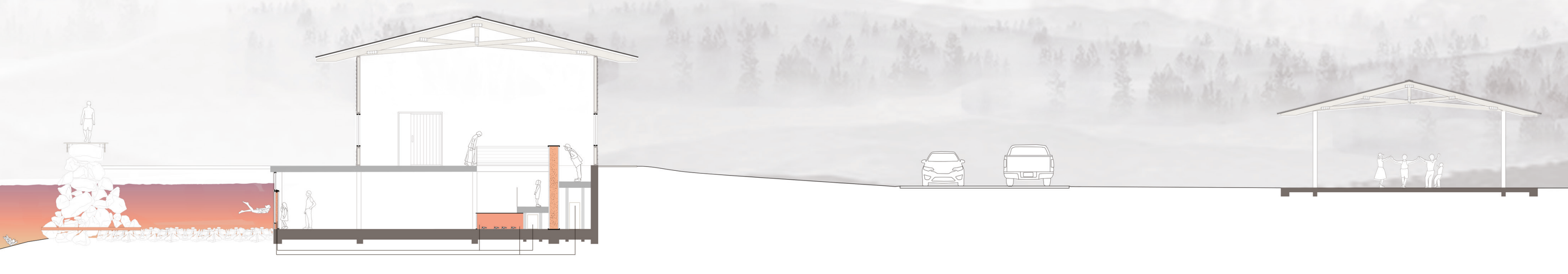

FIGURE 47
2070 lobster

hatchery section

$\boldsymbol{m}={ }_{20 \mathrm{~m}}{ }_{{ }^{\circ} \mathrm{C}}$

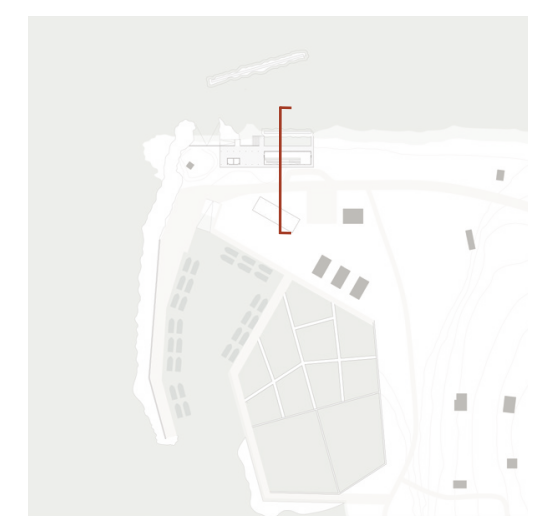




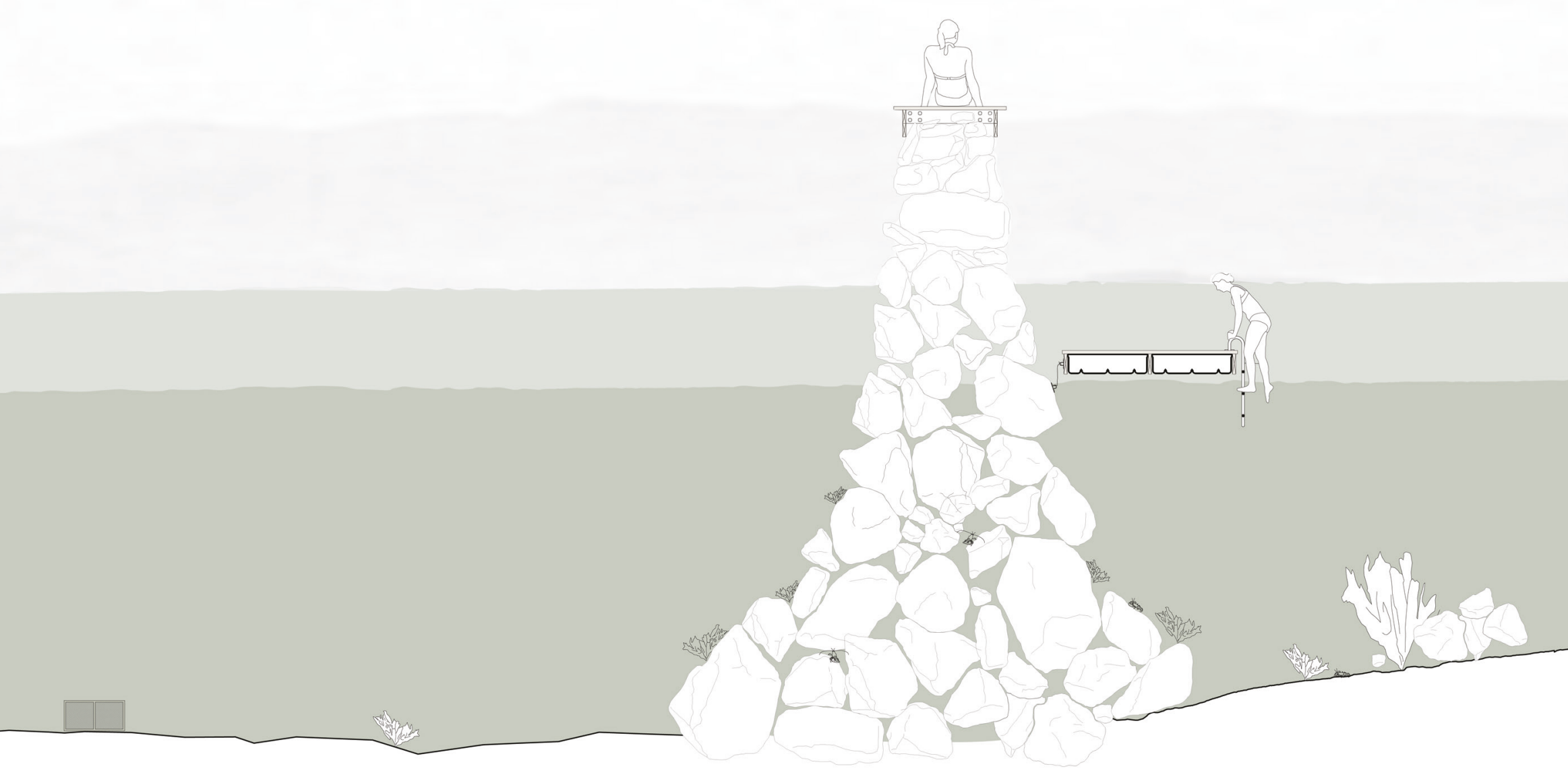

v

FIGURE 48
2070 breakwater
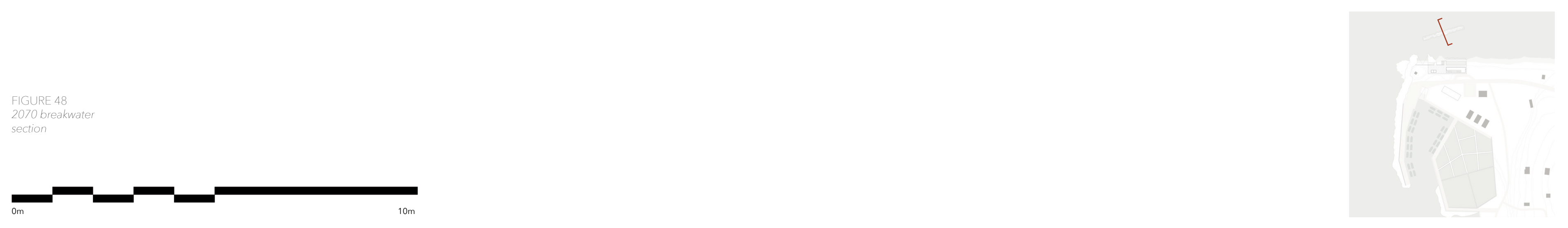



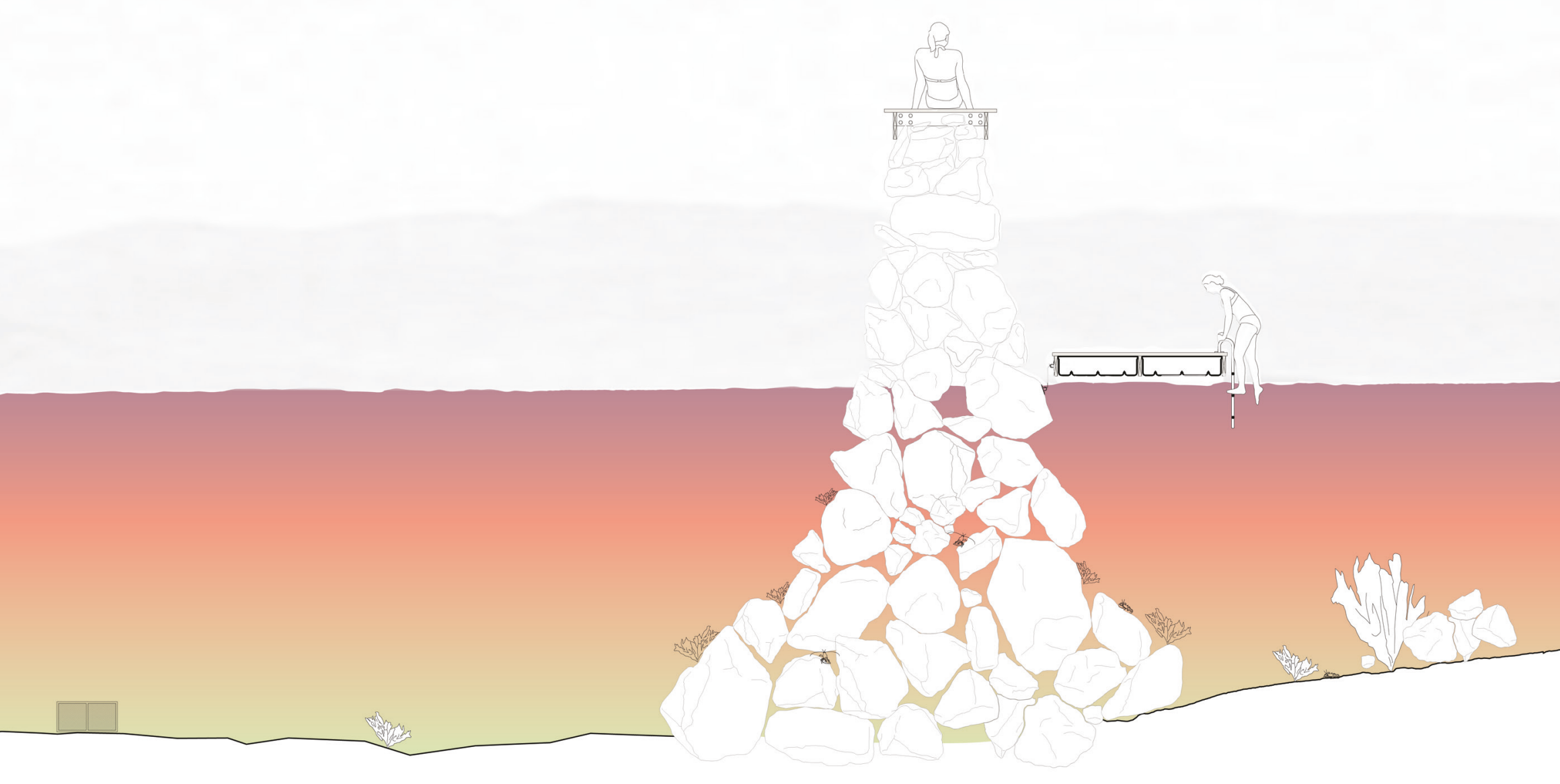






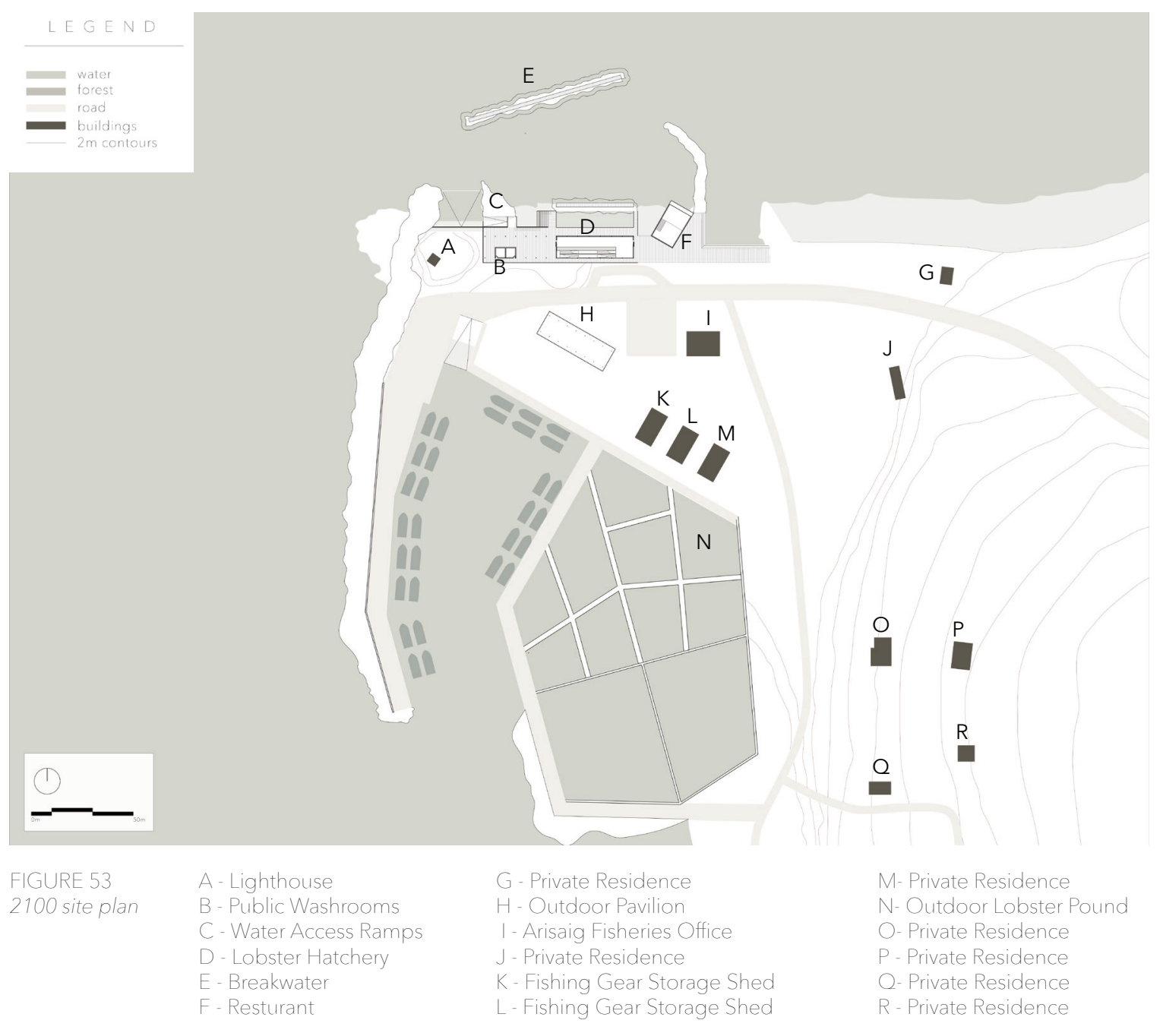

The last stage in this intervention occurs in the year 2100. Water temperatures have increased so much that the spring and autumn of 2100 look almost like the summer of 2020. (Figure 23) Water is comfortable to swim in for almost $75 \%$ of the year. A restaurant is added to the site. (Figure 53F) A breakwater outstretches on the north side, where one can walk out from the restaurant, and feel a sense of distance from the land. The entrance to the restaurant is at ground level, where a. The formal dining room is below ground level, along with the kitchen. The thick stone wall separates the interior from the ocean. Crevices in the wall provide homes for lobsters, and are separated from the dining room by thick windows, providing an intriguing experience for diners. (Figure 56) As the tide changes, the crevices allow for water to remain, 
and the thick stone walls, sheltered from the sun, allow for a cooler water temperature. Figures 59 and 60 show that this element of the walls creates favorable microclimates for lobsters, while creating entertaining view for the people inside. 


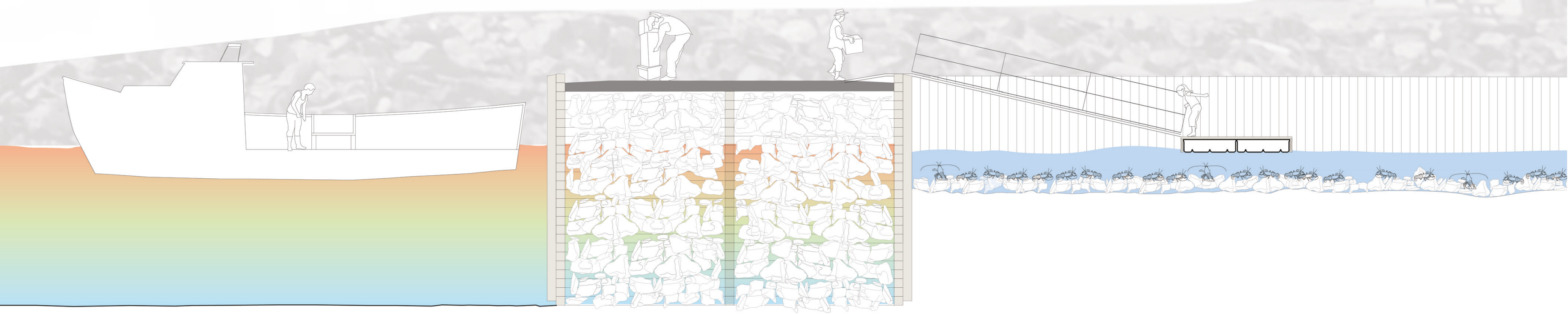


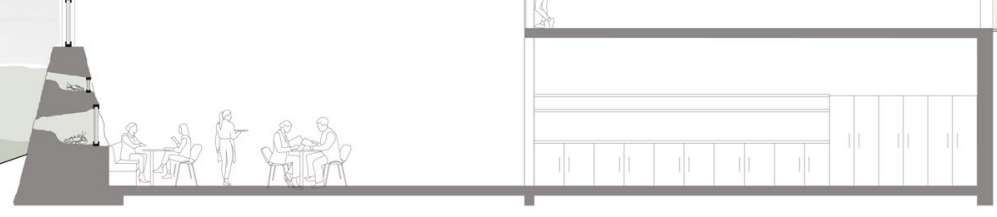





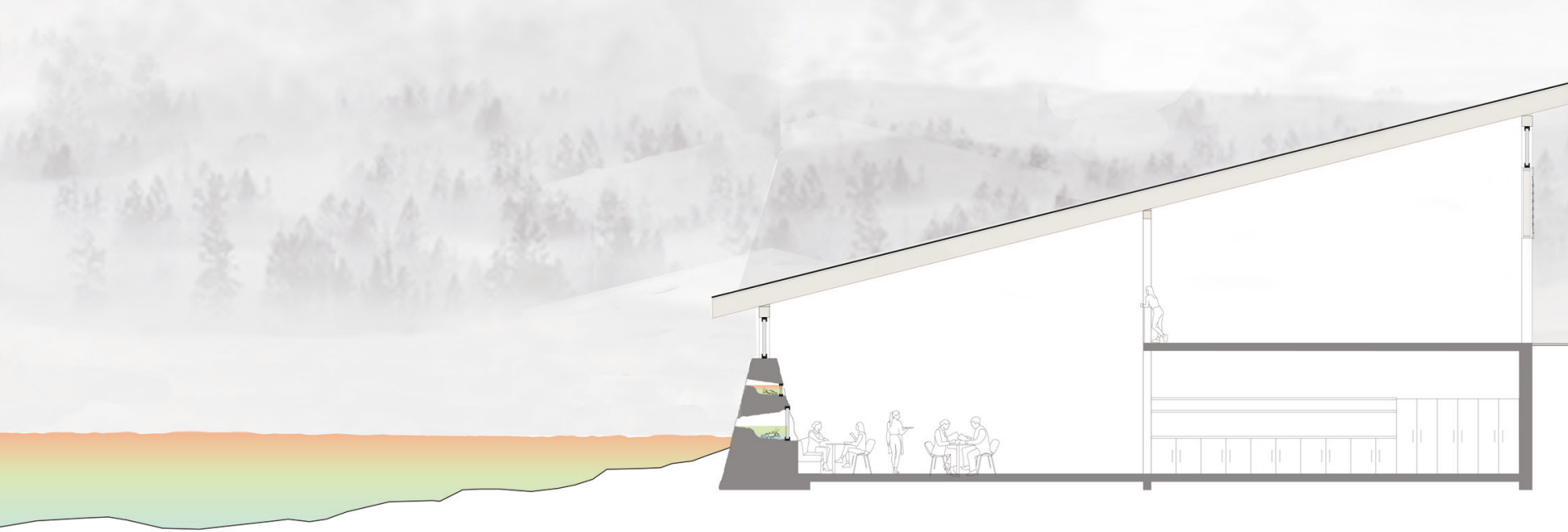

FIGURE 58
2100 restaurant

water temperatures

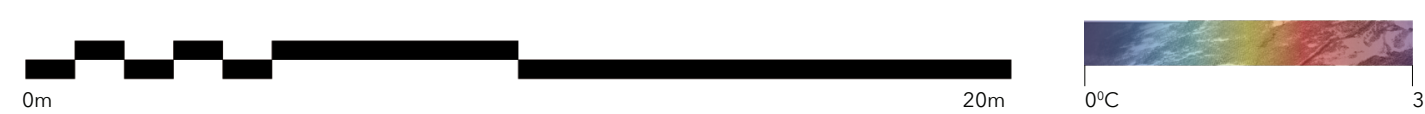

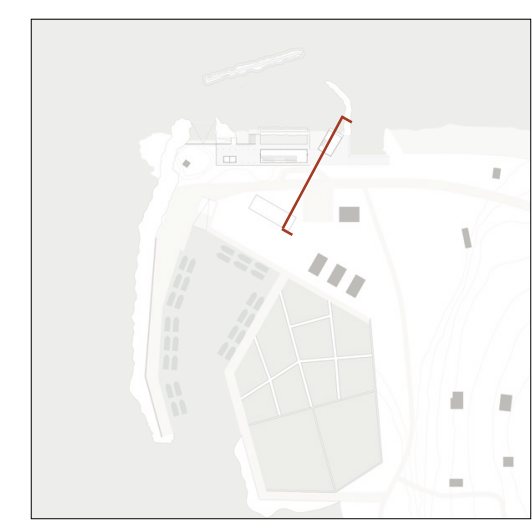


FIGURE 59

2100 restaurant

stone wall

section with spring

water temperatures

(high tide)

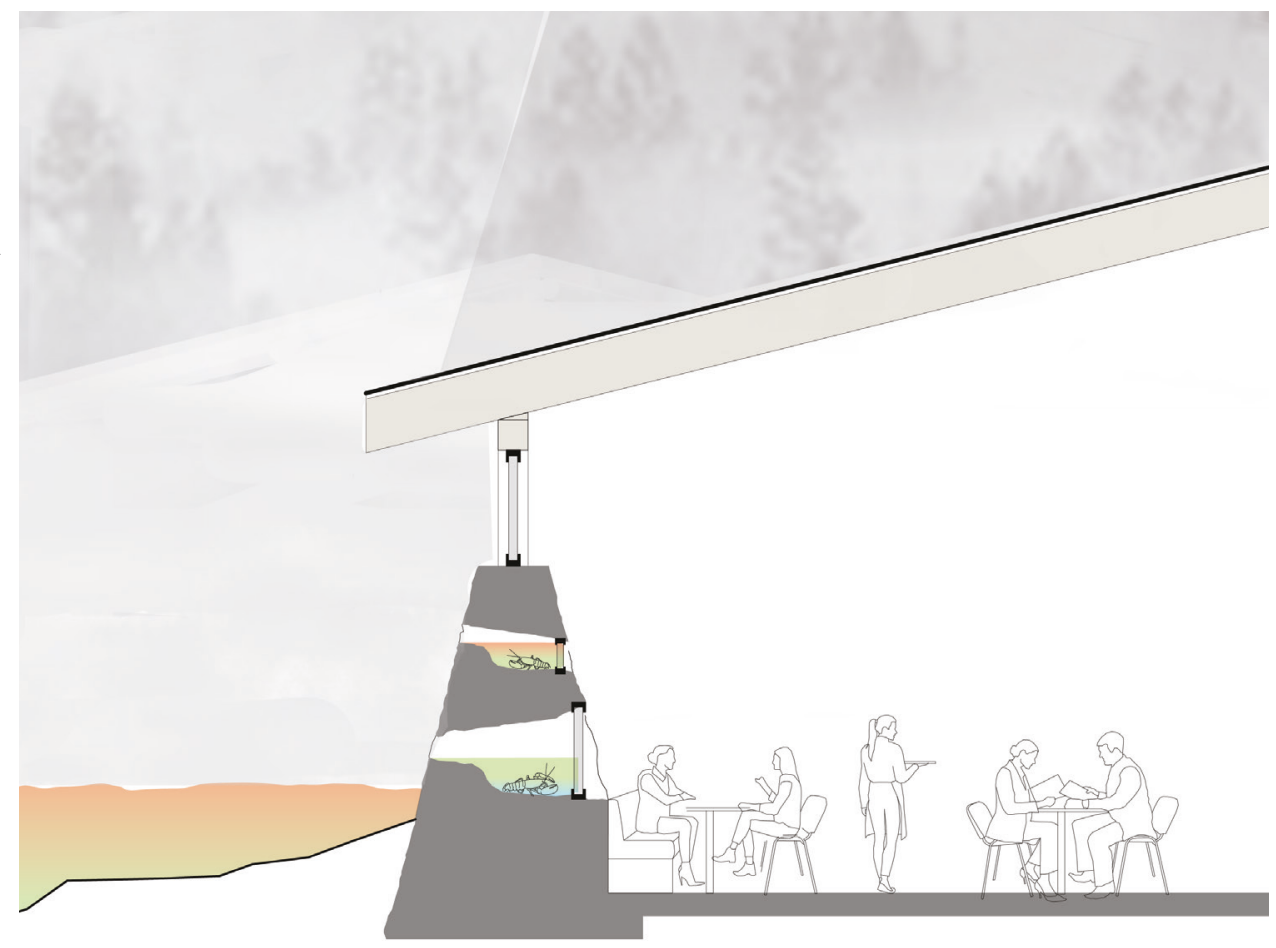

FIGURE 60

2100 restaurant

stone wall

section with spring

water temperatures

(low tide)

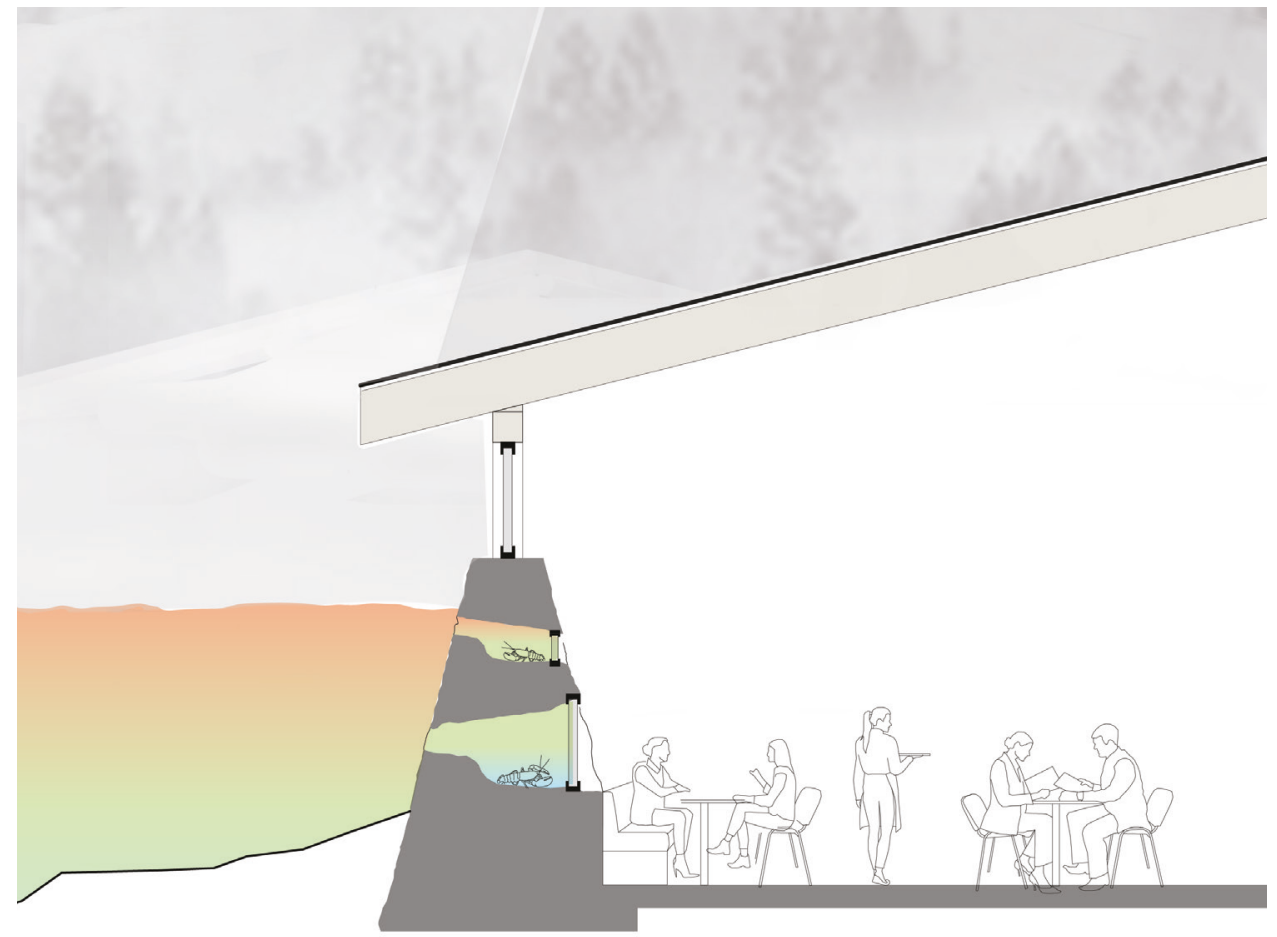



Diary One: Dave, a lobster fisherman

June 15, 2040

We found 3 berried females in the traps today. Instead of throwing them back, we kept them, separate from the day's catch. It was so strange, not to throw them back immediately, as I've been instinctively doing for the past 30 years. Never in my life would I think our quiet little Arisaig would be home to this newfangled research centre. They say It'll bring people here. We'll see. I put the three of them in a cooler of water, and once we got to shore, I walked it over to the new building. Bill's young fella was working there. He's here for the summer, home from University, studying marine biology. He explained how the lobsters are in a "maternity ward", like mothers-to-be in a hospital. They're there until the eggs hatch, and then are released. I guess this is supposed to keep the lobsters from dying off. Good for us, I guess.

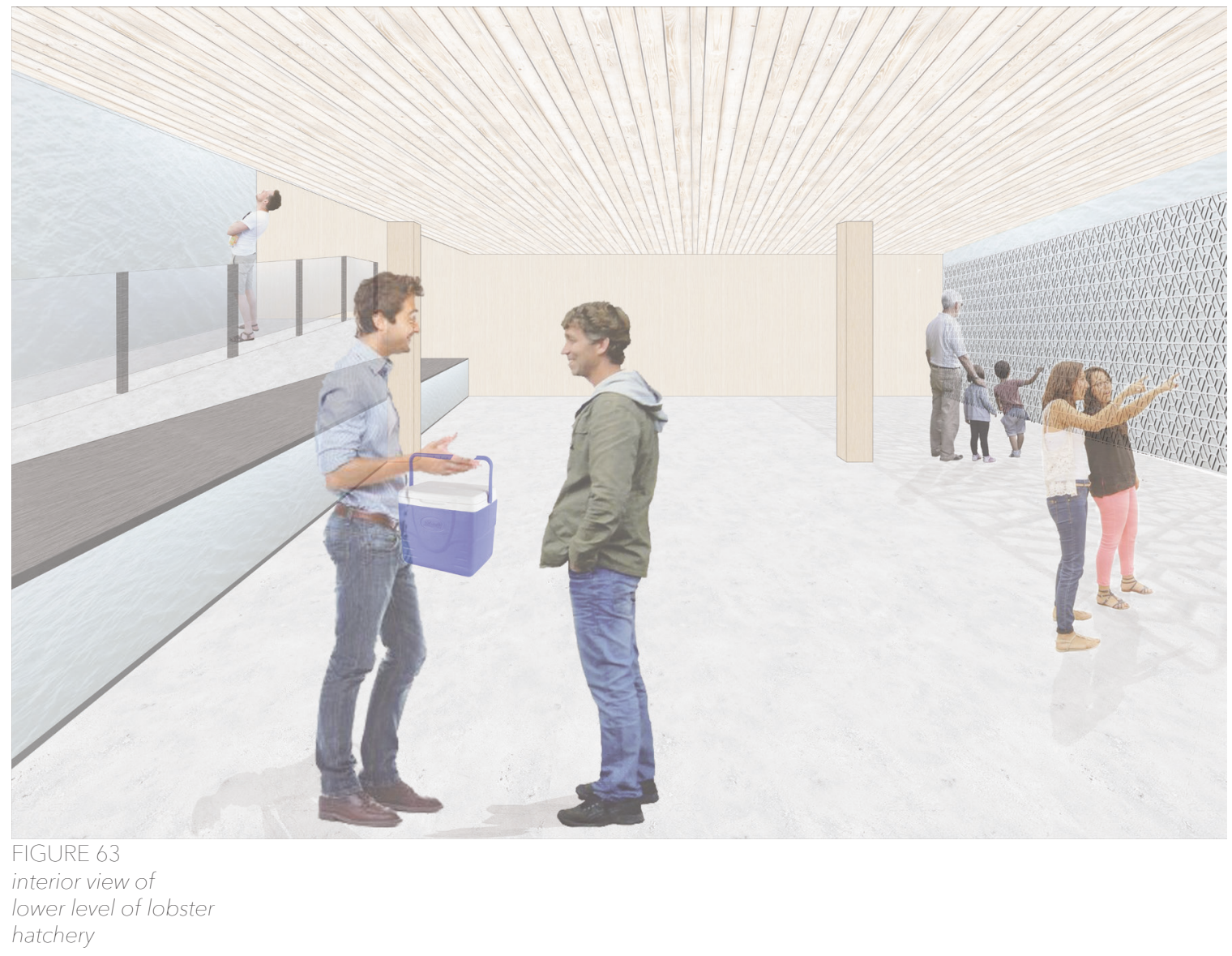


Diary Two: Pete, a 7-year old tourist

July 29,2070

I just got home from our vacation in Arisaig. At first, I thought it was going to be so boring, it is so far away from everything. I don't even like lobster. But it was actually really fun. I didn't eat any lobster, but I saw them when I was swimming. I wore my mask so I could look for them in the rocks underwater. They poked out of the rocks but swam back in when I got too close. Dad got mad when I fed them french fries. One lobster took a french fry and ripped it apart with its claws.

My favourite place was the stairs to the ocean. Sometimes there was water at the bottom, sometimes it was farther out. Mom explained to me that it was the tides. Low tide was more fun because I could look for shells and play in the little puddles of water that pooled in the rocks.

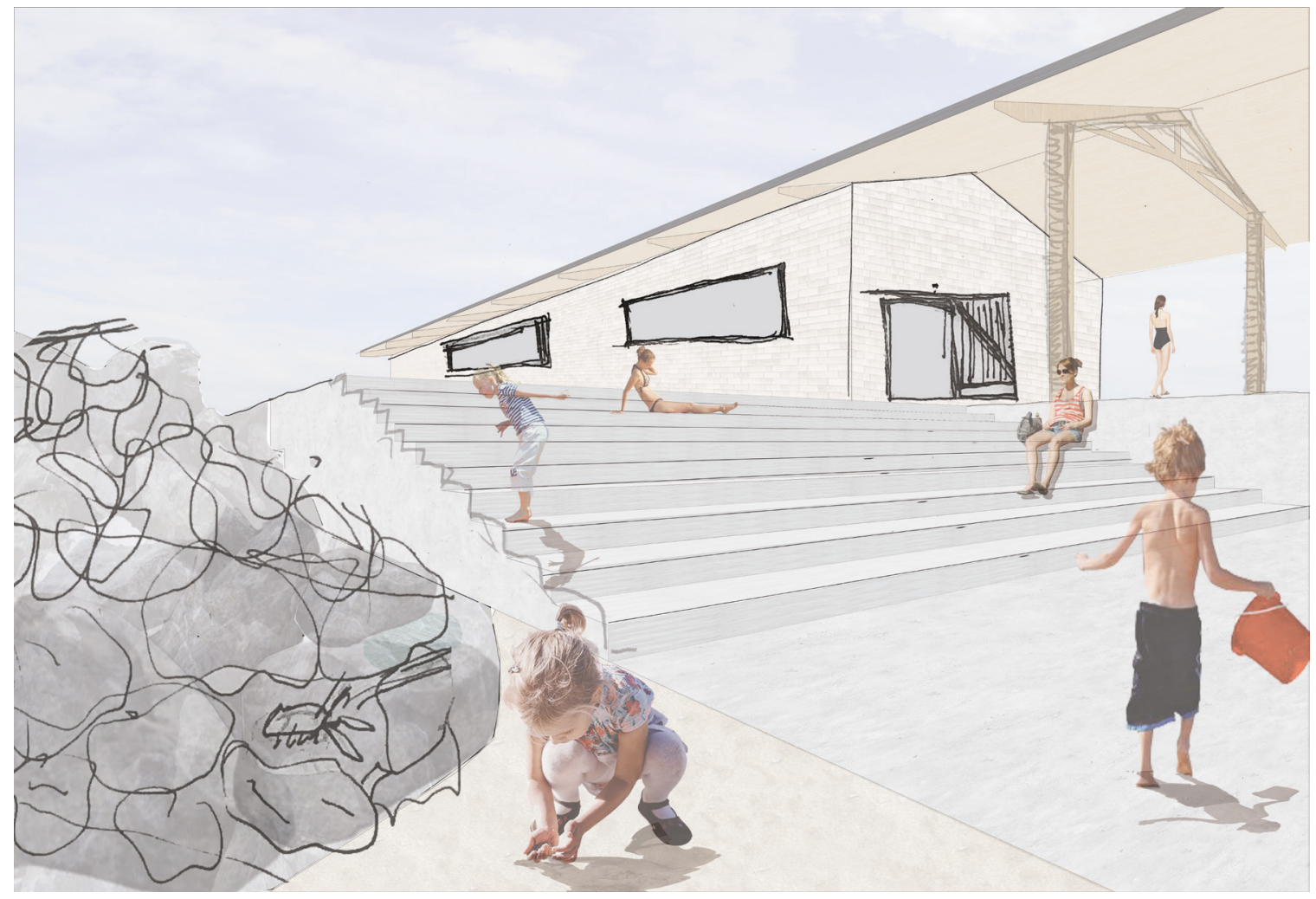

FIGURE 64

exterior view of

hatchery from the ocean 
Diary Three: Jane, a local resident

October 3, 2100

I went for a swim after my shift at the restaurant this evening. I never noticed before, but when you're in the pool beside the hatchery, it's like you're on display too. I made eye contact with a kid on the other side of the wall, and it was very awkward. It was a brisk evening, but I wanted to go for a swim. The pool is warmer than the ocean. The rock breakwater absorbed heat from the sun all day, and retained the heat into the evening, providing warmth against the chilly air. Underwater, I watched the little lobsters that had been released today, as they burrowed into the rocks. In a few years, they will move on to the crevices in the rock wall of the restaurant, and then a few years later, I will be serving them on a plate. Yum.

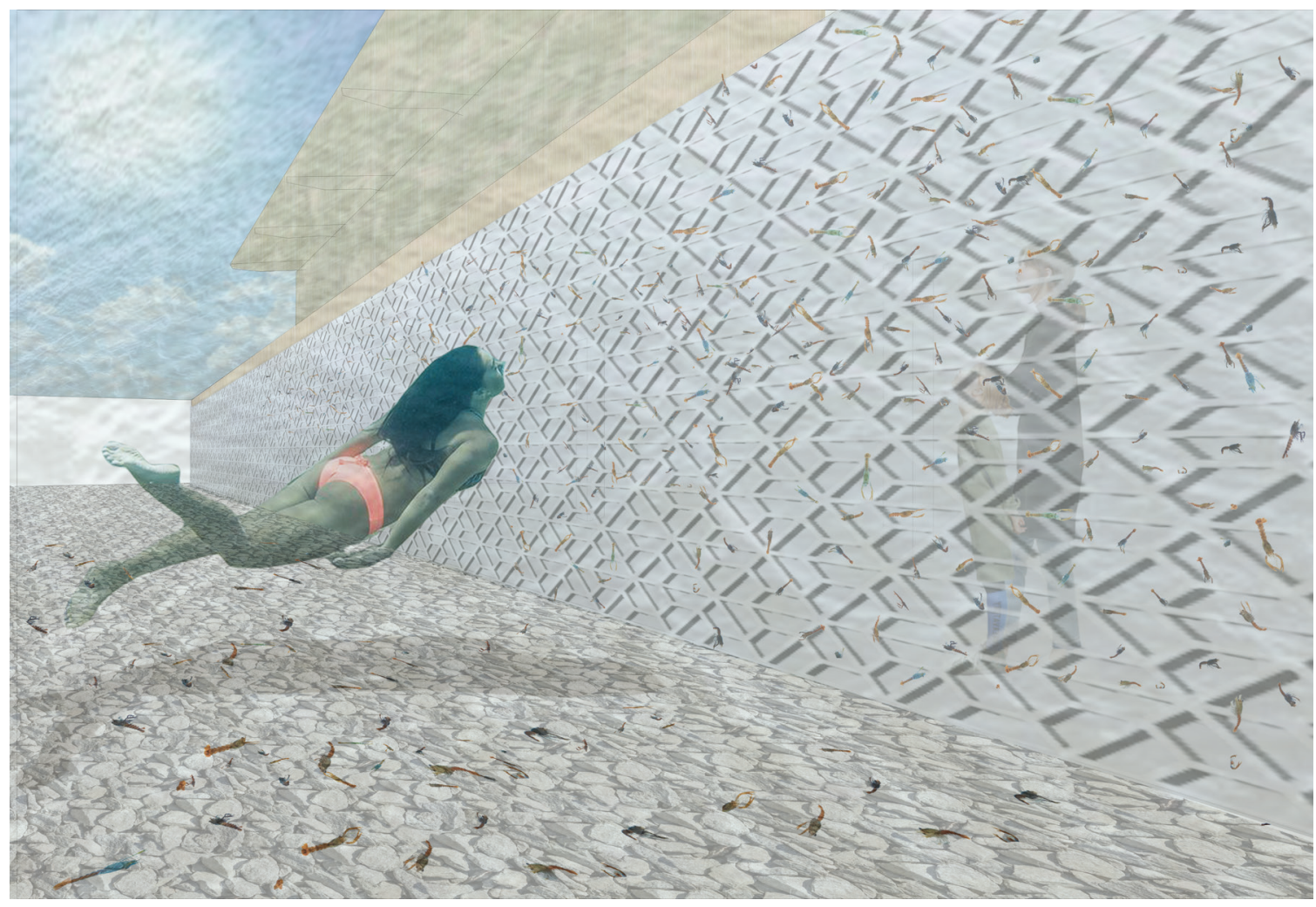

FIGURE 65

underwater view of juvenile lobster wall

from the tidal pool 
The initial aim of this thesis was to use an architectural strategy to integrate the separate elements of rural coastal life; fisheries, tourism, and community as outlined in the Arisaig Community Development slogan. Throughout the research, what resulted was a new collection of interrelated elements. Lobsters, climate change, ecology, vernacular, leisure, sustenance, weathering, seasons, and water were some of the many subjects that were added to the list over the past eight months. What I have discovered, is that all these elements work together in a network, with layered relationality to one another. What has resulted is a proposal of holistic coastal resiliency. The 'resiliency' here not only refers to protecting the coastline, but the coastal way of life, coastal organisms like lobster, and how they all relate to one another. 
Boa Nova Tea House

Alvaro Siza

Leca Da Palmeira,

Portugal

1963

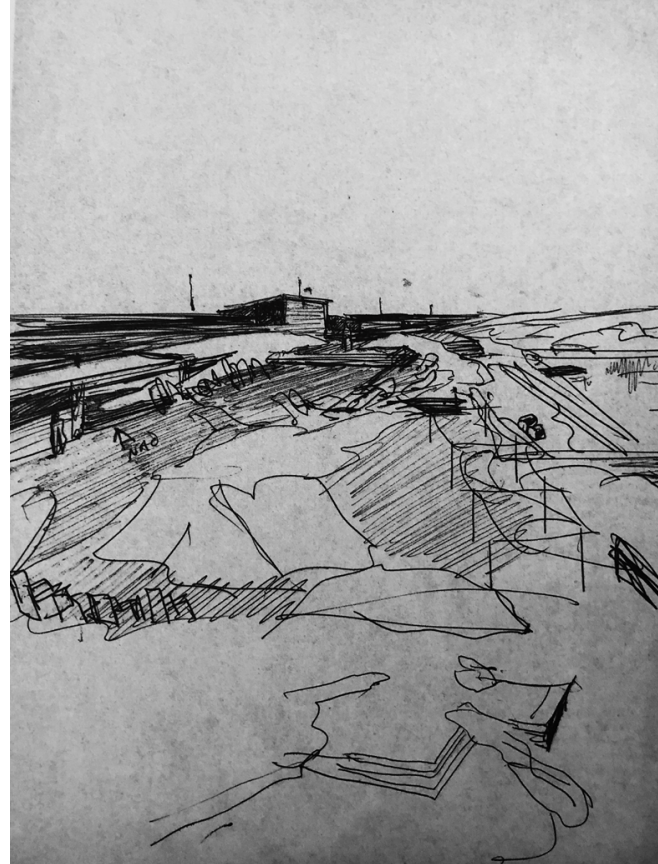

FIGURE 66

Siza, Alvaro, reproduction of original sketch. Mollard Manon. "Revisit Leca De Palmeira." The Architectural Review, April 2019,23.

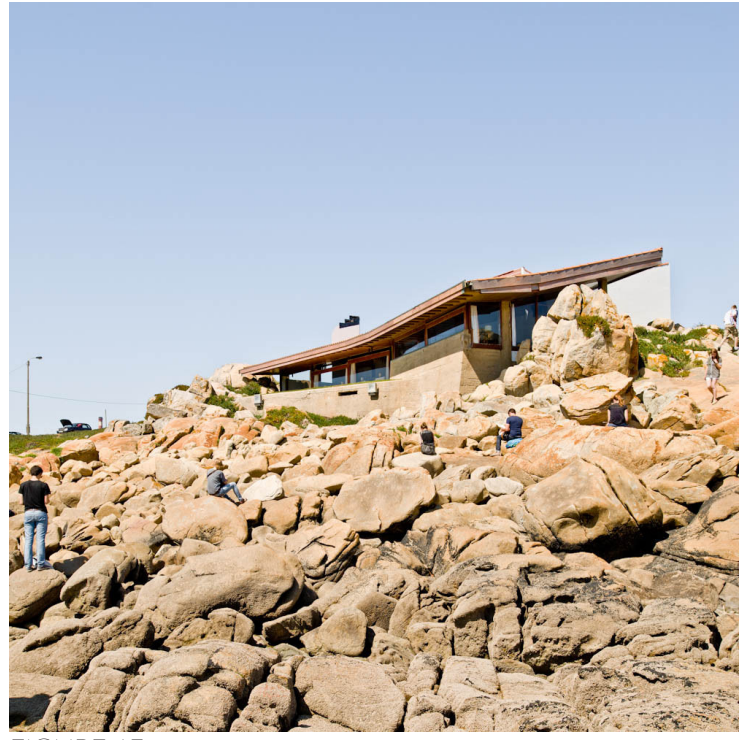

FIGURE 6 .

Ludwig, Samuel. AD Classics: Boa Nova Tea House / Alvaro

Siza Vieira. AD Classics: Boa Nova Tea House / Alvaro

Siza Vieira. ArchDaily, April 5, 2013. https://www. archdaily

com/355077/ad-classics-boa-nova-tea-house-alvaro-siza. 
Leca Swimming Pools

Alvaro Siza

Leca da Palmeira,

Portugal

1966

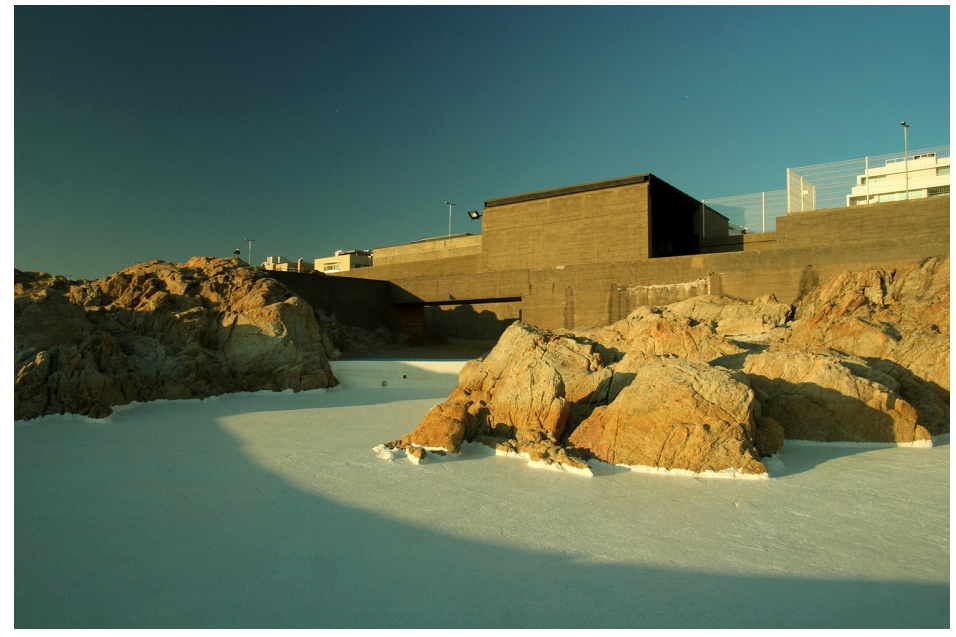

FIGURE 68

Balters, Sofia. AD Classics: Leca Swimming Pools / Alvaro Siza Vieira

ArchDaily, August 6, 2011. https://www. archdaily.com/150272/ad-classics-leca-swimming-pools-alvaro-siza.

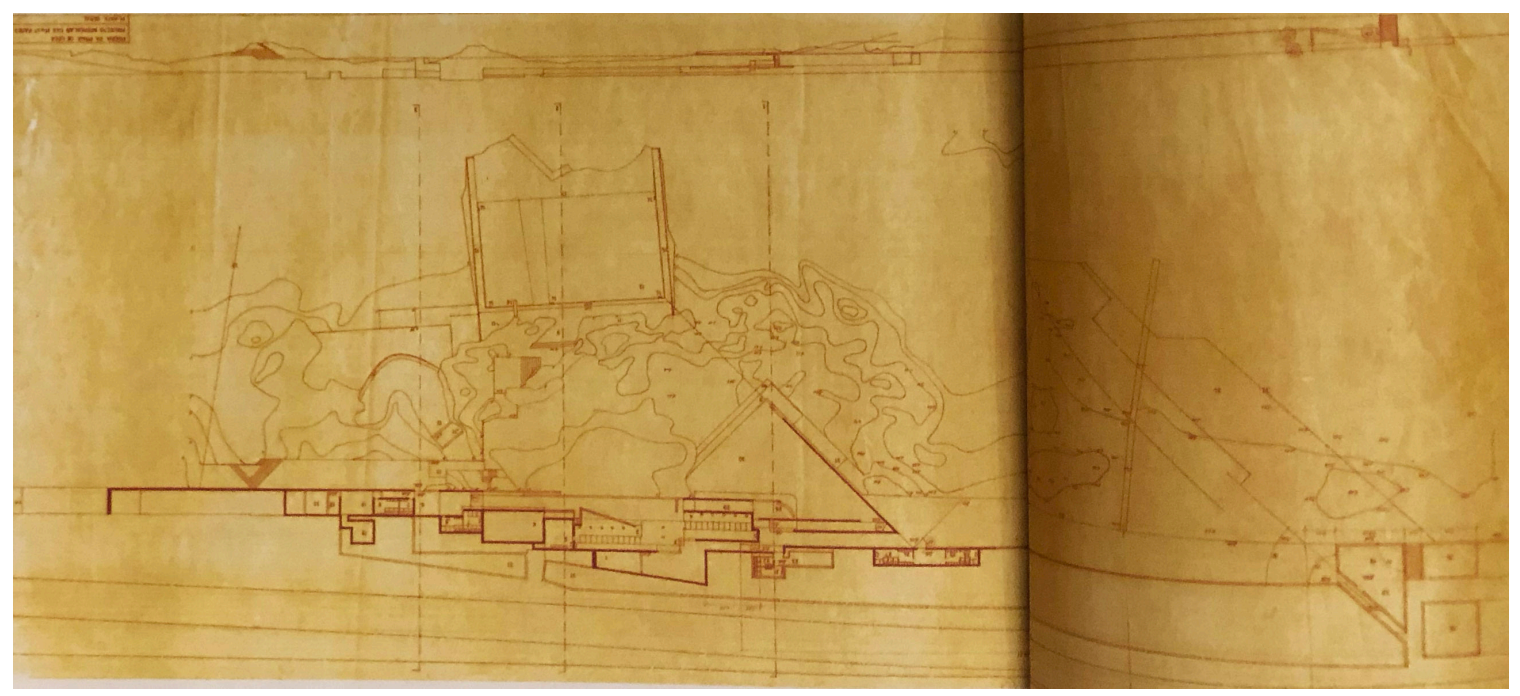

FIGURE 69

Site Plan, Alvaro Siza Fund. Mollard, Manon. "Revisit Leca De Palmeira." The Architectural Review, April 2019, 25. 
Under

Snohetta

Lindesnes, Norway 2019

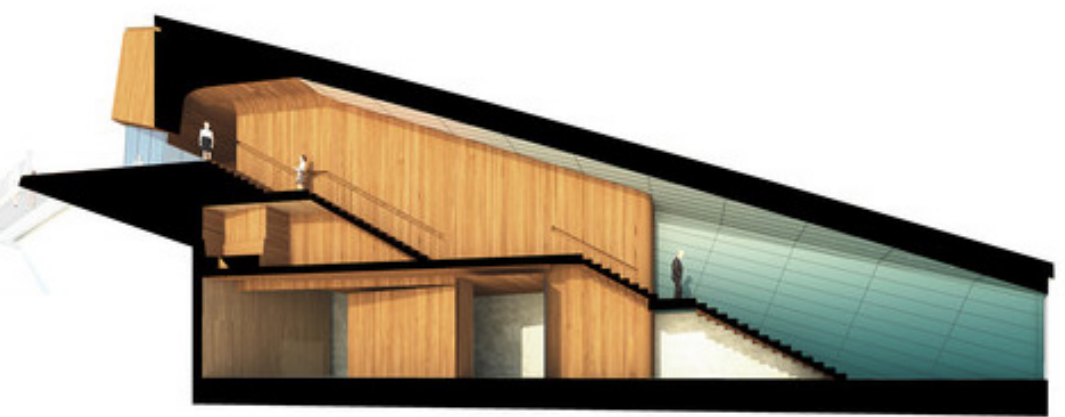

FIGURE 70

Snohetta. Section Diagram of Restaurant. Under (Underwater Restaurant) / Snohetta. ArchDaily, March 22, 2019. https://www.archdaily.com/913575/under-snohetta

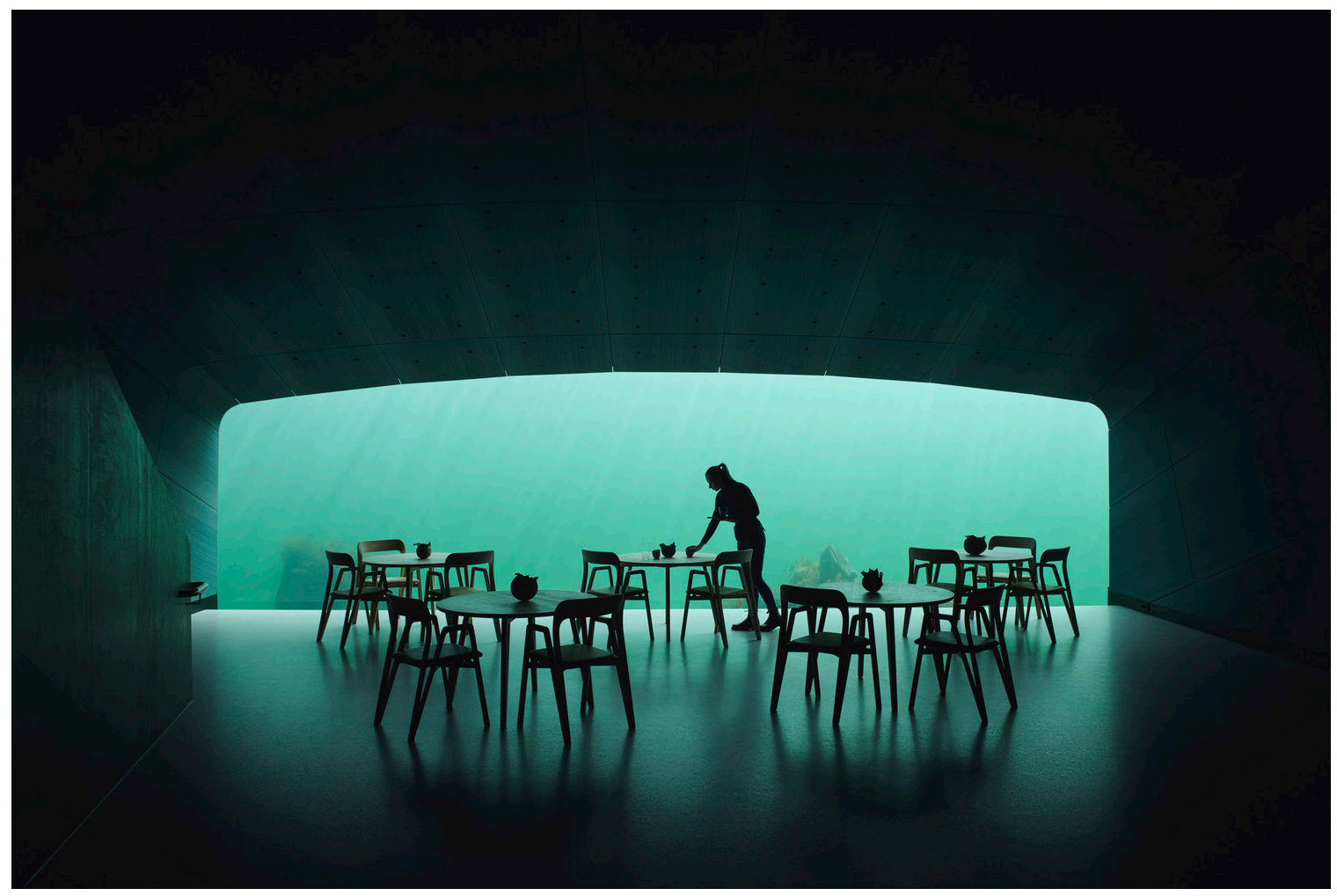

FIGURE 7

Ivar Kvaal. Section Diagram of Restaurant. Under (Underwater Restaurant) / Snohetta. ArchDaily, March 22, 2019. https:// www.arch daily.com/913575/under-snohetta. 
Faaborg Harbour Bath

JDS Architects

Faaborg, Denmark

2014

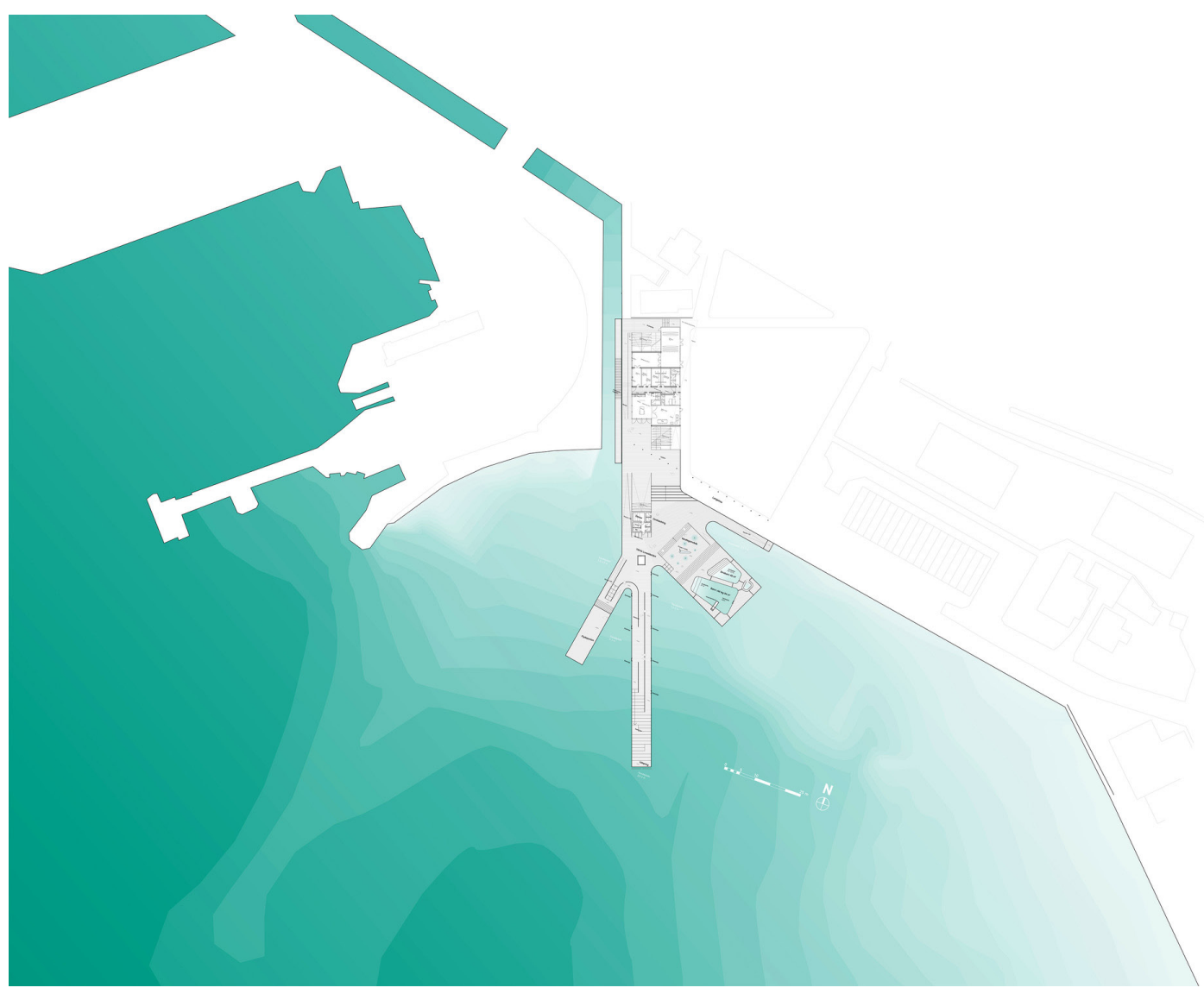

FIGURE 72

Plan. Faaborg Harbor Bath / Urban Agency JDS Creo Arkitekter. ArchDaily, June 23, 2014. https://www.archdaily com/518083/faaborg-harbor-bath-urban-agency-jds-creo-arkitekter

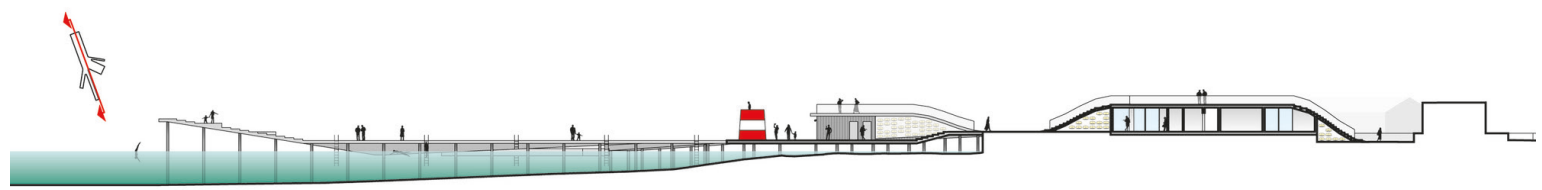

FIGURE 73

Section. Faaborg Harbor Bath / Urban Agency JDS Creo Arkitekter. ArchDaily, June 23, 2014. https://www. archdaily. com/518083/faaborg-harbor-bath-urban-agency-jds-creo-arkitekter. 
Oyster-Tecture

SCAPE Studio

Brooklyn, NY

2009 (exhibition)

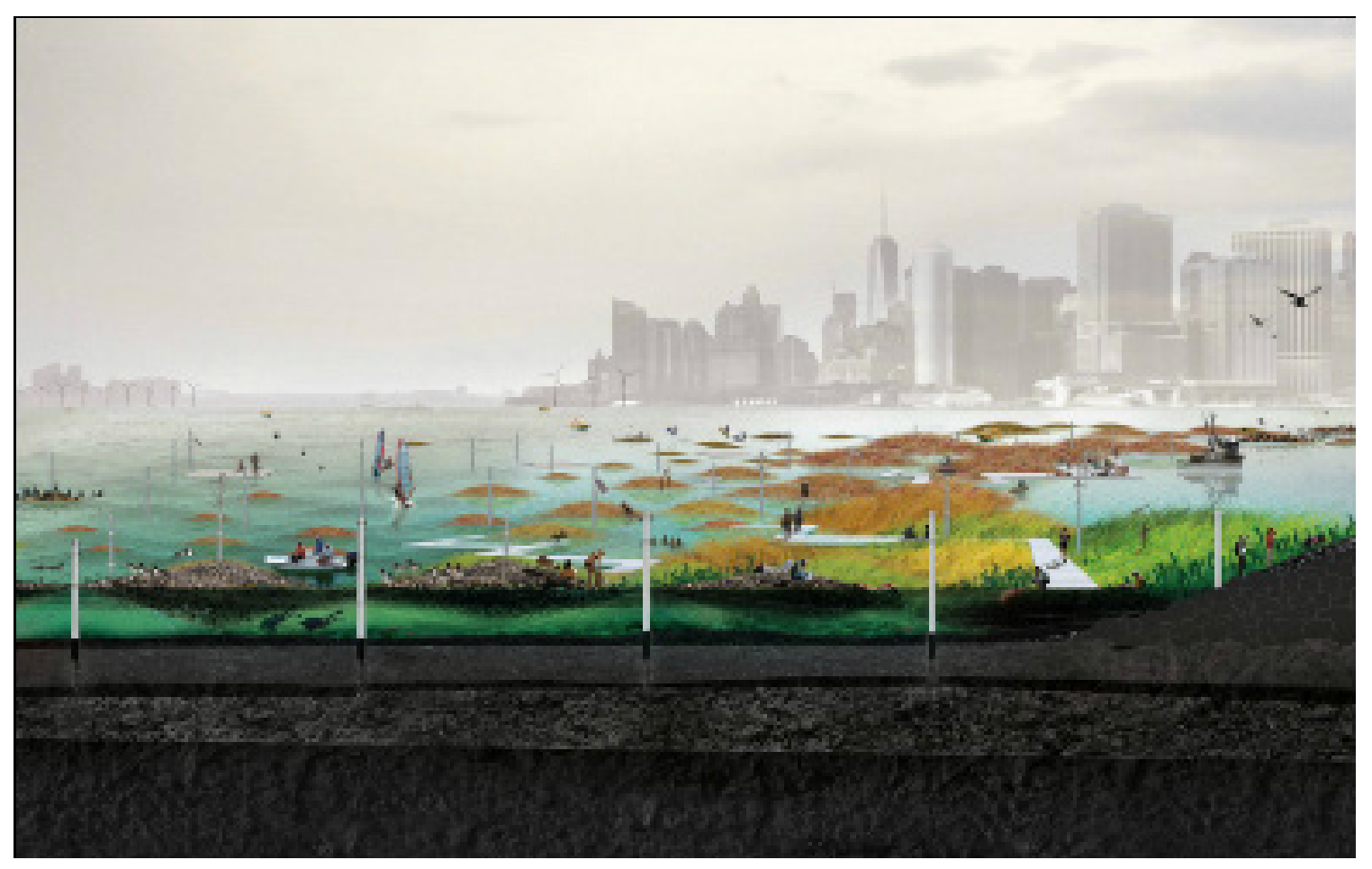

FIGURE 74

Oyster-Tecture. SCAPE Studio. Accessed October 16, 2019

https://www.scapestudio.com/projects/oyster-tecture/.

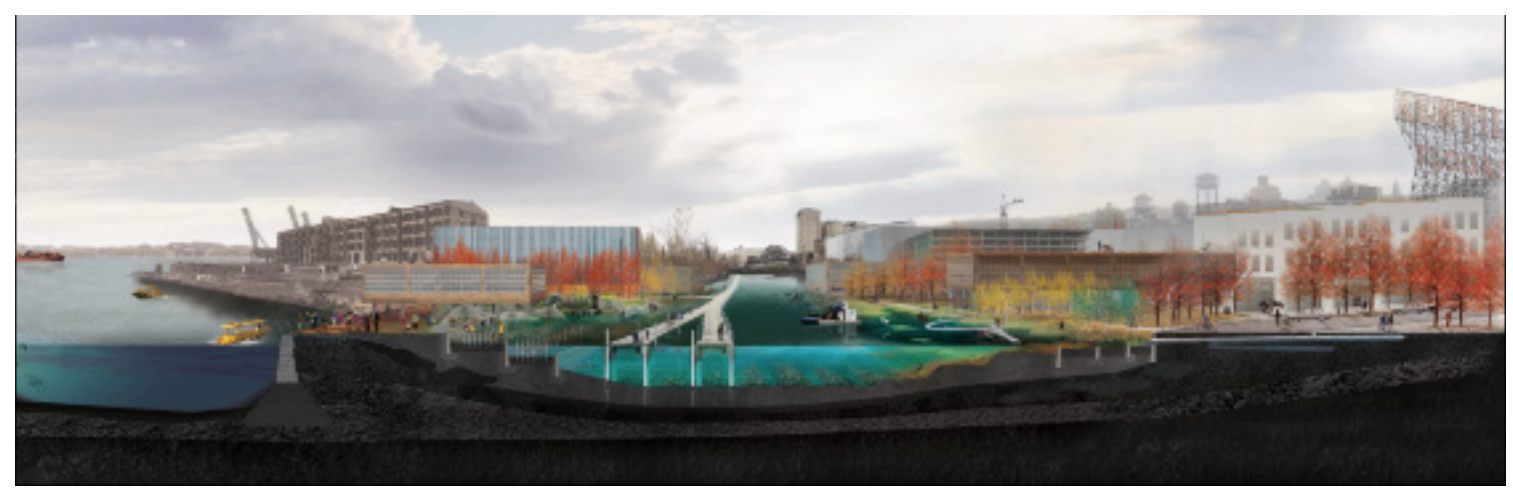

FIGURE 75

Oyster-Tecture. SCAPE Studio. Accessed October 16, 2019

https://www.scapestudio.com/projects/oyster-tecture/. 
Hedmark Museum Sverre Fehn Hedmark, Norway 1967-1971

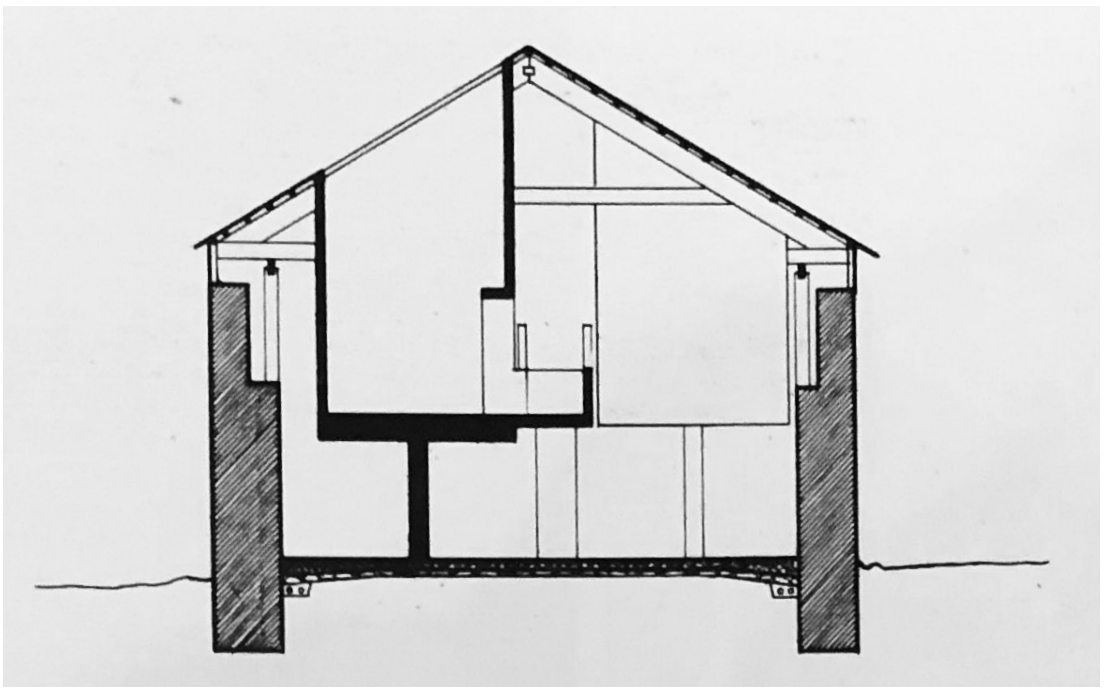

FIGURE 76

Norberg-Schulz, Christian, and Gennaro Postiglione. Sverre Fehn: Works, Projects, Writings, 1949-1996. The Monacelli Press, 1998, 139

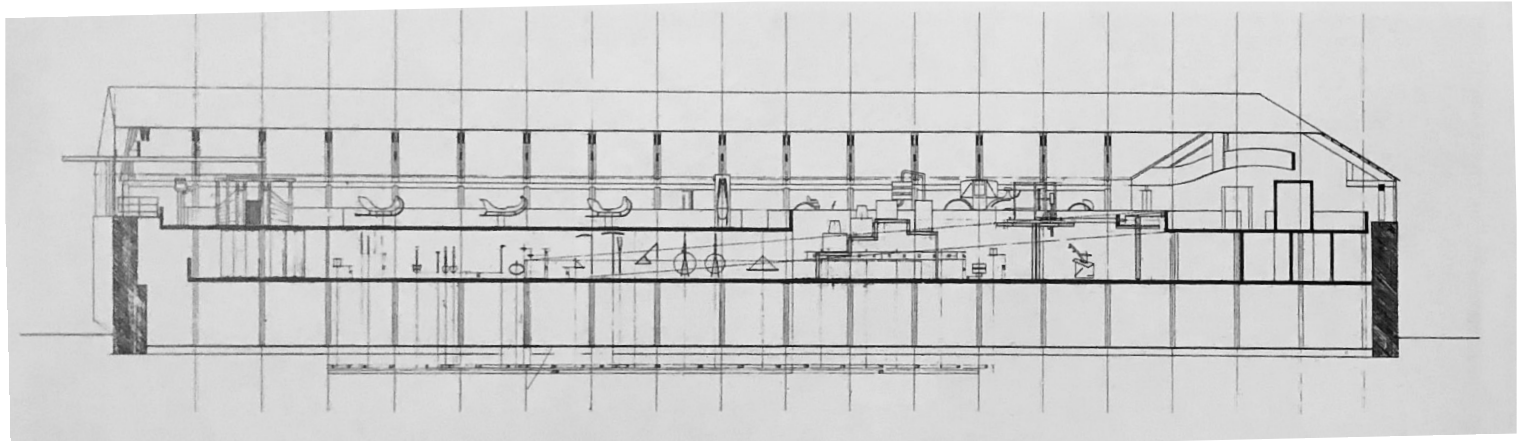

FIGURE 77

Norberg-Schulz, Christian, and Gennaro Postiglione. Sverre Fehn: Works, Projects, Writings, 1949-1996. The Monacelli Press, 1998, 136. 
National Lobster Hatchery

United Kingdom

European Lobster

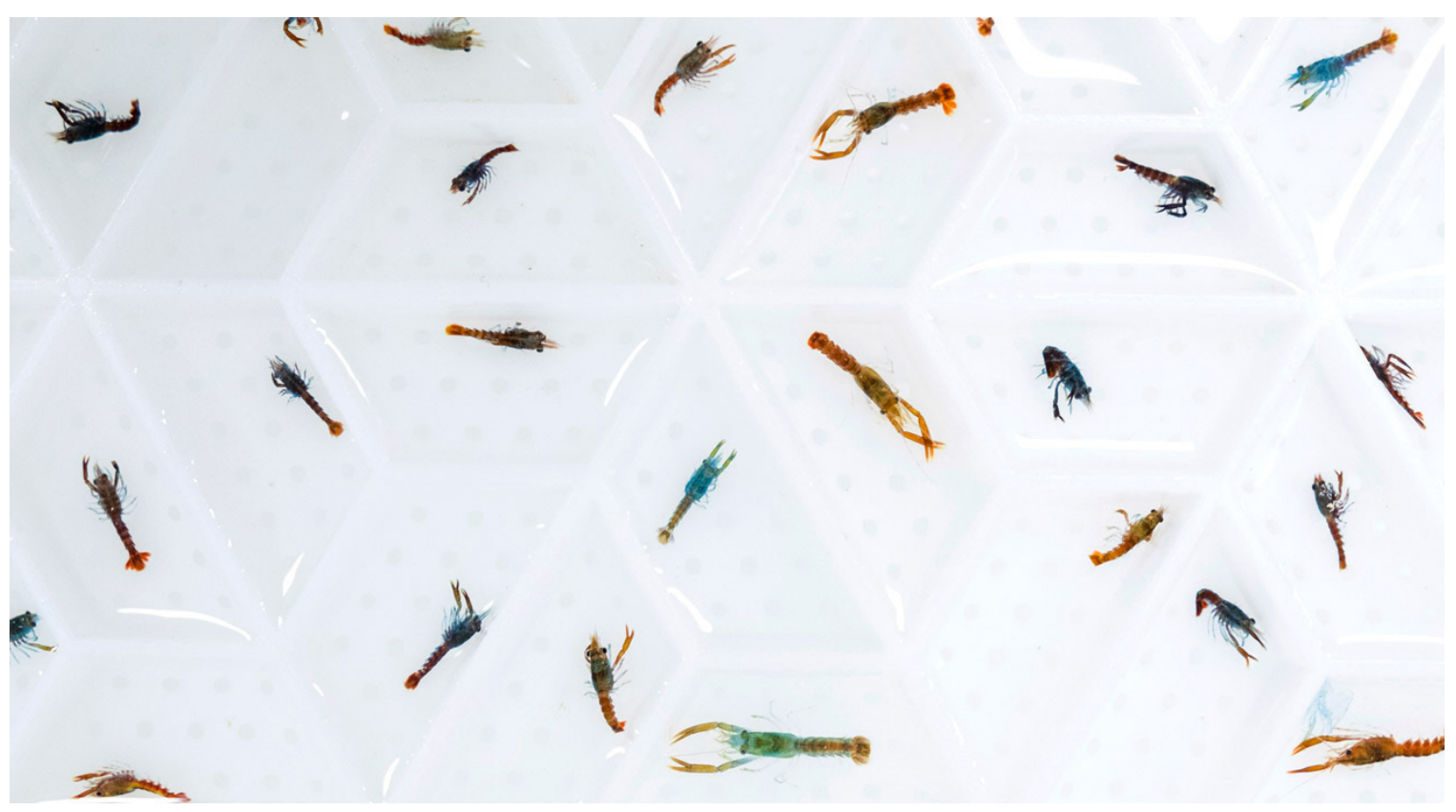

FIGURE 78

Hatchery-Reared Lobsters. The National Lobster Hatchery. Accessed September 28, 2019

https://www.nationallobsterhatchery.co.uk/ 
Lobster Farming

Vietnam

Spiny Lobster

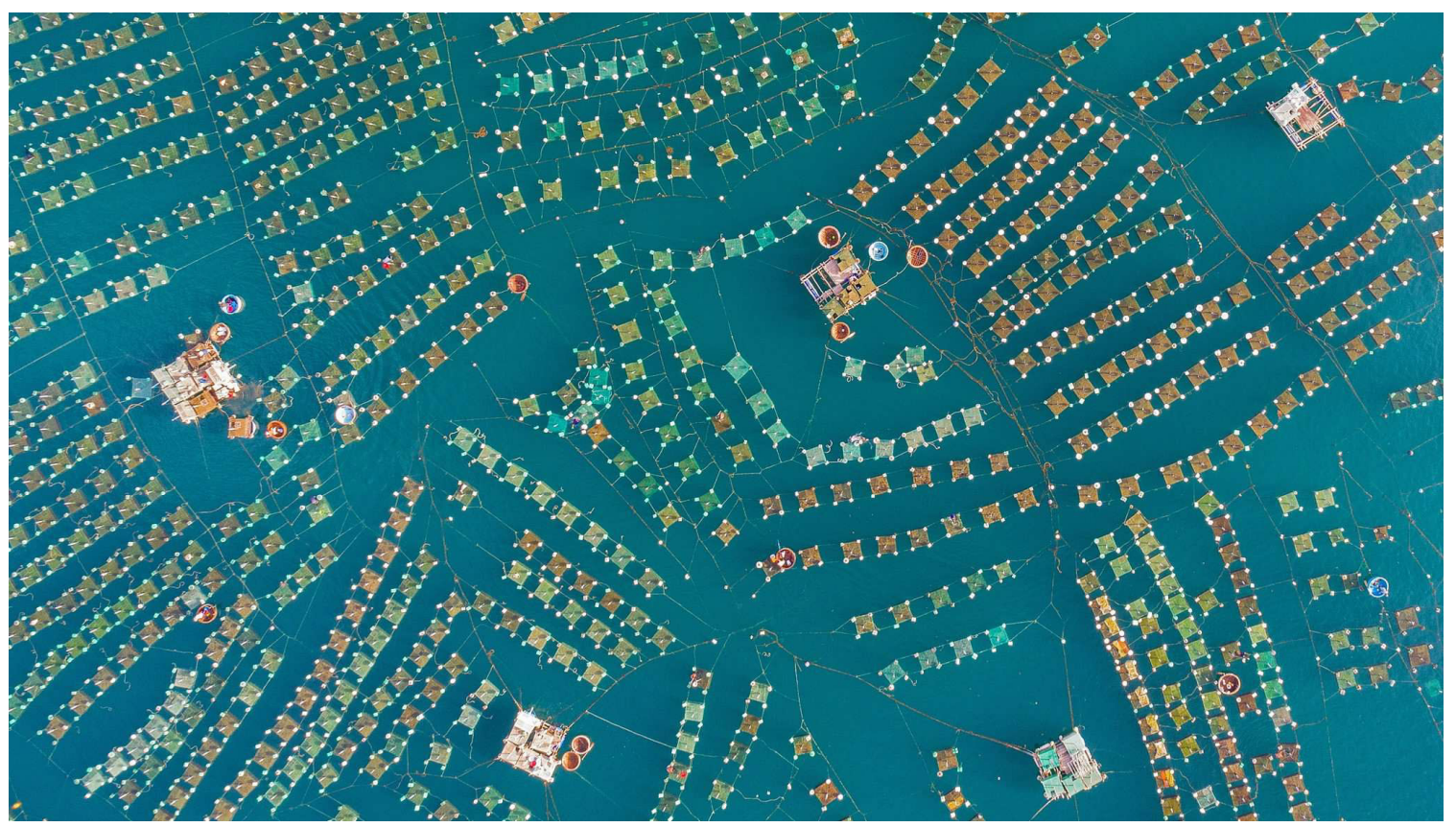

FIGURE 79

Stunning Aerial Photos Show Floating Lobster Cages in Vietnam. Stunning Aerial Photos Show Floating Lobster Cages in Vietnam. CGTN, March 17, 2018. https://news.cgtn.com/news/3549444d7a6b7a6333566d54/share_p.html. 
Archives, Nova Scotia. "'Canada's Ocean Playground' The Tourism Industry in Nova Scotia, 1870-1970." Government of Nova Scotia, Canada, January 11, 2008. https://novascotia.ca/archives/tourism/ government.asp? Language=English.

"Arisaig, Nova Scotia, Canada." Arisaig, Nova Scotia, Canada. Accessed August 20, 2019. https://arisaigns.com/.

Ashraf, Kazi Khaleed. "Fluid Space." The Architectural Review, June 2017, 8-17, 11.

Auld, Alison. "The Big Picture: The Looming Threat of Rising Sea Levels - and What We Can Do about It." Dalhousie News, December 12, 2019. https://www.dal.ca/news/2019/12/12/the-big-picture--the-loomingthreat-of-rising-sea-levels---and-w.html.

Bradley, Susan. "New Bill Will Force Owners to Build Farther Back from Nova Scotia Coastlines | CBC News." CBCnews. CBC/Radio Canada, March 12, 2019. https://www.cbc.ca/news/canada/nova-scotia/coast-protectionbill-building-water-1.5053299.

Brookes, L. A. "Northumberland Strait." Northumberland Strait | The Canadian Encyclopedia. February 7, 2006. Accessed April 23, 2019. https://www. thecanadianencyclopedia.ca/en/article/northumberland-strait.

Chassé, J., Lambert, N., Comeau, M., Galbraith, P.S., Larouche, P., and Pettipas, R.G. 2014. Environmental conditions in the southern Gulf of St. Lawrence relevant to lobster. DFO Can. Sci. Advis. Sec. Res. Doc. 2014/031. v + 25 p.

Chisholm, Kassie. "Districts." Municipality of the County of Antigonish. Accessed March 8, 2020. https://www.antigonishcounty.ns.ca/.

Climate Change Canada. "Government of Canada." Canada.ca. Government of Canada, January 15, 2016. https://www.canada.ca/en/environmentclimate-change/services/ice-forecasts-observations/latest-conditions/ glossary.html.

Davis, Tony. "Lobster Prices Could Be Better Says P.E.I. Marketing Group | CBC News." CBCnews. CBC/Radio Canada, June 4, 2019. https://www.cbc.ca/ news/canada/prince-edward-island/pei-lobster-prices-2019-1.5161255.

"Digestible Gulf Stream." Philippe Rahm Architectes. Accessed March 10, 2020. http://www.philipperahm.com/data/projects/digestiblegulfstream/index. html.

Ennals, Peter, and Deryck Holdsworth. 1981. "Vernacular Architecture and the Cultural Landscape of the Maritime Provinces - A Reconnaisance". Acadiensis 10 (2), p 93. https://journals.lib.unb.ca/ index.php/Acadiensis/article/view/11174. 
"Environment Index." Canadian Aquaculture Industry Alliance. Accessed March 27, 2020. https://www.aquaculture.ca/environment-index.

"European Lobster Biology: Biology of the Homarus Gammarus." The National Lobster Hatchery. Accessed March 27, 2020. https://www. nationallobsterhatchery.co.uk/lobster-biology/.

Ezban, Michael. Aquaculture Landscapes: Fish Farms and the Public Realm. Milton Park, Abingdon, Oxon: Routledge, 2020.

Finch, Paul. "Water Needs an Architectural Embrace." The Architectural Review, June 2017.

Fisheries. "Integrated Fisheries Management Plan - Lobster in the Southern Gulf of St. Lawrence." Department of Fisheries and Oceans. January 20, 2015. Accessed April 23, 2019. http://www. glf.dfo-mpo.gc.ca/Gulf/FAM/IMFP/2014-Lobster-Gulf-Region.

Fisheries. "Tides, Currents, and Water Levels." Department of Fisheries and Oceans, May 1, 2019. https://www.waterlevels.gc.ca/eng/data/ predictions/2019.

Frampton, Kenneth. "Towards a Critical Regionalism: Six Points for an Architecture of Resistance." In Postmodern Culture, 16-30. London: Pluto Press, 1985.

Frampton, Kenneth. Studies in Tectonic Culture: the Poetics of Construction in Nineteenth and Twentieth Century Architecture. Chicago, IL: Graham Foundation for Advanced Studies in the Fine Arts, 2007.

Hall, Colin Michael, and Stephen J. Page. The Geography of Tourism and Recreation: Environment, Place and Space. London: Routledge, 2014.

Heschong, Lisa. Thermal Delight in Architecture. Cambridge, MA: M.I.T. Press, 1979.

Hoare, Philip. "The Ocean's Skin." The Architectural Review, April 2019, 6-15.

Lefaivre, Laine, and Alexander Tzonis. Architecture of Regionalism in the Age of Globalization: Peaks and Valleys in the Flat World.(Abingdon:Routledge, 2012)

"Lobster Conservation Charity." The National Lobster Hatchery. Accessed March 27, 2020. https://www.nationallobsterhatchery.co.uk/whats-it-allabout/.

Maudlin, Daniel. "Architecture and Identity on the Edge of Empire: The Early Domestic Architecture of Scottish Settlers in Nova Scotia, Canada, 18001850." Architectural History 50 (2007): 95-123. https://doi.org/10.1017/ s0066622×00002896. 
McKay, Ian. "'O, So True \& Real Like the Sea \& the Rocks' : The Folk and the Pursuit of the Simple Life." In The Quest of the Folk: Antomodernism and Cultural Selection in Twentieth-Century Nova Scotia, 214-73. Montreal, QU: McGill-Queen's University Press, 2009.

McKay, lan, and Robin Bates. "Marketing Race: Angus L. MacDonald, Tartanism, and the Cultural Politics of Whiteness." In In the Province of History, 253316. Montreal, QU: McGill-Queen's University Press, 2010.

McPhee, John. "Out in the Sort." The New Yorker, April 18, 2005.

NOAA. "American Lobster." National Oceanic and Atmospheric Administration. Accessed March 10, 2020. https://www.fisheries.noaa.gov/species/ american-lobster\#overview.

Norberg-Schulz, Christian. Genius Loci : Towards a Phenomenology of Architecture (Rizzoli, 1996).

Ryan, Haley. "The Lobster Trap." thestar.com, June 10, 2019. https://projects. thestar.com/climate-change-canada/nova-scotia/.

Shaw, Gareth, and Allan M. Williams. Tourism and Tourism Spaces. Los Angeles: SAGE, 2004.

Sutherland, Adam. "Reinventing the Rural- Our Skewed Perception of the Countryside." The Architectural Review, April 2018, 8-17.

"Tides, Currents, and Water Levels." Department of Fisheries and Oceans, May 1, 2019. https://www.waterlevels.gc.ca/eng/data/predictions/2019.

Wagner, John, and Anthony Davis. "Property as a Social Relation: Rights of "Kindness" and the Social Organization of Lobster Fishing among Northeastern Nova Scotian Scottish Gaels." Human Organization63, no. 3 (2004): 320-33. doi:10.17730/humo.63.3.gtywjfbpb8pgqn9j.

Wilkenson, Tom. "Typology: Buildings for Animals." The Architectural Review, April 2018, 100. 